\title{
Experimental Study on Seawater and Sea Sand Concrete Filled GFRP and Stainless Steel Tubular Stub Columns
}

\author{
Y.L. Li $^{1}$, X.L. Zhao ${ }^{* 1}$, R.K. Raman $\operatorname{Singh}^{2,3}$ and S. Al-Saadi ${ }^{2}$ \\ ${ }^{1}$ Department of Civil Engineering, Monash University, Clayton, Victoria, Australia \\ (*corresponding author, Email: ZXL@monash.edu) \\ ${ }^{2}$ Department of Mechanical and Aerospace Engineering, \\ ${ }^{3}$ Department of Chemical Engineering, \\ Monash University, Clayton, Victoria, Australia
}

\begin{abstract}
:
This paper presents an experimental investigation on mechanical and associated properties of seawater and sea sand concrete (SWSSC) filled glass fibre reinforced polymer (GFRP) and stainless steel (SS) circular tubes. A proper SWSSC mix was developed to achieve the target strength and desirable workability. A total of 24 stub columns, including hollow sections and SWSSC fully filled tubes or double-skin tubes, were tested under axial compression with the load applied to concrete and tubes simultaneously. The stress-strain curves of the core concrete indicate that concrete strength and ductility is enhanced due to the confinement effect. Discussion focuses on the influence of tube diameter-to-thickness ratio, outer tube types and inner tube types on concrete confinement. Capacity formulae are proposed to estimate the load carrying capacity of SWSSC fully filled SS or GFRP tubes, and that of double skin tubes with four combinations of inner and outer tubes, i.e. SS and SS, SS and GFRP, GFRP and GFRP and GFRP and SS.
\end{abstract}

\section{Keywords:}

Seawater sea sand concrete (SWSSC), GFRP, stainless steel, axial compression, local buckling 


\section{Symbols}

\begin{tabular}{|ll|}
\hline$A_{\mathrm{c}}$ & Cross-section area of concrete \\
$A_{\mathrm{cn}}$ & Nominal concrete area \\
$A_{\mathrm{i}}$ & Cross-section area of inner tube \\
$A_{\mathrm{o}}$ & Cross-section area of outer tube \\
$A_{\mathrm{s}}$ & Cross-section area of steel tube \\
$D_{\mathrm{i}}$ & Diameter of inner tube \\
$D_{\mathrm{o}}$ & Diameter of outer tube \\
$E_{\mathrm{h}}$ & Elastic modulus of GFRP in hoop direction \\
$E_{l}$ & Elastic modulus of GFRP in longitudinal direction \\
$E_{\mathrm{o}}$ & Initial elastic modulus of stainless steel \\
$f_{\mathrm{av}, \mathrm{i}}$ & Average stress for the inner tube \\
$f_{0.2}$ & 0.2\% proof stress \\
$f_{\mathrm{c}}{ }^{\prime}$ & Concrete strength \\
$f_{\mathrm{cc}}{ }^{\prime}$ & Confined concrete strength \\
$f_{\mathrm{ck}}$ & Characteristic strength of concrete \\
$f_{l}$ & Confining stress \\
$f_{\mathrm{scy}}$ & Nominal yielding strength of composite sections \\
$f_{\mathrm{un}}$ & Nominal ultimate strength \\
$f_{\mathrm{y}}$ & Yield strength (= f. .0 .2 for SS) \\
$f_{\mathrm{yi}}$ & Yield strength of inner tube \\
$f_{\mathrm{yo}}$ & Yield strength of outer tube \\
$L$ & Specimen length \\
$N_{p}$ & Predicted capacity \\
$N_{\mathrm{t}}$ & Test capacity \\
$t_{\mathrm{i}}$ & Thickness of inner tube \\
$t_{\mathrm{o}}$ & Thickness of outer tube \\
$\Delta$ & Axial end shortening \\
$\varepsilon_{\mathrm{co}}$ & Ultimate strain of concrete \\
$\varepsilon_{\mathrm{cu}}$ & Ultimate strain of confined concrete \\
$\varepsilon_{\mathrm{uh}}$ & Ultimate strain of GFRP in hoop direction \\
$\varepsilon_{\mathrm{ul}}$ & Ultimate strain of GFRP in longitudinal direction \\
$\chi$ & Void ratio \\
$\sigma_{\mathrm{res}}$ & Poisson's ratio \\
\hline
\end{tabular}




\section{Introduction}

Concrete-filled tubes (CFTs), which are composed of core concrete and encasing tubes, have been widely used in civil engineering, such as for high-rise buildings and bridge piers. CFTs exhibit large load-carrying capacity and good seismic performance mainly due to the confinement effect on core concrete provided by the encasing tube. Past researches (as summarised in [1]) have indicated that the circular tubes can provide substantial strength enhancement and ductility in comparison to the square or rectangular tubes. The confinement effect of circular CFT is considered in most of the current design codes. Based on the cross-section configuration, concrete-filled tubes can be divided into fully concrete filled tubes and concrete-filled double-skin tubes.

The increase in global population [2] has led to an increasing demand for resources (e.g. fresh water) and infrastructure (e.g. buildings, bridges). The huge demand of concrete, which is the most commonly used material for building infrastructure, is exacerbating the resource shortages (e.g. fresh water, river sand) and causing serious environmental impact (e.g. emission of $\mathrm{CO}_{2}$ during the production of Portland cement). One solution to these problems is to utilize seawater, sea sand, and geo-polymers (e.g. slag, fly ash) to replace fresh water, river sand and ordinary Portland cement (OPC) respectively. Another benefit of using geo-polymers is that the expansion caused by alkali silica reaction (ASR), which potentially causes concrete cracking, is considerably less in geopolymer-based concrete than in OPC-based concrete [3]. The mechanical properties of alkali-activated seawater and sea sand concrete (SWSSC) are generally similar to those of conventional Portland concrete [4]. However, conventional carbon steel tubes are not suitable to provide confinement to SWSSC because of the highly corrosive condition caused by chloride ions of seawater in SWSSC itself [5]. Therefore, the stainless steel (SS) and fibre reinforced polymer 
(FRP) are adopted in this research due to their greater corrosion resistance.

Extensive studies have been conducted on concrete-filled carbon steel tubes (for fully filled tubes: e.g. [1, 6 to 9] ; for double-skin tubes: e.g. [10 to 13]). In recent years, there is an increasing interest in replacing carbon steel by stainless steel (SS) in marine environment due to its greater corrosion resistance. Several experimental investigations (e.g. [14 to 16]) have been conducted on fully concrete filled SS tubular columns, which indicate that the performance is quite good and current design codes are conservative for concrete-filled SS tubes. However, very little studies have been conducted on concrete-filled double-skin SS tubes [17].

As a promising material, fibre reinforced polymer (FRP) is now increasingly used in concrete-filled tubes. Several studies (e.g. [18, 19]) have been carried out on concrete-filled FRP wraps (with fibres exclusively oriented in hoop stress direction) and some stress-strain models have been proposed for the FRP wrap confined concrete [18, 20]. In recent years, some researchers (e.g. [21, 22]) also looked into fully concrete filled FRP tubes (with fibres oriented both in hoop and longitudinal directions) for the use of tubes as formwork. To the best of authors' knowledge, only one experimental study [21] has been conducted on concrete-filled double-skin tubes (using specimens with FRP as both outer and inner tubes) but no study on concrete-filled double-skin tubes (FRP as outer and SS as inner tube) is reported.

This paper reports an overall experimental investigation on seawater and sea sand concrete (SWSSC) filled circular tubular columns, including SWSSC fully filled tubes and double-skin tubes with different combinations of tube materials (stainless steel (SS) or glass fibre reinforced polymer (GFRP)). Firstly, a proper SWSSC mix was developed to achieve the target strength and desirable workability. The material properties of stainless steel and GFRP were determined by standard tensile tests. Axial compressive test was conducted on a total of 24 stub columns, 
including SWSSC-filled SS tubes, SWSS-filled GFRP tubes and corresponding hollow section tubes. An understanding of comparative properties has been developed based on the existing theories and the test results of this study. Finally, new methods are proposed to estimate the strength of SWSSC-filled SS tubes and GFRP tubes. It is worthwhile to mention that this paper forms part of a large research program on hybrid SWSSC construction being carried out at Monash University in collaboration with The Hong Kong Polytechnic University and Southeast University, China. In the next stage, the SWSSC-filled tubes will be immersed in seawater for different durations to assess the influence of corrosive environment.

\section{Experimental investigation}

\subsection{Specimens}

A total of 24 circular stub columns, including 8 hollow tubes, 8 SWSSC fully filled tubes, and 8 SWSSC-filled double-skin tubes, were prepared and tested in the present study. The specimens were made of seawater sea sand concrete (SWSSC), or stainless steel (SS) tube, and /or GFRP tubes. Four sizes of tubes (with nominal diameter of $50 \mathrm{~mm}, 101 \mathrm{~mm}, 114 \mathrm{~mm}$, and $165 \mathrm{~mm}$ and with nominal thickness of $3 \mathrm{~mm}$ ) were used for the specimens and the length of all the specimens was around $400 \mathrm{~mm}$ long which avoided the global buckling and the influence of end effect.

The dimensions of the test specimens are presented in Table 1, where the failure loads $\left(N_{\mathrm{t}}\right)$ are also given. The label of specimen consists of outer tube material ("S" for stainless steel and " $F$ " for GFRP), outer tube nominal diameter (“50”, “101”, “114”, and "165”), inner tube material (only for double-skin tubes), inner tube nominal diameter (only for double-skin tubes), and cross-section type indicator ("H" for hollow section and "C" for concrete-filled section). For example, S114-C refers to fully SWSSC-filled stainless steel tube with $D_{\mathrm{o}}$ of $114 \mathrm{~mm}$, and S114-F50-C refers to SWSSC-filled double-skin tube with an outer stainless steel tube ( $D_{\mathrm{o}}$ of $\left.114 \mathrm{~mm}\right)$ and an inner 
GFRP tube $\left(D_{\mathrm{i}}\right.$ of $\left.50 \mathrm{~mm}\right)$.

\subsection{Material properties}

\subsubsection{Seawater and sea sand concrete (SWSSC)}

Alkali activated slag concrete with seawater and sea sand was used in this research. The 3\% (percentage weight of slag) sodium meta-silicate activator, which is composed of $47 \% \mathrm{SiO}_{2}$ and $36 \%$ $\mathrm{Na}_{2} \mathrm{O}$, was pre-blended with slag in the dry form before mixing. The seawater and sea sand were obtained from Brighton beach in Melbourne. The chemical composition of the seawater is: Na (11940 mg/L), Mg (1430 mg/L), K (622 mg/L), Cl (20700 mg/L), SO 4 (3420 mg/L), and that of the sea sand is (weight percentage): $\mathrm{SiO}_{2}(96.5 \%), \mathrm{CaO}(1.3 \%), \mathrm{Cl}(0.13 \%), \mathrm{SO}_{4}(0.01 \%)$. Sieve analysis was carried out according to AS1141.11.1 [23] to determine the particle size distribution (PSD) of sea sand. The PSD for the sea sand in this study is compared in Fig. 2 with those of river sand and desert sand reported in Chuah et al. [24]. The fineness of sea sand is between those of river sand and desert sand. Another parameter to describe the fineness of sand is so-called fineness modulus which is an empirical factor obtained by adding the cumulative percentages of aggregate retained on each of the standard sieves ranging from $80 \mathrm{~mm}$ to 150 micron and dividing this sum by 100 . The larger the fineness modulus, the coarser is the sand. The measured fineness modulus of the sea sand in the current study is 2.39 , which is similar to that of some sea sand in China reported in Huang [25] with a fineness modulus ranging from 1.98 to 2.85 and in Nong [26] with a fineness modulus of 2.43 .

The coarse aggregate consisted of 14 maximum size basalts with a specific gravity of 2.95 . In order to improve the concrete workability, $1 \%$ (percentage weight of slag) hydrated lime slurry was added with water. As a result, the slump of fresh concrete could reach $160 \mathrm{~mm}$. The concrete mixture proportions are reported in Table 2 and the seawater-to-slag ratio is 0.53 . 
Six identical concrete cylinders with diameter of $100 \mathrm{~mm}$ and height of $200 \mathrm{~mm}$ were cast for measuring compressive strength. All the specimens and cylinders were cured in the curing chamber with relative humidity $>90 \%$ and temperature of $20^{\circ} \mathrm{C}$ before testing for 28 days. The averaged 28-day strength $\left(f_{\mathrm{c}}{ }^{\prime}\right)$ was $31.4 \mathrm{MPa}$.

\subsubsection{Stainless steel (SS)}

The SS tubes are 316 grade austenitic stainless steel in accordance with AS/NZS 4673 [27]. The ends of the tensile coupons were flattened in order to be gripped by the test machine. The tensile coupon test was conducted in accordance with AS 1391 [28] with a loading rate of 1.0 $\mathrm{mm} / \mathrm{min}$. The averaged test data are summarised in Table 3 , where $f_{0.2}$ is $0.2 \%$ proof stress, $f_{\mathrm{u}}$ is the ultimate strength. The averaged initial elastic modulus $\left(E_{\mathrm{o}}\right)$, total elongation and Ramberg-Osgood parameter $(n)$ are $178 \mathrm{GPa}, 55 \%$, and 8.3 respectively. It should be noted that the $f_{0.2}, E_{0}$, and $n$ are determined based on strain gauges, which are attached on both the concave and convex sides of tensile coupons. The typical full-range stress-strain curve (from extensometer) and the stress-strain curve during the initial stage (from averaged strain gauge readings) are plotted in Fig. 3.

\subsubsection{Glass fibre reinforced polymer (GFRP)}

The GFRP tubes were fabricated by filament winding process with different glass fibre orientations. Based on the manufacturer data, $20 \%, 40 \%$, and $40 \%$ fibres were in the angles of $15^{\circ}$, $\pm 40^{\circ}$ and $\pm 75^{\circ}$ with respect to longitudinal axis of tubes. Therefore, the GFRP tube can provide strength and stiffness in both hoop and longitudinal directions.

Tensile coupon test was conducted to evaluate the GFRP properties in longitudinal direction. As the ends of coupon were not flat, two sets of gripping pieces made of aluminum were used to ensure the gripping head of test machine did grip the coupon specimen tightly (Fig. 4 (a)). A total 
of 4 strain gauges were attached at the middle part of each coupon: on the convex and concave sides, as well as in the longitudinal and transverse directions. The averaged stress-strain curve is shown in Fig. 5, in which the strain is the averaged value of longitudinal strain gauge readings on both sides. As shown in Fig. 5, the stress-strain curves display certain nonlinearity after the strain exceeds 0.003 which is mainly caused by the failure of resin matrix. The results of tensile coupon tests are summarised in Table 4 , in which $f_{\mathrm{u} l}$ is the ultimate strength, $E_{l}$ is the elastic modulus calculated based on ASTM-D3039 [29], $v$ is Poisson's ratio, and $\varepsilon_{\mathrm{ul}}$ is the ultimate strain.

The hoop strength of GFRP tubes was obtained using the "disk-split" method, which is similar to the test method used in ASTM D2290 [30]. Two $13 \mathrm{~mm}$ wide rings were cut from each size of GFRP tubes. The test setup is shown in Fig. 4 (b), which consisted of U-shaped headers and semi-circular steel cylinders with the same curvature as the tested rings. All the rings failed at the gap area between the semi-circular cylinders.

In order to obtain the elastic modulus, 3 strain gauges were installed on the test rings, among which one was centered at gaps, and the others were located at $25 \mathrm{~mm}$ and $50 \mathrm{~mm}$ away from the gap. Due to the bending effect around the gap, the strain gauge reading around the gap may not be reliable. Hence the strain is taken as the averaged reading of the other two strain gauges away from the gap for generating stress-strain curves in Fig. 5 (in which the stress was obtained by dividing the applied force by twos times the cross-section area of the GFRP ring. Fig. 5 shows the stress-strain curve in hoop direction to have less nonlinearity than that in longitudinal direction. The ultimate strength of GFRP in hoop direction $\left(f_{\mathrm{uh}}\right)$ is reported in Table 4 . The average elastic modulus $\left(E_{\mathrm{h}}\right)$ in hoop direction is $25.2 \mathrm{GPa}$, which is higher than that in longitudinal direction $(20.1 \mathrm{GPa})$ and the average ultimate $\operatorname{strain}\left(\varepsilon_{\mathrm{uh}}\right)$ in hoop direction is 0.014 , which is lower than that 
in longitudinal direction (0.019).

\subsection{Mechanical test setup}

The concrete-filled specimens were tested on a $5000 \mathrm{kN}$ capacity Amsler machine, whilst all the hollow section specimens were tested on a $500 \mathrm{kN}$ capacity Baldwin machine. The axial compressive load was directly applied on the specimens. For concrete-filled specimens, cement paste was used to fill the gap caused by concrete shrinkage to assure the load was simultaneously applied on both tube and concrete. The loading rate is $0.5 \mathrm{~mm} / \mathrm{min}$ with displacement control.

Three linear variable displacement transducers (LDVTs) were equally placed around tested tubes and their averaged data were used to estimate the axial end shortening. Three longitudinal and three circumferential strain gauges were affixed to all columns at mid-height. All the loads, displacements and strains were automatically recorded by a data acquisition system. A typical test setup illustration is shown in Fig. 6.

\subsection{Test results}

\subsubsection{Hollow sections}

The failure modes of stainless steel hollow section under axial compression were slightly different due to the differences in the length-to-diameter ratios $\left(L / D_{\mathrm{o}}\right)$ and diameter-to-thickness ratios $\left(D_{\mathrm{o}} / t\right)$. Specimen $\mathrm{S} 50-\mathrm{H}$, being the most slender specimen, failed by both global and local buckling, while the other specimens failed only by local buckling (e.g. S114-H shown in Fig. 7).

A comparison of stress-strain curves of hollow sections and tensile coupons is shown in Fig. 8, in which the strain for hollow sections is based on the ratio of axial end shortening to specimen length, whereas the strain for tensile coupons is the averaged strain gauge readings. Because of the occurrence of global buckling, specimen S50-H could not fully utilize its strength and failed much earlier than the other specimens. As shown in Fig. 8, with the increase of diameter-to-thickness 
ratio (i.e. from $\mathrm{S} 101-\mathrm{H}$ to $\mathrm{S} 165-\mathrm{H}$ ), the strain corresponding to peak load decreases as the section becomes more slender. During the initial stage (strain $<0.5 \%$ ), the stress-strain curves of hollow sections (except S50-H) and tensile coupons are fairly close to each other. Then, the increase in load of hollow section became lower than that of tensile coupons as the elastic-plastic local buckling happened.

Fig. 9 shows the stress-strain curves for GFRP tubes under axial compression. The load increased linearly until the local buckling (mainly caused by fibre's buckling) along the longitudinal direction near the ends. After this sudden failure, the GFRP hollow section still had a residual strength and could sustain the load until the axial strain reached about $8 \%$. Based on the stress-strain curves of tested specimens, a simplified stress-strain model of GFRP hollow section is proposed in Fig. 10, in which $\sigma_{\mathrm{u}}$ is the ultimate compressive strength, $\varepsilon_{\mathrm{u}}$ is the ultimate strain and $\sigma_{\text {res }}$ is the residual strength. The ultimate compressive strength, ultimate strain and residual strength of the hollow sections are summarised in Table 5 and the average tensile strength $\left(f_{\mathrm{ul}}\right)$ of GFRP coupons are also given in Table 5. As shown in Table 5, the ultimate compressive strength is slightly lower than the tensile strength of GFRP due to the influence of local buckling.

\subsubsection{SWSSC-filled tubes}

Based on the material type of tubes, the SWSSC-filled tubes are divided into two groups: concrete-filled stainless steel tubes and concrete-filled GFRP tubes. Each group includes both fully filled tubes and double-skin tubes. All the load-axial strain curves are summarised in Fig. 11. In general, the bilinear response of SWSSC-filled GFRP tubes is much more obvious than that of SWSSC-filled SS tubes, while SWSSC-filled SS tubes display much higher ductility. 
folding failure mechanism (local buckling) as shown in Fig. 12 (a-b), which are in agreement with other researchers' observation (e.g. $[14,16])$. Due to the large length-to-diameter ratio $\left(\mathrm{L} / \mathrm{D}_{\mathrm{o}}\right)$, specimen $\mathrm{S} 50-\mathrm{C}$ failed by global and local buckling. For double-skin tubes (SS as outer and GFRP as inner tube), there are sudden drops of applied load due to the buckling of inner GFRP tube (Fig. 12 (c). The load-strain curves for SWSSC-filled SS tubes indicate that after reaching peak load, the tubes can still sustain the load which displays high ductility (Fig. $12(\mathrm{a}-\mathrm{c}))$. The test was terminated due to the limited stroke of test machine (about $60 \mathrm{~mm}$ ). It is necessary to mention that there is obvious load drop after peak load for double-skin tubes with large void ratio (e.g. S165-S101-C) as a result of buckling of the inner tube. As shown in Fig.12 (a-c), similar behaviour is found in stress-strain relationship for fully filled tubes and double-skin tubes (except the bulking of the inner GFRP tube).

The failure of SWSSC-filled GFRP tubes was caused by the GFRP tube rupture in hoop direction (Fig. 12 (d-e)). Before reaching the ultimate load, the GFRP tube first buckled in longitudinal direction, which led to a sudden drop of applied load. Based on the test observation, the buckling of the inner GFRP tube in SWSSC-filled double-skin tubes took place earlier than that of outer GFRP tube. It should be mentioned that the GFRP tube buckling in longitudinal direction happened more than once during the loading process (as indicated by the load-strain curves in Fig. 12 (d-e)). There is not much difference in the shape of stress-strain curves for fully filled tubes and double-skin tubes. Compared to SWSSC-filled stainless steel tubes, the ultimate strain of SWSSC-filled GFRP tubes is much lower and they display a "brittle" behaviour.

As shown in Fig. 10 (a), the load-strain curves of SWSSC-filled stainless steel tubes in 
this research did not exhibits much strain-hardening responses. These load-strain curves can be classified as “Type B" curve based on Uy's research [16] and the tested failure load $\left(N_{\mathrm{t}}\right)$ is taken as the first peak load during the test. The tested failure load of SWSSC-filled GFRP tube is the maximum load during the test, which is also the load at which GFRP tube rupture happens. The tested failure loads of all specimens are summarised in Table 1.

\section{Discussion}

\subsection{Axial strain}

The axial strain can be obtained in two ways: (1) the averaged reading from axial strain gauges at mid-height (called "localised strain", $\varepsilon$ ) and (2) the ratio of axial end shortening to specimen length (called "overall strain", $\Delta / \mathrm{L}$ ). The localised strain can represent the strain of outer tubes and the overall strain can be regarded as the average strain throughout the whole length of the specimen. The latter is closer to the strain of confined concrete.

Comparisons of the localised strain and the overall strain of some specimen configurations of SS and GFRP are summarised in Fig. 13, which also consists the corresponding non-dimensional load (a ratio of applied load to the maximum load) versus strain $\left(N / N_{\mathrm{t}^{-}} \varepsilon\right)$ curves. Fig.13 indicates that: (1) at the initial loading stage, because of the possible gaps between loading plate and specimen end, the value of $\Delta / L$ can be much higher than $\varepsilon ;(2)$ when stainless steel tube is experiencing large deformation, such as elephant foot, $\Delta / L$ is much higher than $\varepsilon$; (3) For specimens containing GFRP tubes, once GFRP tube buckles, the $\Delta / L$ is much different from $\varepsilon$. As shown in Figure 13, the value of $(\Delta / L) / \varepsilon$ is more or less around 1.0 after the initial loading stage and before the collapse of the specimen.

The overall strain $(\Delta / L)$ is adopted as the axial strain of specimens throughout this paper. 
Nevertheless, it should be emphasised that the axial strain probably cannot represent the real strain of confined concrete after experiencing large deformation.

\subsection{Ultimate strain of GFRP tube}

The ultimate longitudinal strain is taken as the overall strain at which first buckling appeared in GFRP tube in longitudinal direction and the results are summarised in Table 6. Except specimen S114-F50-C, the ultimate longitudinal strain of GFRP inner tube is in good agreement with that of corresponding hollow sections. For fully filled tubes, the ultimate longitudinal strain of GFRP tube is slightly higher than that of corresponding hollow sections. The ultimate longitudinal strain of GFRP outer tube in double-skin tubes is much higher than that of corresponding hollow sections. It is believed that the filled-in concrete can delay the occurrence of local buckling of GFRP outer tubes. Furthermore, the stress condition in the tubes probably also affects the local buckling. The GFRP inner tube is under longitudinal compression and hoop compression, while the outer tube is under longitudinal compression and hoop tension.

The ultimate hoop rupture strain of GFRP tube is taken as the averaged reading of strain gauges in hoop direction and the results are summarised in Table 7, in which the rupture strain obtained from material test (disk-split test) is also listed. The ultimate hoop rupture strain of GFRP tube agrees well with that from disk-split test. This conclusion is different from that for concrete-filled FRP wraps, in which FRP hoop rupture strain in confined cylinders is much lower than that from flat coupon test [31]. The reason for the difference is that the hoop strength of GFRP tube in the present study is obtained by disk-split test on GFRP rings whereas the hoop strength of FRP wrap [31] was from flat 
coupon test.

\subsection{Axial stress-strain curves of concrete}

\subsubsection{Load distribution}

It is well known that due to the bi-axial stress condition, the confined concrete strength $\left(f_{\mathrm{cc}}{ }^{\prime}\right)$ is higher than that of unconfined concrete strength $\left(f_{\mathrm{c}}{ }^{\prime}\right)$. In order to discuss the confinement effect, the stress-strain curves of the concrete should be determined. As the tubes and concrete resist the applied load simultaneously, the load distribution among them will be first discussed here.

The load carried by the concrete is assumed equal to the difference between the applied load and the load carried by the tubes at the same strain. The load carried by stainless steel tube can be determined based on the stress-strain curve of corresponding hollow sections. If the strain of the concrete-filled tubes exceeds ultimate strain of corresponding hollow section, the load carried by stainless steel tube is assumed to be equal to the ultimate load of corresponding hollow section (as shown in Fig. 14). The load carried by the outer GFRP tube is calculated by multiplying the secant elastic modulus (obtained from GFRP hollow section test, 17.3GPa) with axial strains of GFRP tube (from strain gauges). The load carried by the inner GFRP tubes is determined by the simplified stress-strain model (Fig. 10) of corresponding hollow sections. The load distribution curves of typical test specimens are plotted in Fig. 15.

The specimen S50-H failed by global and local buckling, but the global buckling of inner SS tube with diameter of $50 \mathrm{~mm}$ in specimen S114-S50-C and F114-S50-C was avoided due to the filled-in concrete. Therefore, the stress-strain curves of S50-H cannot be 
used to calculate the load distribution in S114-S50-C and F114-S50-C. For specimen F50-C and F114-C, the strain gauges went out of function before specimen reaching peak load. The stress-strain curves of specimen S50-C, S114-S50-C, F114-S50-C, F50-C and F114-C are excluded in the discussion.

The stress in the concrete is equal to the load resisted by concrete divided by concrete area. It is emphasized that because the load in tube is derived from axial strain and the buckling of GFRP tube led to a sudden drop of applied load, the stress-strain curves in concrete are probably not accurate enough. Nevertheless, the relative comparison between them is still helpful in understanding the influence of some key parameters on the behaviour of confined-concrete.

\subsubsection{Effects of tube diameter to thickness ratio}

As shown in Fig. 16, with the increase of tube diameter to thickness ratio, the concrete stress to unconfined concrete strength ratio $\left(\sigma_{\mathrm{c}} / f_{\mathrm{c}}{ }^{\prime}\right)$ decreases. This is consistent with previous findings [1], i.e. the increase of tube diameter to thickness ratio can lead to the decrease of confining pressure acting on the concrete, which decreases the confined concrete strength. Fig. 16 also indicates that the concrete enhancement caused by SS tube is slightly lower than that by GFRP tube, but the confinement lasts for larger axial strain.

\subsubsection{Effects of outer tube types}

As shown in Fig. 17, the types of outer tube (SS tube or GFRP tube) can obviously affect the shape of $\sigma_{\mathrm{c}} / f_{\mathrm{c}}$ '-strain curves. The strength enhancement caused by GFRP tube is more significant than that by stainless steel tube, but the ultimate strain in SWSSC-filled GFRP tube is much lower than that in SWSSC-filled stainless steel tube. The $\sigma_{\mathrm{c}} / f_{\mathrm{c}}$-strain behaviour 
of SWSSC-filled GFRP tube is generally characterised by a bilinear response. When the expansion of concrete exceeds that of GFRP tube, the GFRP tube is fully activated in confinement and the confining pressure increases continually until the hoop rupture of GFRP tube. This kind of confinement effect is called as "active confinement effect". The behaviour of SWSSC-filled stainless steel tube is slightly different. After the stainless steel tube reaches yielding strength ( $0.2 \%$ proof strength), the increase of confining pressure slows down (for carbon steel with yielding plateau, the confining pressure will keep constant). This kind of confinement effect is called as "passive confinement effect". The different confinement behaviour of stainless steel tube and GFRP tube is substantially attributed by their different material properties.

\subsubsection{Effects of inner tube types}

The inner tube in SWSSC-filled double-skin tubes can effectively restrain the inward expansion of the concrete. Research by Fam \& Rizkalla [21] indicated that the addition of inner tube could enhance the confinement effect.

As mentioned before, the buckling of inner GFRP tube can cause a sudden drop of applied load and the type of inner tube can affect the shape of load-strain curves (as shown in Fig. 18). Fig. 18 shows that when the outer tube is GFRP the influence of inner tube type is negligible. However, when the outer tube is stainless steel, the ultimate stress is similar, but the inner SS tube will result in a much more ductile behaviour than that with GFRP inner tube.

\section{Capacity prediction of SWSSC-filled tubes}

\subsection{Capacity prediction of SWSSC fully filled stainless steel tubes}

Extensive research has been conducted on concrete-filled carbon steel tubes [1]. A design 
method was documented in detail by Han et al [32] where a confinement factor $(\xi)$ was adopted to address the passive confinement of carbon steel tube on concrete. The term $\xi$ can be determined by Eq. (1):

$$
\xi=\frac{A_{s} f_{y}}{A_{c} f_{c k}}
$$

where $A_{\mathrm{s}}$ is the cross-section area of steel tube, $f_{\mathrm{y}}$ is the yield strength of steel, $A_{\mathrm{c}}$ is the cross-section area of concrete, $f_{\text {ck }}$ is the characteristic strength of concrete. As given in [32], the predicted load carrying capacity $\left(N_{p}\right)$ of concrete-filled circular stub columns can be determined by Eq. (2) and Eq. (3):

$$
\begin{aligned}
& N_{p}=\left(A_{s}+A_{c}\right) f_{s c y} \\
& f_{s c y}=(1.14+1.02 \xi) f_{c k}
\end{aligned}
$$

where $f_{\text {scy }}$ is the "nominal yielding strength" of composite sections. The relationship between $f_{\text {scy }}$ and $f_{\text {ck }}$ (i.e. Eq. (3)) is obtained by using the regression analysis method.

Comparison to carbon steel, the major difference of stainless steel is its rounded-shape stress-strain curves without obvious yielding plateau. Therefore Eq. (3) cannot be directly used to determine the capacity of concrete-filled stainless steel tube. Furthermore, in some countries (e.g. US, Australia), the concrete cylinder strength $\left(f_{\mathrm{c}}{ }^{\prime}\right)$ is more widely used in design than concrete characteristic strength $\left(f_{\mathrm{ck}}\right)$.

Eq. (1) can be rewritten as:

$$
\xi=\frac{A_{s} f_{y}}{A_{c} f_{c}^{\prime}}
$$

and the new relationship between $f_{\text {scy }} / f_{\mathrm{c}}$, and $\xi$ is obtained by regression analysis method. The test data used in regression analysis $[14,15,16,33]$ are summarised in Table 8 . The regression analysis result is summarised in Fig.19. Therefore the compression capacity of 
circular concrete-filled stainless steel stub column can be determined by Eq. (5) and Eq. (6):

$$
\begin{aligned}
& N_{p}=\left(A_{s}+A_{c}\right) f_{s c y} \\
& f_{s c y}=(1.14+1.4 \xi) f_{c}^{\prime}
\end{aligned}
$$

The comparison between the test capacity $N_{\mathrm{t}}$ and predicted capacity by this modified method is shown in Fig. 20 for all the data collected. As shown in Fig. 20, the modified method can estimate the capacity accurately with an error generally less than $15 \%$. The comparison for SWSSC filled SS tubes is shown in Table 9, which suggests a good agreement.

\subsection{Capacity prediction of SWSSC-filled double-skin tubes (SS as the outer tube)}

The studies on concrete-filled double-skin stainless steel tube are rather limited. Han et al. [17] investigated the behaviour of double skin tubes with SS as the outer tube and carbon steel as the inner tube. They found that the outer tube behaves like a tube fully filled with concrete, whereas the inner tube behaves like an empty one without local buckling when the void ratio $(\chi)$ is less than 0.8 . This is similar to that observed for double skin tubes with carbon steel as both outer and inner tubes [34]. A design capacity model was presented in [17] for double skin tubes, which is a summation of the capacity of outer steel tube with sandwiched concrete and the capacity of inner tube. The formulae in [17] are adopted here with some modifications, i.e. replacing $f_{\mathrm{ck}}$ by $f_{\mathrm{c}}$, and replacing the term $(1.14+1.02 \xi)$ by $(1.14+1.4 \xi)$ as derived in Section 4.1 .2 of this paper.

The modified formulae are listed below:

$$
\begin{aligned}
& N_{p}=\left(A_{o}+A_{c}\right) f_{s c y}+A_{i} f_{y i} \\
& f_{s c y}=\frac{\alpha}{1+\alpha} \chi^{2} f_{y o}+\frac{1+\alpha_{n}}{1+\alpha}(1.14+1.4 \xi) f_{c}^{\prime} \\
& \xi=\frac{A_{o} f_{y o}}{A_{c} f_{c}^{\prime}}
\end{aligned}
$$




$$
\begin{aligned}
& \alpha=A_{o} / A_{c} \\
& \alpha_{n}=A_{o} / A_{c n} \\
& \chi=D_{i} / D_{o}
\end{aligned}
$$

where $A_{\mathrm{o}}$ is the outer tube cross-section area, $A_{\mathrm{c}}$ is the concrete area, $A_{\mathrm{i}}$ is the inner tube cross-section area, $A_{c n}$ is the nominal concrete area $\left(=\pi D_{\mathrm{o}}{ }^{2} / 4\right), f_{\mathrm{yo}}$ is the yield strength of the outer tube $\left(f_{0.2}\right.$ for stainless steel $), f_{\mathrm{yi}}$ is the yield strength of inner tube ( $f_{0.2}$ for stainless steel or residual strength, $\sigma_{\text {res }}$ for GFRP defined in Fig. 10), $f_{\mathrm{c}}$ ' is the concrete strength and $\chi$ is the void ratio.

A comparison between the test results and prediction using Eq. (7-12) is summarised in Table 10. As shown in Table 10, the modified formula can be extended to estimate the capacity of double skin tubes with SS as the outer tube and SS or GFRP as the inner tube.

\subsection{Capacity prediction of SWSSC-filled GFRP tubes}

\subsubsection{Existing model for FRP-confined concrete}

Teng et al. [20] proposed a design-oriented stress-strain model for FRP-confined concrete. This model has been widely adopted by other researchers. Teng's model consists of a parabolic portion followed by a linear portion. This model allows the effects of confinement stiffness and the jacket strain capacity to be separately reflected in both the axial strain and the compressive strength equations. It accounts for the effect of confinement stiffness explicitly instead of having it reflected only through the confinement ratio [20]. More details of this model can be found in Teng et al. [20].

A comparison between the stress-strain curves determined by Teng's model and test results of fully SWSSC-filled GFRP tube is shown in Fig. 21. The predicted ultimate stress, 
ultimate strain and the test results are also reported in Table 11 , in which $f_{\mathrm{cc}}$ ' and $\varepsilon_{\mathrm{cu}}$ are the ultimate strength and strain of confined concrete, $f_{\mathrm{c}}$, and $\varepsilon_{\mathrm{co}}$ are the corresponding values of unconfined concrete. As shown in Fig. 21, there is obvious difference between the model prediction and test results: the stress-strain curves from tests are lower than that from Teng's model. Table 11 indicates that Teng's model over-estimates the ultimate stress, whereas the ultimate strain prediction is reasonable. It should be noted that Teng's model was derived from FRP-confined concrete where all the FRP fibres were in the hoop direction, whereas in the current tests, $20 \%, 40 \%$, and $40 \%$ fibres are in the angles of $15^{\circ}, \pm 40^{\circ}$ and $\pm 75^{\circ}$ with respect to longitudinal axis of GFRP tubes. It is worthwhile to mention that a similar study recently carried out by Zhang et al. [22] indicated that Teng's model can predict the stress-strain response of concrete confined by FRP tubes that had strength in both longitudinal and hoop directions. However, the ratio of hoop strength to longitudinal strength of FRP in Zhang et al.'s test [22] $\left(f_{\mathrm{uh}} / f_{\mathrm{ul}}=6.8\right)$ is much higher than that in this research $\left(f_{\mathrm{uh}} / f_{\mathrm{ul}}=1.4\right)$.

\subsubsection{Proposed capacity formulae}

As discussed in previous section, because the longitudinal strength of GFRP tube cannot be ignored, Teng's model is not appropriate to estimate the ultimate capacity of concrete-filled GFRP tubes. Therefore, it is necessary to propose a new method to determine the capacity of concrete-filled GFRP tubes.

The formulae to determine the capacity of concrete fully filled GFRP tubes are listed below:

$$
N_{p}=f_{u n}\left(A_{c}+A_{o} \frac{f_{u l}}{f_{u h}}\right)
$$




$$
\begin{aligned}
& f_{u n} / f_{c}^{\prime}=1.12+2.64 \frac{f_{l}}{f_{c}^{\prime}} \\
& f_{l}=\frac{2 f_{u h} t_{o}}{D_{o}}
\end{aligned}
$$

where $A_{\mathrm{c}}$ is the concrete area, $A_{\mathrm{o}}$ is the FRP tube cross-section area, $f_{\mathrm{ul}}$ is the longitudinal strength of FRP, $f_{\text {uh }}$ is the hoop strength of FRP, $f_{\mathrm{c}}$ ' is the concrete strength, $t_{\mathrm{o}}$ is the thickness of outer FRP tube, $D_{\mathrm{o}}$ is the diameter of outer FRP tube, $f_{l}$ is the confining pressure, and $f_{\text {un }}$ is the nominal ultimate strength. The expression in Eq. (14) is determined by regression analysis of test data from Fam and Rizkalla's test [21], Zhang et al.'s test [22] and the current paper. A comparison between the predicted capacity and test capacity for all the existed data is summarised in Fig. 23 (the double-skin tubes in section 4.4 are also included). A reasonable agreement is found. Table 12 summarizes the comparison of capacity obtained by this new method and the current test results. The averaged ratio of test capacity to predicted capacity $\left(N_{p} / N_{\mathrm{t}}\right)$ ratio is 0.99 with coefficient of variation $(\mathrm{COV})$ of 0.03 .

\subsection{Capacity prediction of SWSSC-filled double-skin tubes (GFRP as the outer tube)}

\subsubsection{Existing model}

Yu et al. [35] applied Teng's model [20] to concrete in hybrid FRP-concrete-steel double-skin tubular columns (referred as "modified Teng's model” in this paper). Based on their research, the compressive strength of confined concrete is mainly dependent on the confinement stiffness and the FRP rupture strain but not the void ratio. They also found that the ultimate axial strain is related to void ratio and proposed a modified version to calculate the ultimate axial strain of the confined concrete.

A comparison between the stress-strain curves determined by the modified Teng's model and test results is shown in Fig. 24. The predicted ultimate stress, ultimate strain and the test 
results are also reported in Table 13. As shown in Fig. 24, similar to fully filled tubes, there is obvious difference between the model prediction and test results: the stress-strain curves from tests are lower than those from modified Teng's model. Table 13 indicates that Teng's model over-estimate the ultimate stress, whereas the ultimate strain prediction is reasonable. This is consistent with that observed for fully filled GFRP tubes described in Section 4.3.1 of this paper.

\subsubsection{Proposed capacity formulae}

For concrete-filled double-skin tubes, based on an earlier study [35] on concrete-filled double-skin FRP wraps, it is assumed that the capacity of double-skin tubes consists of the capacity of outer tube with sandwiched concrete and the capacity of inner tube. Therefore the capacity of SWSSC-filled double-skin GFRP tubes (GFRP as the outer tube) can be determined by:

$$
\begin{aligned}
& N_{p}=N_{c o}+N_{i} \\
& N_{i}=f_{a v, i} A_{i}
\end{aligned}
$$

where $N_{\text {co }}$ is the capacity of outer tube with sandwiched concrete, which can be determined by Eq. (15), $N_{\mathrm{i}}$ is the capacity of inner tube. Because of the inner tube is surrounded by concrete, SS inner tube can reach stresses higher than the yield stress $\left(f_{0.2}\right)$ and GFRP inner tube can reach stresses higher than the residual stress $\left(\sigma_{\text {res }}\right)$. For SS inner tube, an average stress between the yield stress $\left(f_{0.2}\right)$ and the ultimate strength $\left(f_{\mathrm{u}}\right)$ is adopted, i.e. $f_{\mathrm{av}, \mathrm{i}}$ in Eq. (17) is taken as $\left(f_{0.2}+f_{\mathrm{u}}\right) / 2$. For GFRP inner tube, an average stress between the residual stress $\left(\sigma_{\text {res }}\right)$ and the ultimate strength $\left(f_{\mathrm{ul}}\right)$ is adopted, i.e. $f_{\mathrm{av}, \mathrm{i}}$ in Eq. $(17)$ is taken as $\left(\sigma_{\mathrm{res}}+f_{\mathrm{ul}}\right) / 2$.

Table 14 summarizes the comparison of capacity obtained by this new method and test 
results in the present study. A reasonable agreement (within $7 \%$ on average) is achieved.

\section{Conclusions}

This paper presents an experimental investigation on seawater and sea sand concrete (SWSSC) filled glass fibre reinforced polymer (GFRP) and stainless steel (SS) circular tubes. A total of 24 stub columns, including hollow SS or GFRP tubes, SWSSC fully filled tubes and double-skin tubes, were tested under axial compression with the load applied to concrete and tubes simultaneously. The following observations and conclusions are made based on limited experimental data.

1. The proposed SWSSC mix achieved a compressive strength $\sim 31 \mathrm{MPa}$ with desired workability for fully filled tubes and double skin tubes.

2. The ultimate hoop rupture strain of GFRP tube agrees well with that from disk-split test. The ratio of hoop strength to longitudinal strength of GFRP in this paper is about 1.4 .

3. The behaviour of SWSSC-fully filled SS tubes is similar to that of double skin tubes with SS as the outer tube. They are much more ductile than SWSSC-fully filled GFRP tubes and double skin tubes with GFRP as the outer tube.

4. The concrete enhancement caused by SS tube is slightly lower than that by GFRP tube, but the confinement lasts for larger axial strain. When the outer tube is GFRP the influence of inner tube type on concrete confinement is negligible. However, when the outer tube is stainless steel, the ultimate stress is similar, but the inner SS tube will result in a much more ductile behaviour than that with GFRP inner tube. 
5. Capacity formulae were proposed to estimate the load carrying capacity of SWSSC fully filled SS or GFRP tubes, and that of double skin tubes with four combinations of inner and outer tubes, i.e. SS and SS, SS and GFRP, GFRP and GFRP and GFRP and SS. Reasonable agreement with experimental data has been achieved.

Research is being conducted on the durability of SWSSC-filled SS tubes and FRP tubes.

\section{Acknowledgement}

The authors wish to acknowledge the financial support provided by the Australian Research Council (ARC) through an ARC Discovery Grant (DP160100739), and CST composites for suppling the GFRP tubes. The tests were conducted in the Civil Engineering Laboratory at Monash University. Thanks are given to Mr. YaoYuan Zhang and Mr. RuiFeng Nie for conducting part of the tests and to Mr. Long Goh and Mr. Jeff Doddrell for their assistance. We thank Mr. Damian Carr of Bayside City Council for his permission to obtain seawater and sea sand from Brighton Beach in Melbourne.

\section{References:}

[1] X.L. Zhao, L.H. Han, H. Lu, Concrete-filled tubular members and connections. Taylor \& Francis, Oxford, UK, 2010.

[2] R. Kochhar, 10 projections for the global population in 2050, Pew Research Report. http://www.pewresearch.org/author/rkochhar/, 2014, (accessed 3 February 2014).

[3] K. Kupwade-Patil, E. Allouche, Impact of alkali silica reaction on fly ash-based Geopolymer concrete, Journal of Materials in Civil Engineering, ASCE, 2013, 25(1), 131-139. 
[4] T.U.T. Mohammed, H. Hamada, T. Yamaji, Performance of seawater-mixed concrete in the tidal environment. Cement and Concrete Research, 2004, 34(4), 593-601.

[5] S.K. Kaushik, S. Islam, Suitability of sea water for mixing structural concrete exposed to a marine environment. Cement and Concrete Composites, 1995, 17(3), 177-185.

[6] M. Shams, M.A. Saadeghvaziri, State of the art of concrete-filled steel tubular columns. ACI Structural Journal, 1997, 94(5), 558-571.

[7] N.E. Shanmugam, B. Lakshmi, State of the art report on steel-concrete composite columns. Journal of Constructional Steel Research, 2001, 57(10), 1041-1080.

[8] L.H. Han, Y.F. Yang, Technology of modern concrete-filled steel structures. China Architecture \& Building Press, Beijing, P.R. China, 2007.

[9] B.C. Gourley, C. Tort, M.D. Denavit, P.H. Schiller, J.F. Hajjar, A synopsis of studies of the monotonic and cyclic behaviour of concrete-filled steel tube members, connections, and frames, Report No. NSEL-008, NSEL Report Series, Department of Civil and Environmental Engineering, University of Illinois at Urbana-Champaign, USA, 2008.

[10] K. Nakanishi, T. Kitada, H. Nakai, Experimental study on ultimate strength and ductility of concrete filled steel columns under strong earthquakes. Journal of Constructional Steel Research, 1999, 51(3), 297-319.

[11] M.L. Lin, K.C. Tsai, Behaviour of double-skinned composite steel tubular columns subjected to combined axial and flexural loads. In Proceedings of the First International Conference on Steel \& Composite Structures, Pusan, edited by Choi, C.K. and Kwak, H.G. (Taejon: Techno-Press), 2005, pp. 1145-1152.

[12] X.L. Zhao, L.H. Han, Double skin composite construction. Progress in Structural Engineering and Materials, 2006, 8(3), 93-102. 
[13] Y. Wang, X.D. Qian, J.Y.R. Liew, M.H. Zhang, Experimental behavior of cement filled pipe-in-pipe composite structures under transverse impact. International Journal of Impact Engineering, 72(2014), 1-16.

[14] D. Lam, L. Gardner, Structural design of stainless steel concrete filled columns. Journal of Constructional Steel Research, 2008, 64(11), 1275-1282.

[15] V.W.Y. Tam, Z. Wang, Z. Tao, Behaviour of recycled aggregate concrete filled stainless steel stub columns. Materials and Structures, 2014, 47(1-2), 293-310.

[16] B. Uy, Z. Tao, L.H. Han, Behaviour of short and slender concrete-filled stainless steel tubular columns. Journal of Constructional Steel Research, 2011, 67(3), 360-378.

[17] L.H. Han, Q.X. Ren, W. Li, Tests on stub stainless steel-concrete-carbon steel double-skin tubular (DST) columns, Journal of Constructional Steel Research, 67 (2011), 437-452.

[18] J.G. Teng, L. Lam, Behavior and modeling of fiber reinforced polymer-confined concrete. Journal of Structural Engineering, ASCE, 2004, 130(11), 1713-1723.

[19] T. Ozbakkaloglu, J.C. Lim, T. Vincent, FRP-confined concrete in circular sections: Review and assessment of stress-strain models. Engineering Structures, 49(2013), 1068-1088.

[20] J.G. Teng, T. Jiang, L. Lam, Y.Z. Luo, Refinement of a design-oriented stress-strain model for FRP-confined concrete. Journal of Composites for Construction, ASCE, 2009, 13(4), 269-278.

[21] A.Z. Fam, S.H. Rizkalla, Behavior of axial loaded concrete-filled circular fiber-reinforced polymer tubes. ACI Strucural Journal, 2001, 98(3), 280-289.

[22] B. Zhang, T. Yu, J.G. Teng, Behavior of concrete-filled FRP tubes under cyclic axial compression. Journal of Composites for Construction, 2015, 19(3), 10.1061/(ASCE)CC.1943-5614.0000523, 04014060.

[23] AS 1141.11.1. Methods for sampling and testing aggregates - Particle size distribution - Sieving method, Standards Australia, Sydney, 2009. 
[24] S. Chuah, W.H. Duan, Z. Pan, A.H. Korayem, X.L. Zhao, F. Collins, J.G. Sanjayan, The properties of fly ash based geopolymer mortarsmade with dune sand. Materials and Design, 92(2016), 571-578.

[25] H.X. Huang, An experimental study on the durability of sea sand concrete, Master thesis, Jinan University, Jinan, China (in Chinese), 2007.

[26] R. Nong, The experimental study on mechanical properties of sea sand concrete components, Master thesis, Harbin Institute of Technology, Harbin, China (in Chinese), 2008.

[27] AS/NZS 4673. Cold-formed stainless steel structures, Standards Australia, Sydney, 2001.

[28] AS 1391. Metallic materials-Tensile testing at ambient temperature, Standards Australia, Sydney, 2007.

[29] ASTM D3039/D3039M-14. Standard test method for tensile properties of polymer matrix composite materials, American Society for Testing and Materials, West Conshohocken, PA, 2014.

[30] ASTM D2290-12. Standard test method for apparent hoop tensile strength of plastic or reinforced plastic pipe, American Society for Testing and Materials, West Conshohocken, PA, 2012.

[31] L. Lam, J.G. Teng, Ultimate condition of fiber reinforced polymer-confined concrete. Journal of Composites for Construction, ASCE, 2004, 8(6), 539-548.

[32] L.H. Han, G.H. Yao, X.L. Zhao, Tests and calculations for hollow structural steel (HSS) stub columns filled with self-consolidating concrete (SCC). Journal of Constructional Steel Research, 61(2005), 1241-1269.

[33] Y.F. Yang, G.L. Ma, Experimental behaviour of recycled aggregate concrete filled stainless steel tube stub columns and beams. Thin-Walled Structures, 66 (2013), 62-75.

[34] Z. Tao, L.H. Han, X.L. Zhao, Behaviour of concrete-filled double skin (CHS inner and CHS outer) steel tubular stub columns and beam-columns. Journal of Constructional Steel Research, 60(2004), 1129-1158.

[35] T. Yu, J.G. Teng, Y.L. Wong, Stress-strain behavior of concrete in hybrid FRP-concrete-steel double-skin tubular columns. Journal of Structural Engineering, ASCE, 2010, 136(4), 379-389. 
Tables

Table 1 Details of specimens

\begin{tabular}{llllllll}
\hline \multirow{2}{*}{ Specimen } & \multicolumn{3}{l}{ Outer tube (mm) } & \multicolumn{3}{l}{ Inner tube $(\mathrm{mm})$} & $N_{\mathrm{t}}$ \\
& $D_{\mathrm{o}}$ & $t_{\mathrm{o}}$ & Mat. & $D_{\mathrm{i}}$ & $t_{\mathrm{i}}$ & Mat. & $(\mathrm{kN})$ \\
\hline S50-H & 47.9 & 2.79 & SS & N/A & N/A & N/A & 118 \\
S101-H & 101.2 & 2.81 & SS & & & & 335 \\
S114-H & 114.0 & 2.86 & SS & & & & 355 \\
S165-H & 168.3 & 3.23 & SS & & & & 545 \\
F50-H & 51.2 & 3.20 & GFRP & & & & 98 \\
F101-H & 100.2 & 2.94 & GFRP & & & & 199 \\
F114-H & 115.3 & 3.03 & GFRP & & & & 206 \\
F165-H & 158.0 & 2.96 & GFRP & & & & 213 \\
S50-C & 47.9 & 2.77 & SS & & & & 199 \\
S101-C & 101.2 & 2.83 & SS & & & & 729 \\
S114-C & 113.9 & 2.88 & SS & & & & 800 \\
S165-C & 168.2 & 3.15 & SS & & & & 1522 \\
F50-C & 51.1 & 3.07 & GFRP & & & & 244 \\
F101-C & 100.1 & 3.13 & GFRP & & & & 670 \\
F114-C & 115.2 & 3.13 & GFRP & & & & 813 \\
F165-C & 158.2 & 3.14 & GFRP & & & & 1336 \\
S114-S50-C & 114.5 & 2.87 & SS & 47.9 & 2.73 & SS & 909 \\
S165-S101-C & 167.8 & 3.18 & SS & 101.2 & 2.80 & SS & 1409 \\
S114-F50-C & 114.2 & 2.95 & SS & 51.2 & 3.20 & GFRP & 799 \\
S165-F101-C & 168.4 & 3.22 & SS & 100.3 & 3.06 & GFRP & 1167 \\
F114-S50-C & 114.8 & 2.91 & GFRP & 47.9 & 2.82 & SS & 795 \\
F165-S101-C & 158.0 & 2.92 & GFRP & 101.8 & 2.91 & SS & 880 \\
F114-F50-C & 114.7 & 2.93 & GFRP & 51.3 & 3.09 & GFRP & 872 \\
F165-F50-C & 158.3 & 3.13 & GFRP & 100.3 & 3.13 & GFRP & 1301 \\
\hline
\end{tabular}


Table 2 Concrete mixture

\begin{tabular}{ll}
\hline Constituents & $\begin{array}{l}\text { weight } \\
\left(\mathrm{kg} / \mathrm{m}^{3}\right)\end{array}$ \\
\hline Slag & 360 \\
Seawater & 190 \\
Sea sand & 830 \\
Coarse aggregate & 1130 \\
Sodium & \\
meta-silicate & 38.4 \\
Hydrated lime slurry & 14.4 \\
\hline
\end{tabular}


Table 3 Tensile coupon test results of stainless steel

\begin{tabular}{lll}
\hline Tube & $\begin{array}{l}f_{0.2} \\
(\mathrm{MPa})\end{array}$ & $\begin{array}{l}f_{\mathrm{u}} \\
(\mathrm{MPa})\end{array}$ \\
\hline $50 \times 3$ & 306.8 & 618.2 \\
$101 \times 3$ & 324.4 & 647.2 \\
$114 \times 3$ & 270.3 & 579.4 \\
$165 \times 3$ & 280.1 & 575.3 \\
\hline
\end{tabular}


Table 4 Material properties of GFRP

\begin{tabular}{lllllll}
\hline & \multicolumn{3}{l}{ Longitudinal direction } & & Hoop direction \\
\cline { 2 - 4 } Tube size & $f_{\mathrm{ul}}(\mathrm{MPa})$ & $\varepsilon_{\mathrm{ul}}$ & $E_{l}(\mathrm{GPa})$ & $v$ & & $f_{\mathrm{uh}}(\mathrm{MPa})$ \\
\hline $50 \times 3$ & 242.4 & 0.020 & 23.2 & 0.32 & & 272.9 \\
$101 \times 3$ & 229.3 & 0.026 & 18.7 & 0.30 & 368.0 \\
$114 \times 3$ & 211.7 & 0.018 & 19.2 & 0.33 & 328.3 \\
$165 \times 3$ & 186.8 & 0.012 & 20.7 & 0.32 & & 266.0 \\
Mean & 217.6 & 0.019 & 20.1 & 0.32 & & 308.8 \\
COV & 0.11 & 0.31 & 0.10 & 0.08 & 0.16 \\
\hline
\end{tabular}


Table 5. Test results of GFRP hollow sections

\begin{tabular}{lllll}
\hline Specimen & $\sigma_{\mathrm{u}}(\mathrm{MPa})$ & $\varepsilon_{\mathrm{u}}$ & $\sigma_{\text {res }}(\mathrm{MPa})$ & $f_{\mathrm{u} l}$ average $(\mathrm{MPa})$ \\
\hline F50-H & 202.9 & 0.012 & 111.6 & \\
F101-H & 221.4 & 0.012 & 53.9 & 217.6 \\
F114-H & 192.5 & 0.011 & 43.7 & \\
F165-H & 148.1 & 0.009 & 32.6 & \\
\hline
\end{tabular}


Table 6. Ultimate longitudinal strain of GFRP tube

\begin{tabular}{lllllll}
\hline Specimen & $\begin{array}{l}\text { Inner } \\
\text { Tube }\end{array}$ & $\begin{array}{l}\text { Corresponding } \\
\text { hollow section }\end{array}$ & $\begin{array}{l}\text { Ratio of } \\
\text { inner to } \\
\text { hollow }\end{array}$ & $\begin{array}{l}\text { Outer } \\
\text { tube }\end{array}$ & $\begin{array}{l}\text { Corresponding } \\
\text { hollow section }\end{array}$ & $\begin{array}{l}\text { Ratio of } \\
\text { outer to } \\
\text { hollow }\end{array}$ \\
\hline F50-C & N/A & N/A & N/A & 0.015 & 0.012 & 1.26 \\
F101-C & N/A & N/A & N/A & 0.012 & 0.012 & 1.00 \\
F114-C & N/A & N/A & N/A & 0.014 & 0.011 & 1.26 \\
F165-C & N/A & N/A & N/A & 0.011 & 0.009 & 1.26 \\
F114-F50-C & 0.012 & 0.012 & 1.00 & 0.018 & 0.011 & 1.62 \\
F165-F101-C & 0.013 & 0.012 & 1.08 & 0.024 & 0.009 & 2.79 \\
S114-F50-C & 0.019 & 0.012 & 1.62 & N/A & N/A & N/A \\
S165-F101-C & 0.010 & 0.012 & 0.78 & N/A & N/A & N/A \\
F114-S50-C & N/A & N/A & N/A & 0.016 & 0.011 & 1.38 \\
F165-S101-C & N/A & N/A & N/A & 0.021 & 0.009 & 2.47 \\
\hline
\end{tabular}


Table 7 Ultimate hoop rupture strain of GFRP tube

\begin{tabular}{ll}
\hline Specimen & $\begin{array}{l}\text { Outer } \\
\text { tube }\end{array}$ \\
\hline F101-C & 0.013 \\
F165-C & 0.013 \\
F114-F50-C & 0.012 \\
F165-F101-C & 0.008 \\
F114-S50-C & 0.012 \\
F165-S101-C & 0.014 \\
Average hoop strain from & 0.014 \\
disk-split test & \\
\hline
\end{tabular}


Table 8 Test data of concrete-filled stainless steel tube for regression analysis

\begin{tabular}{|c|c|c|c|c|c|}
\hline$D_{\mathrm{o}} / t_{\mathrm{o}}$ & $\begin{array}{l}f_{0.2} \\
(\mathrm{MPa})\end{array}$ & $\begin{array}{l}f_{\mathrm{c}}^{\prime} \\
(\mathrm{MPa})\end{array}$ & $\begin{array}{l}\text { No. of } \\
\text { specimens }\end{array}$ & Reference & Notes \\
\hline 64-102 & $259-320$ & 20,30 & 7 & Uy et al. 2011 [16] & $\begin{array}{l}\text { Only "type B" } \\
\text { specimens }\end{array}$ \\
\hline 19,52 & 266,412 & $31-65$ & 6 & Lam \& Gardner 2008 [14] & $\begin{array}{l}\text { " } N_{\text {test }}(5 \%) " \text { is } \\
\text { used as tested } \\
\text { capacity }\end{array}$ \\
\hline 59 & 340 & $38-42$ & 4 & Tam et al. 2014 [15] & $\begin{array}{l}\text { Recycled } \\
\text { aggregate were } \\
\text { used }\end{array}$ \\
\hline 68 & $287-293$ & $44-50$ & 7 & Yang \& Ma 2013 [33] & $\begin{array}{l}\text { Recycled } \\
\text { aggregate were } \\
\text { used }\end{array}$ \\
\hline $36-53$ & $270-324$ & 31.4 & 3 & This paper & \\
\hline
\end{tabular}


Table 9 Comparison between experimental capacity and estimated capacity for SWSSC filled stainless steel tubes

\begin{tabular}{lllll}
\hline Data & Specimen & $\begin{array}{l}N_{\mathrm{t}} \\
(\mathrm{kN})\end{array}$ & $\begin{array}{l}N_{\mathrm{p}} \\
(\mathrm{kN})\end{array}$ & $N_{p} / N_{\mathrm{t}}$ \\
\hline & S101-C & 729 & 734 & 1.01 \\
This & S114-C & 800 & 786 & 0.98 \\
paper & S165-C & 1522 & 1487 & 0.98 \\
& Mean & & & 0.99 \\
& COV & & & 0.01 \\
\hline All the data & Mean & & & 1.00 \\
listed in Table 8 & COV & & & 0.13 \\
\hline
\end{tabular}


Table 10 Capacity comparison for concrete-filled double-skin tubes (stainless steel as the outer tube)

\begin{tabular}{lllllllll}
\hline Specimen & $f_{\mathrm{yo}}(\mathrm{MPa})$ & $f_{\mathrm{yi}}(\mathrm{MPa})$ & $f_{\mathrm{c}}^{\prime}(\mathrm{MPa})$ & $\chi$ & $\xi$ & $N_{\mathrm{t}}(\mathrm{kN})$ & $N_{\mathrm{p}}(\mathrm{kN})$ & $N_{p} / N_{\mathrm{t}}$ \\
\hline S114-S50-C & 270.3 & 306.8 & 31.4 & 0.42 & 0.93 & 909 & 803 & 0.88 \\
S165-S101-C & 280.1 & 324.4 & 31.4 & 0.60 & 0.72 & 1409 & 1352 & 0.96 \\
S114-F50-C & 270.3 & 113.6 & 31.4 & 0.45 & 0.96 & 799 & 731 & 0.91 \\
S165-F101-C & 280.1 & 53.9 & 31.4 & 0.60 & 0.72 & 1167 & 1143 & 0.98 \\
Mean & & & & & & & & 0.93 \\
COV & & & & & & & & 0.04 \\
\hline
\end{tabular}


Table 11 Comparison of ultimate stress and strain from Teng's model and test results

\begin{tabular}{|c|c|c|c|c|c|c|}
\hline \multirow{2}{*}{ Specimen } & \multicolumn{2}{|c|}{ Teng's model } & \multicolumn{2}{|l|}{ Test } & \multicolumn{2}{|c|}{ Test/Teng's mode } \\
\hline & $f_{\mathrm{cc}}{ }^{\prime} / f_{\mathrm{c}}$, & $\varepsilon_{\mathrm{cu}} / \varepsilon_{\mathrm{co}}$ & $f_{\mathrm{cc}}{ }^{\prime} / f_{\mathrm{c}}$, & $\varepsilon_{\mathrm{cu}} / \varepsilon_{\mathrm{co}}$ & $f_{\mathrm{cc}}{ }^{\prime} / f_{\mathrm{c}}{ }^{\prime}$ & $\varepsilon_{\mathrm{cu}} / \varepsilon_{\mathrm{co}}$ \\
\hline F101-C & 3.4 & 19.8 & 2.2 & 17.7 & 0.64 & 0.90 \\
\hline F165-C & 2.4 & 14.1 & 1.8 & 14.0 & 0.77 & 1.00 \\
\hline Mean & & & & & 0.71 & 0.95 \\
\hline $\mathrm{COV}$ & & & & & 0.09 & 0.05 \\
\hline
\end{tabular}


Table 12 Comparison between new method and test results for fully filled GFRP tubes

\begin{tabular}{lllllllll}
\hline Specimen & $\begin{array}{l}f_{\mathrm{u} l} \\
(\mathrm{MPa})\end{array}$ & $\begin{array}{l}f_{\mathrm{uh}} \\
(\mathrm{MPa})\end{array}$ & $\begin{array}{l}f_{\mathrm{c}}{ }^{\prime} \\
(\mathrm{MPa})\end{array}$ & $\chi \begin{array}{l}\mathrm{f}_{1} \\
(\mathrm{MPa})\end{array}$ & $\begin{array}{l}N_{\mathrm{t}} \\
(\mathrm{kN})\end{array}$ & $\begin{array}{l}N_{\mathrm{p}} \\
(\mathrm{kN})\end{array}$ & $N_{\mathrm{p}} / N_{\mathrm{t}}$ \\
\hline F50-C & 217.6 & 308.8 & 31.4 & 0 & 37.1 & 244 & 1.05 & 0.96 \\
F101-C & 217.6 & 308.8 & 31.4 & 0 & 19.3 & 670 & 0.98 & 1.03 \\
F114-C & 217.6 & 308.8 & 31.4 & 0 & 16.8 & 813 & 0.99 & 1.01 \\
F165-C & 217.6 & 308.8 & 31.4 & 0 & 12.3 & 1336 & 0.97 & 1.03 \\
Mean & & & & & & & & 0.99 \\
COV & & & & & & & & 0.03 \\
\hline
\end{tabular}


Table 13 Comparison of ultimate stress and strain from Teng's model and test results

\begin{tabular}{|c|c|c|c|c|c|c|}
\hline \multirow{2}{*}{ Specimen } & \multicolumn{2}{|c|}{ Teng's model } & \multicolumn{2}{|l|}{ Test } & \multicolumn{2}{|c|}{ Test/Teng's model } \\
\hline & $f_{\mathrm{cc}}{ }^{\prime} / f_{\mathrm{c}}{ }^{\prime}$ & $\varepsilon_{\mathrm{cu}} / \varepsilon_{\mathrm{co}}$ & $f_{\mathrm{cc}}{ }^{\prime} / f_{\mathrm{c}}{ }^{\prime}$ & $\varepsilon_{\mathrm{cu}} / \varepsilon_{\mathrm{co}}$ & $f_{\mathrm{cc}}{ }^{\prime} / f_{\mathrm{c}}{ }^{\prime}$ & $\varepsilon_{\mathrm{cu}} / \varepsilon_{\mathrm{co}}$ \\
\hline F114-F50-C & 2.9 & 19.0 & 2.3 & 18.8 & 0.81 & 0.98 \\
\hline F165-F101-C & 2.4 & 17.0 & 1.5 & 15.9 & 0.65 & 0.93 \\
\hline F114-S50-C & 2.8 & 18.7 & 2.1 & 16.9 & 0.75 & 0.90 \\
\hline F165-S101-C & 2.3 & 16.3 & 1.6 & 18.7 & 0.72 & 1.15 \\
\hline Mean & & & & & 0.73 & 0.99 \\
\hline $\mathrm{COV}$ & & & & & 0.08 & 0.10 \\
\hline
\end{tabular}


Table 14 Comparison between new method and test results for double-skin tubes (GFRP as the outer tube)

\begin{tabular}{|c|c|c|c|c|c|c|c|c|c|}
\hline \multirow{2}{*}{ Specimen } & \multicolumn{2}{|c|}{ Outer (MPa) } & \multirow{2}{*}{$\begin{array}{l}f_{\mathrm{yi}} \\
(\mathrm{MPa})\end{array}$} & \multirow{2}{*}{$\begin{array}{l}f_{\mathrm{c}}, \\
(\mathrm{MPa})\end{array}$} & \multirow[b]{2}{*}{$\chi$} & \multirow{2}{*}{$\begin{array}{l}\mathrm{f}_{1} \\
(\mathrm{MPa})\end{array}$} & \multirow{2}{*}{$\begin{array}{l}N_{\mathrm{t}} \\
(\mathrm{kN})\end{array}$} & \multirow{2}{*}{$\begin{array}{l}N_{\mathrm{p}} \\
(\mathrm{kN})\end{array}$} & \multirow{2}{*}{$N_{\mathrm{p}} / N_{\mathrm{t}}$} \\
\hline & $\mathrm{f}_{\mathrm{ul}}$ & $f_{\mathrm{uh}}$ & & & & & & & \\
\hline F114 & 217.6 & 308.8 & 164.6 & 31.4 & 0.45 & 15.7 & 795 & 688 & 0.87 \\
\hline F165 & 217.6 & 308.8 & 135.8 & 31.4 & 0.63 & 12.2 & 880 & 893 & 1.01 \\
\hline F114 & 217.6 & 308.8 & 462.5 & 31.4 & 0.42 & 15.6 & 872 & 814 & 0.93 \\
\hline F165-S101-C & 217.6 & 308.8 & 485.8 & 31.4 & 0.64 & 11.4 & 1301 & 1160 & 0.89 \\
\hline Mean & & & & & & & & & 0.93 \\
\hline $\mathrm{COV}$ & & & & & & & & & 0.06 \\
\hline
\end{tabular}




\section{Figures}

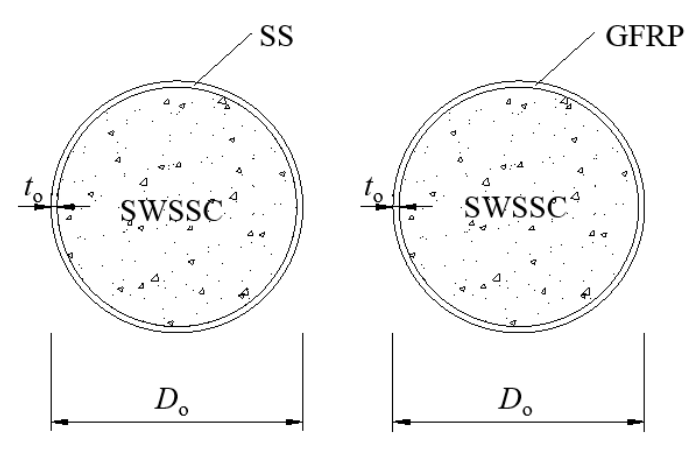

(a) Tubes fully filled with concrete

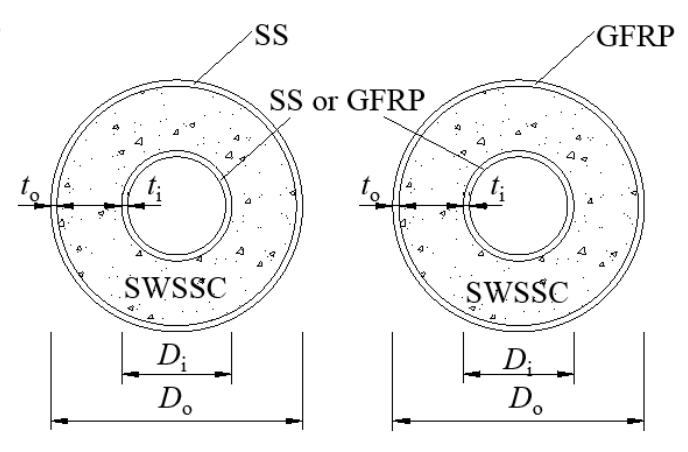

(b) Concrete-filled double-skin tubes

Fig. 1. Type of cross-sections 


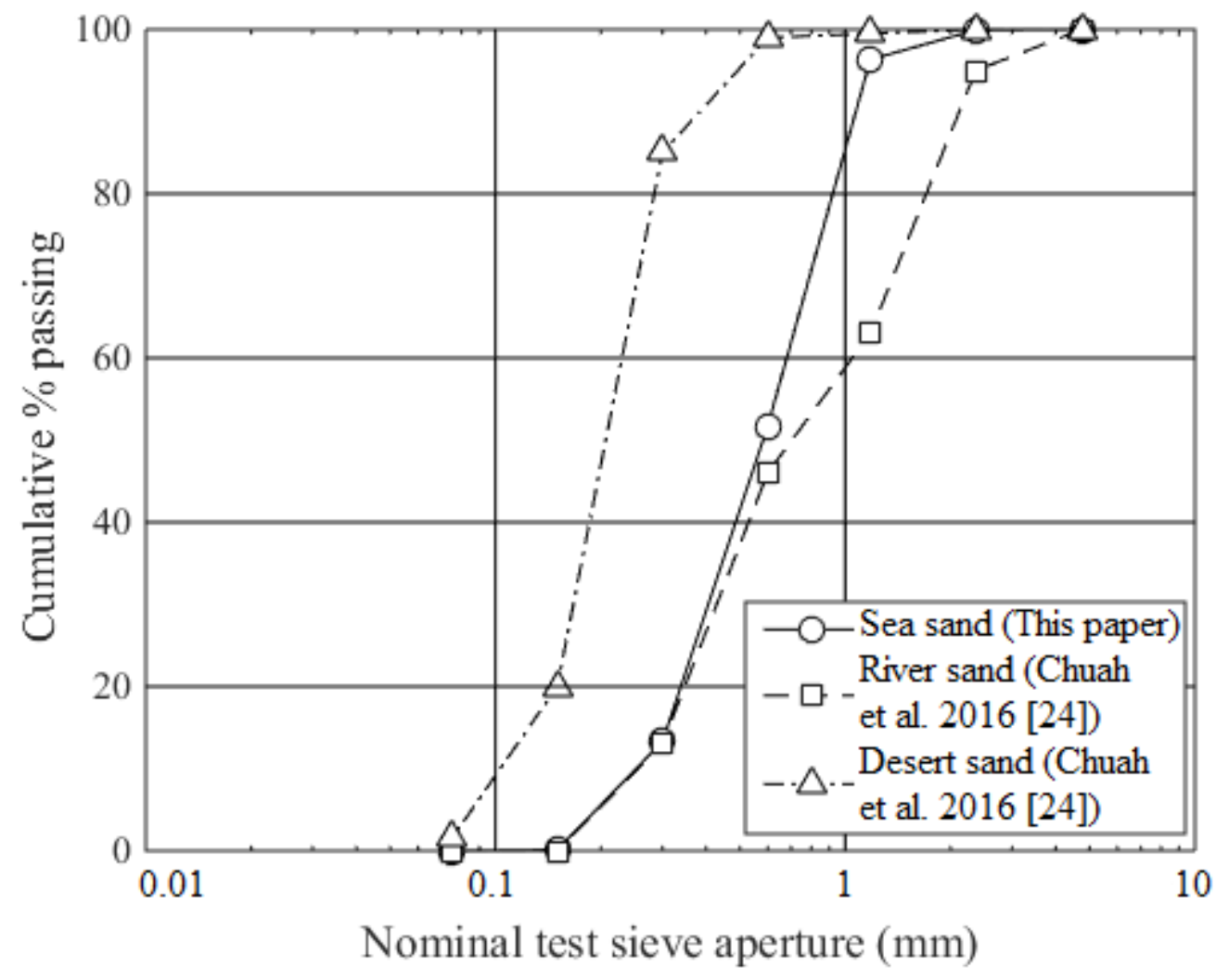

Fig. 2. Particle size distribution curve 


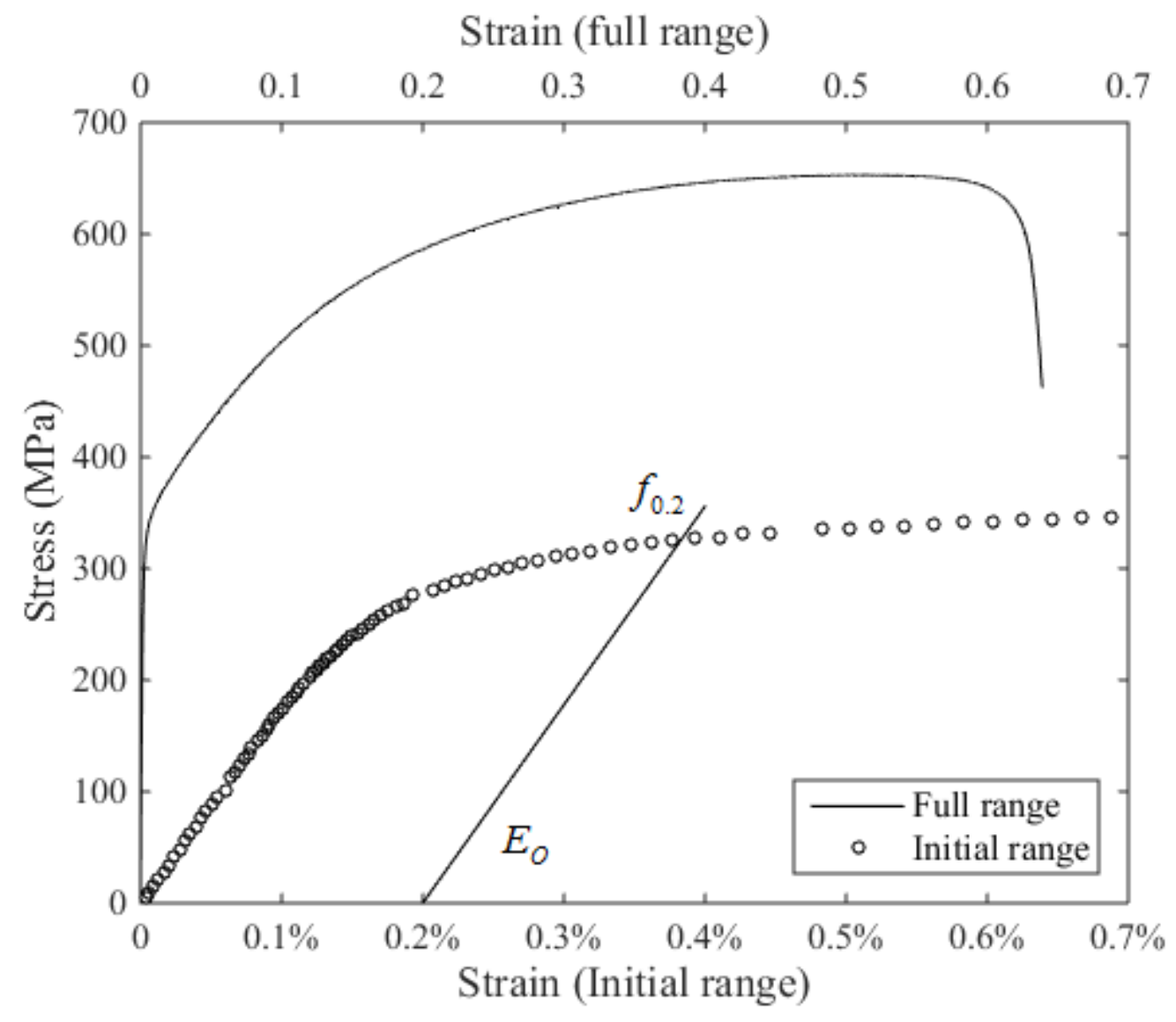

Fig. 3. Typical stress-strain curves of tensile stainless steel coupon 


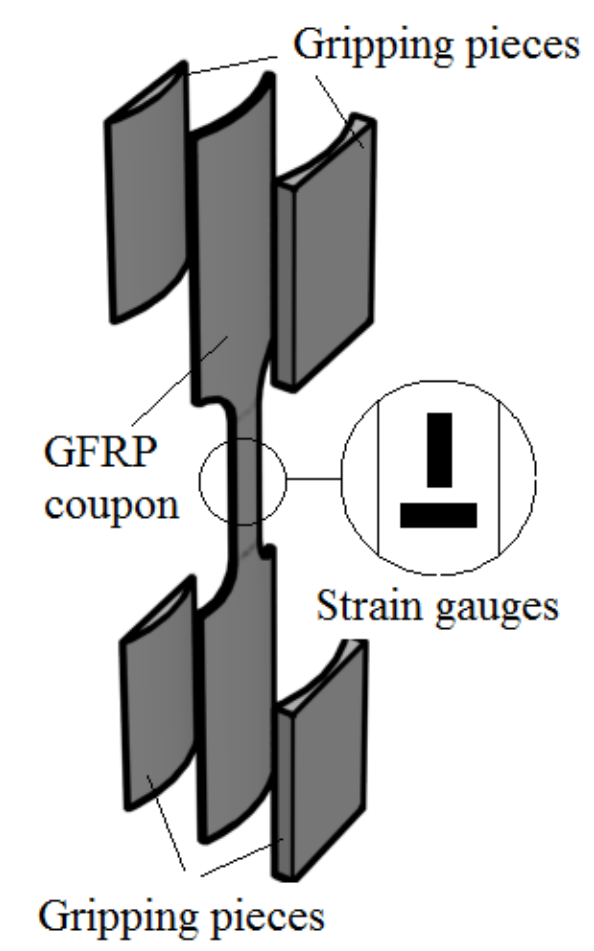

(a) Tensile coupon test

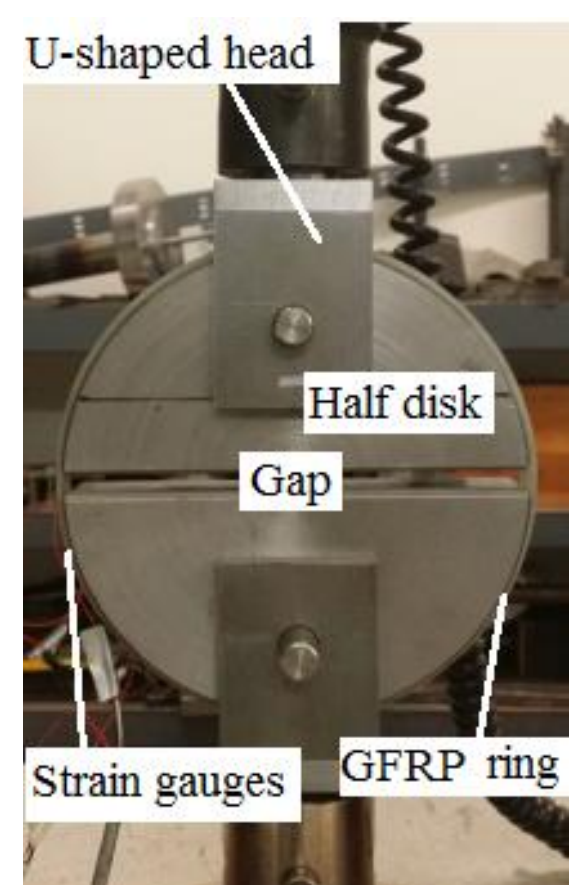

(b) Disk-split test

Fig. 4. Test setup for measuring the material properties of GFRP 


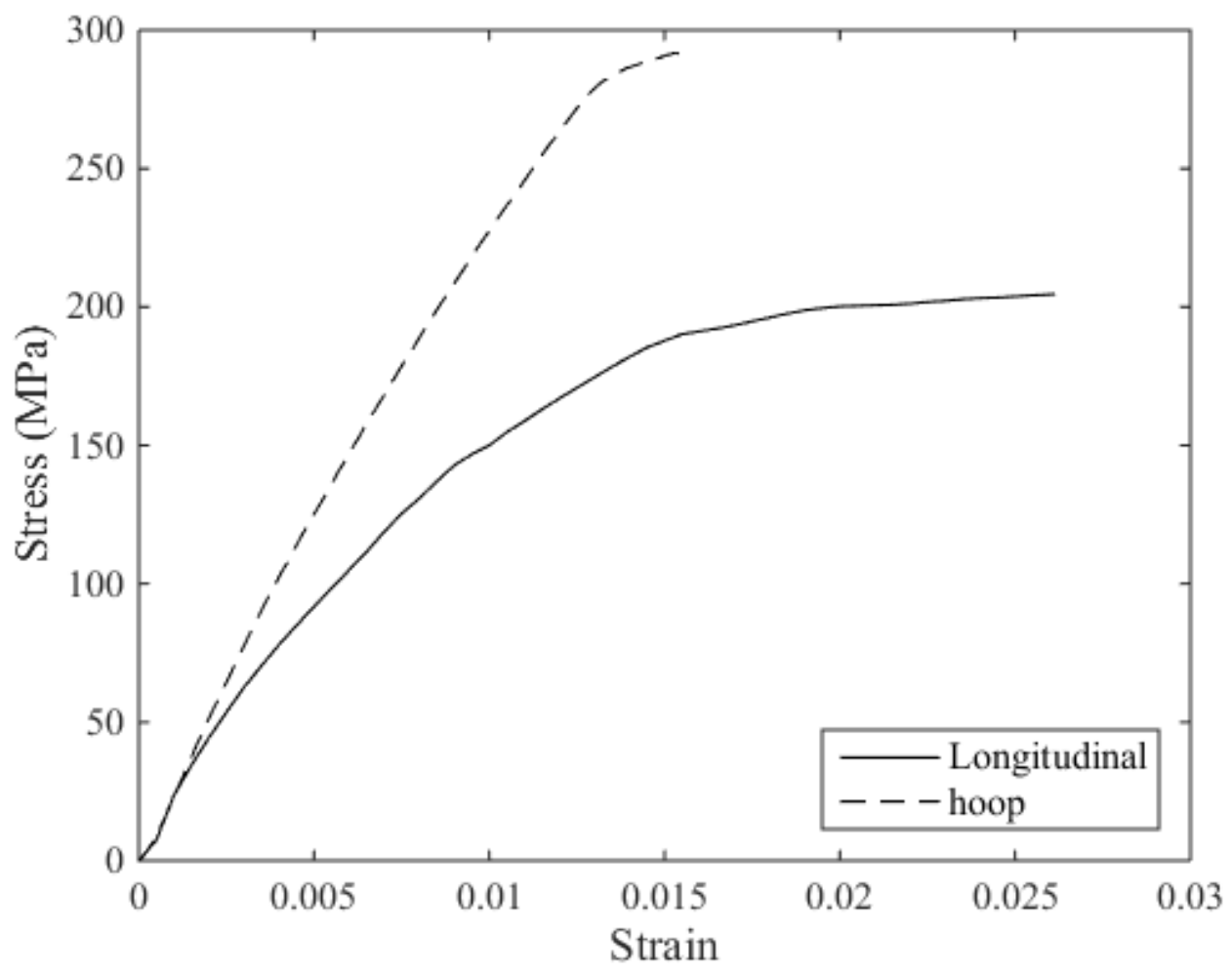

Fig. 5. Average stress-strain curves of tensile GFRP coupons 


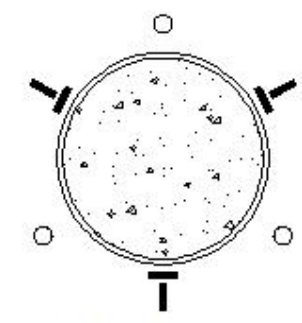

o LVDT

- Strain gauge

(a) Top view

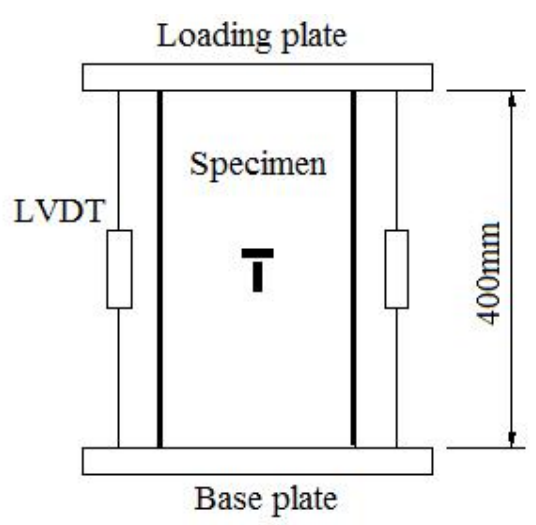

(b) Front view

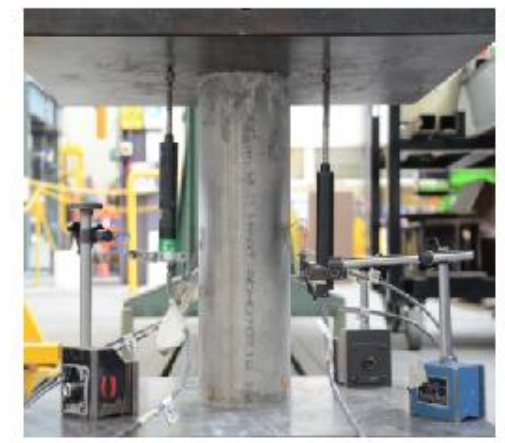

(c) Photo

Fig. 6. Test setup and instrumentation (e.g. S114-C) 


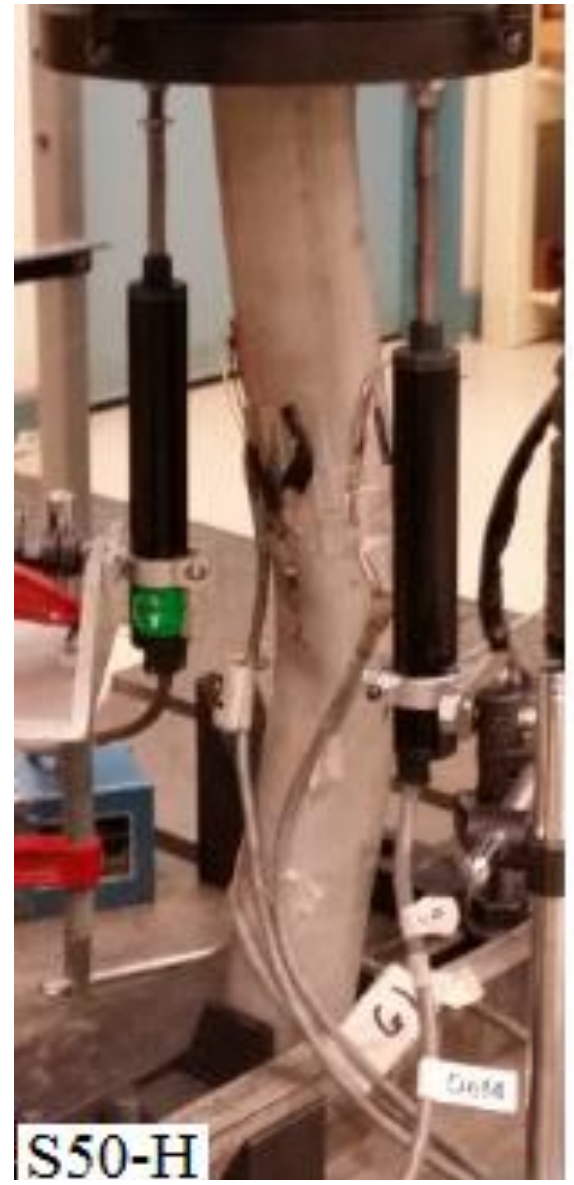

(a) $\mathrm{S} 50-\mathrm{H}$

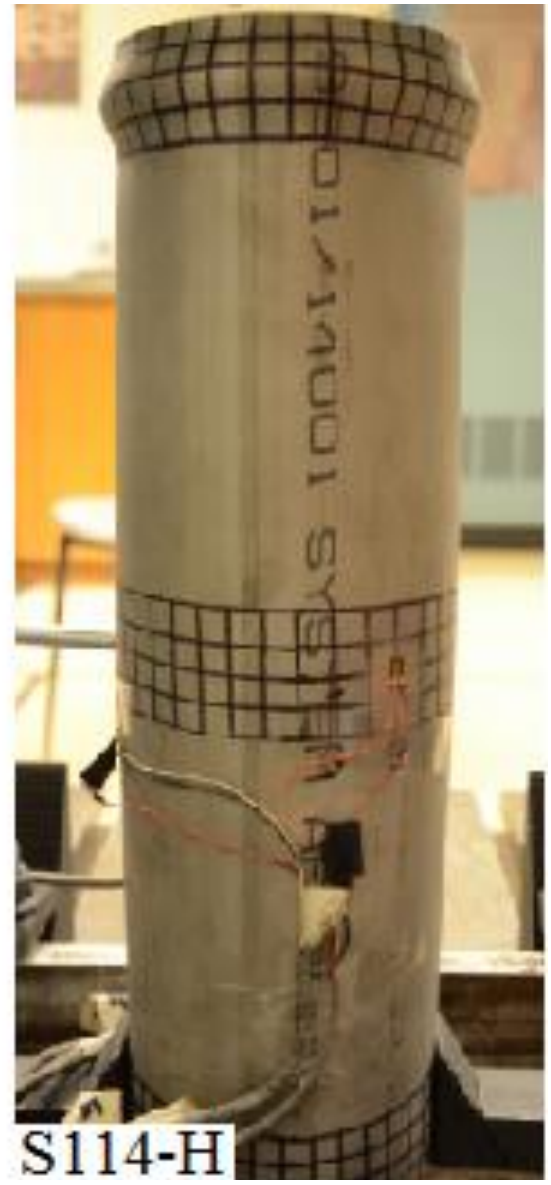

(b) $\mathrm{S} 114-\mathrm{H}$

Fig. 7. Failure modes of stainless steel hollow sections 


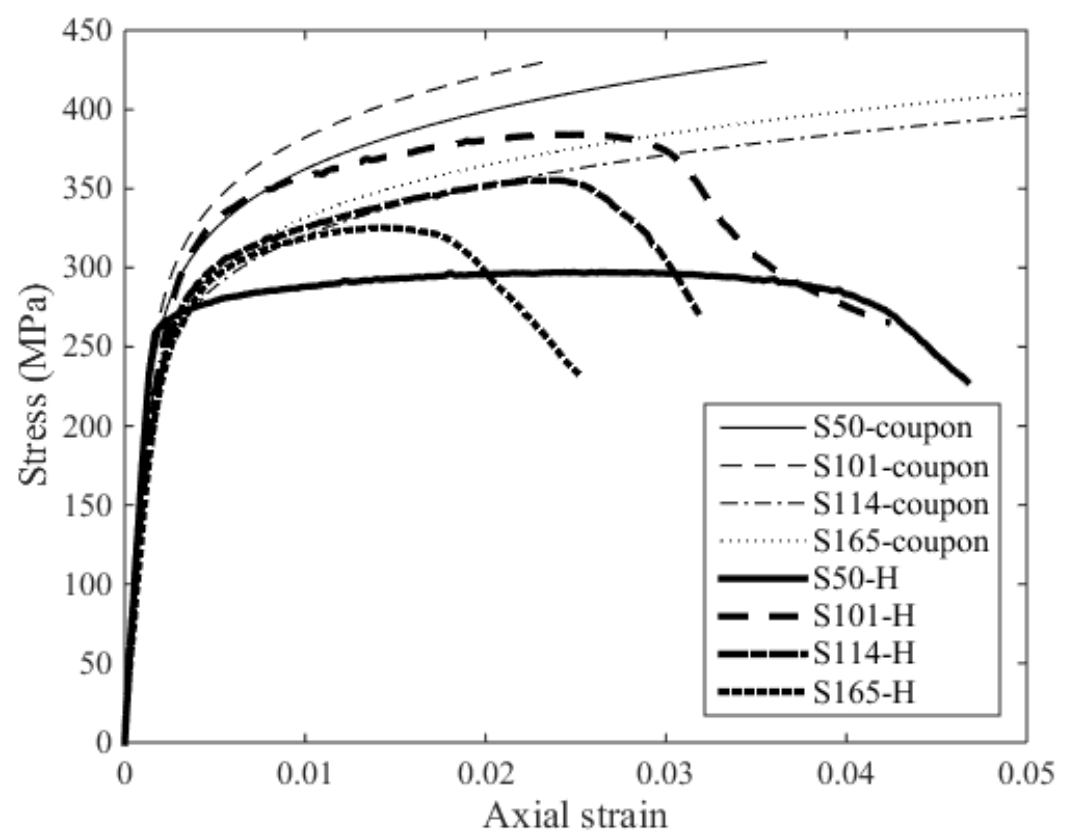

(a) Full range

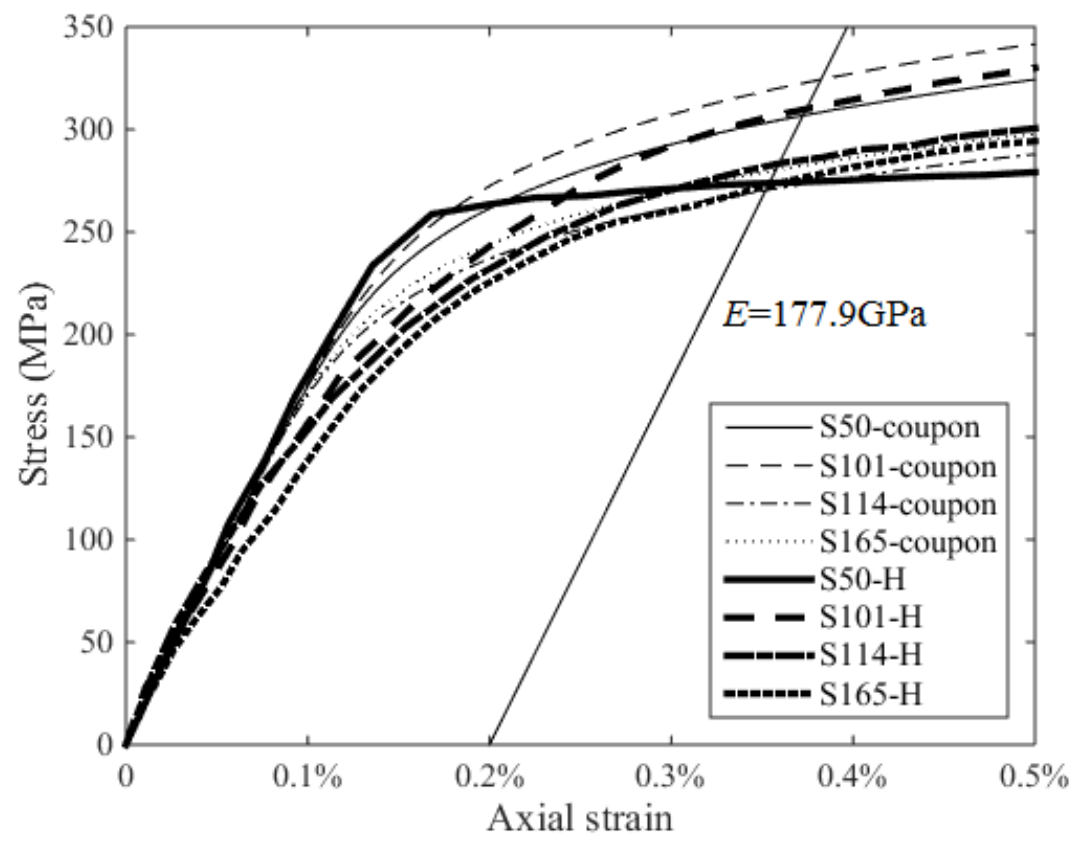

(b) Initial stage

Fig. 8. Stress-strain curves comparison of hollow sections and tensile coupons 


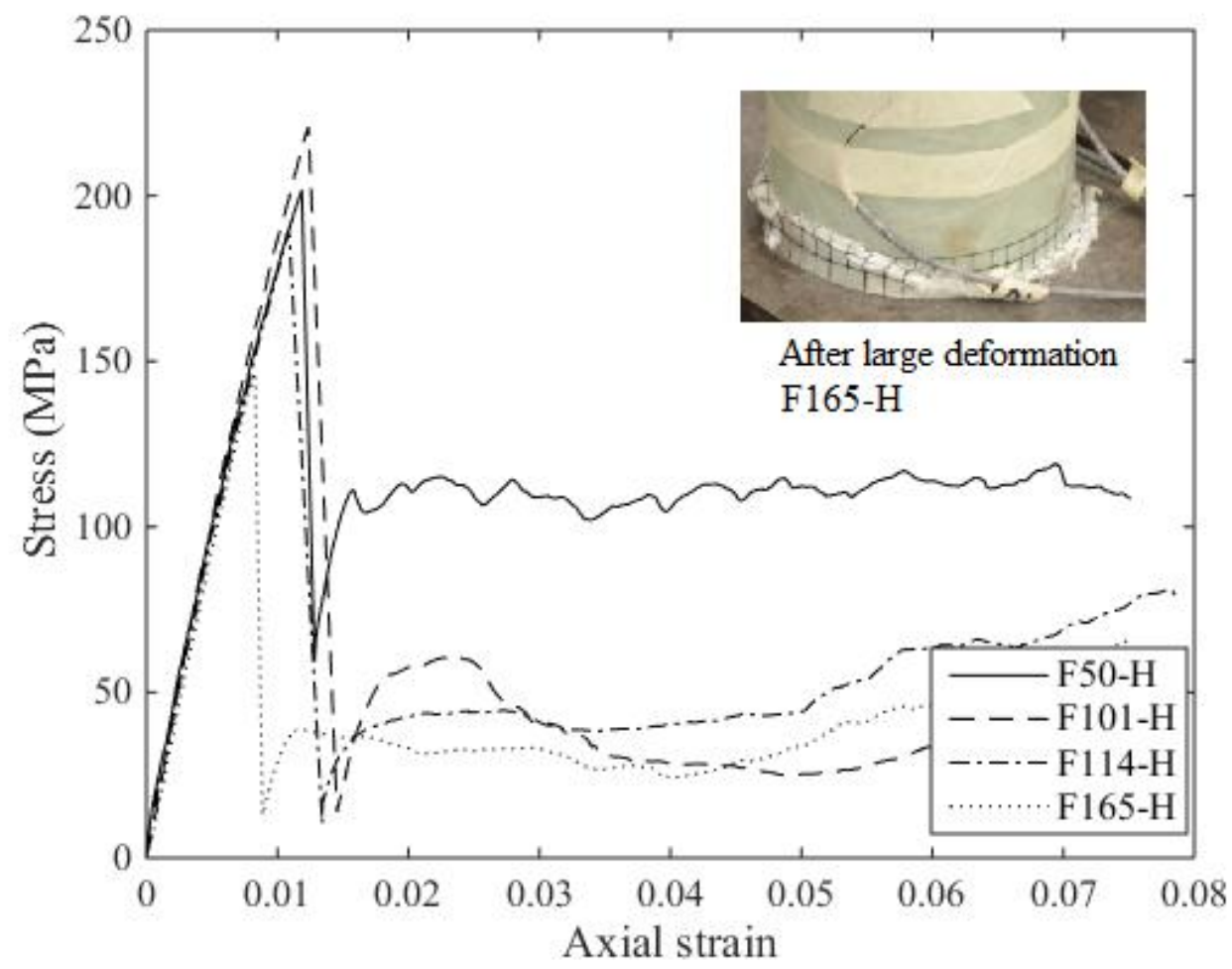

Fig. 9. Stress-strain curves of GFRP hollow sections 


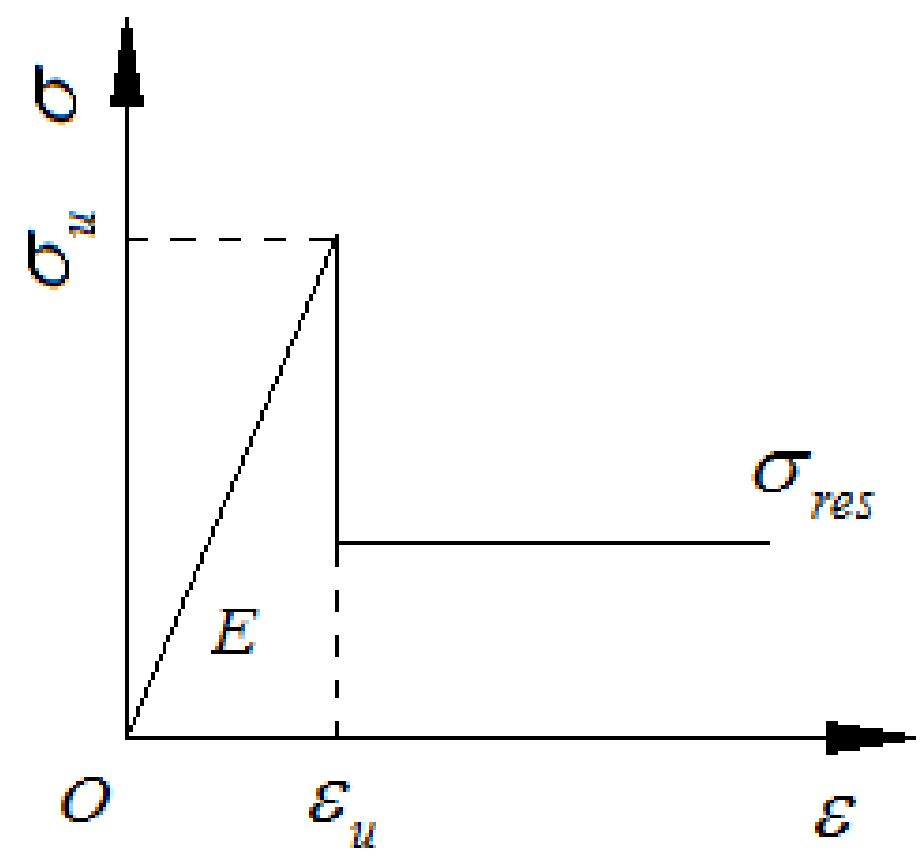

Fig. 10. Simplified stress-strain model for GFRP hollow sections 


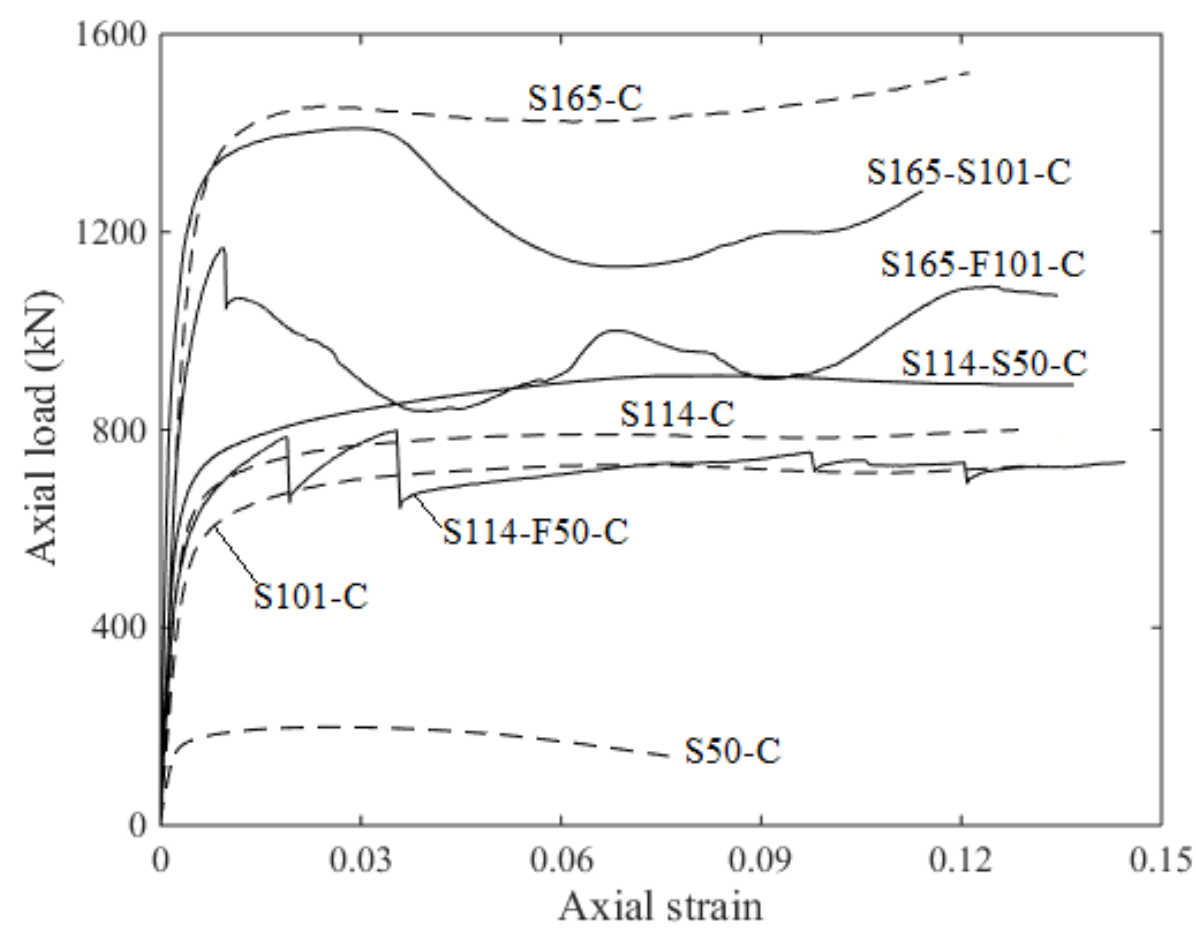

(a) SWSSC-filled stainless steel tubes (fully filled and double-skin with SS as the outer tube)

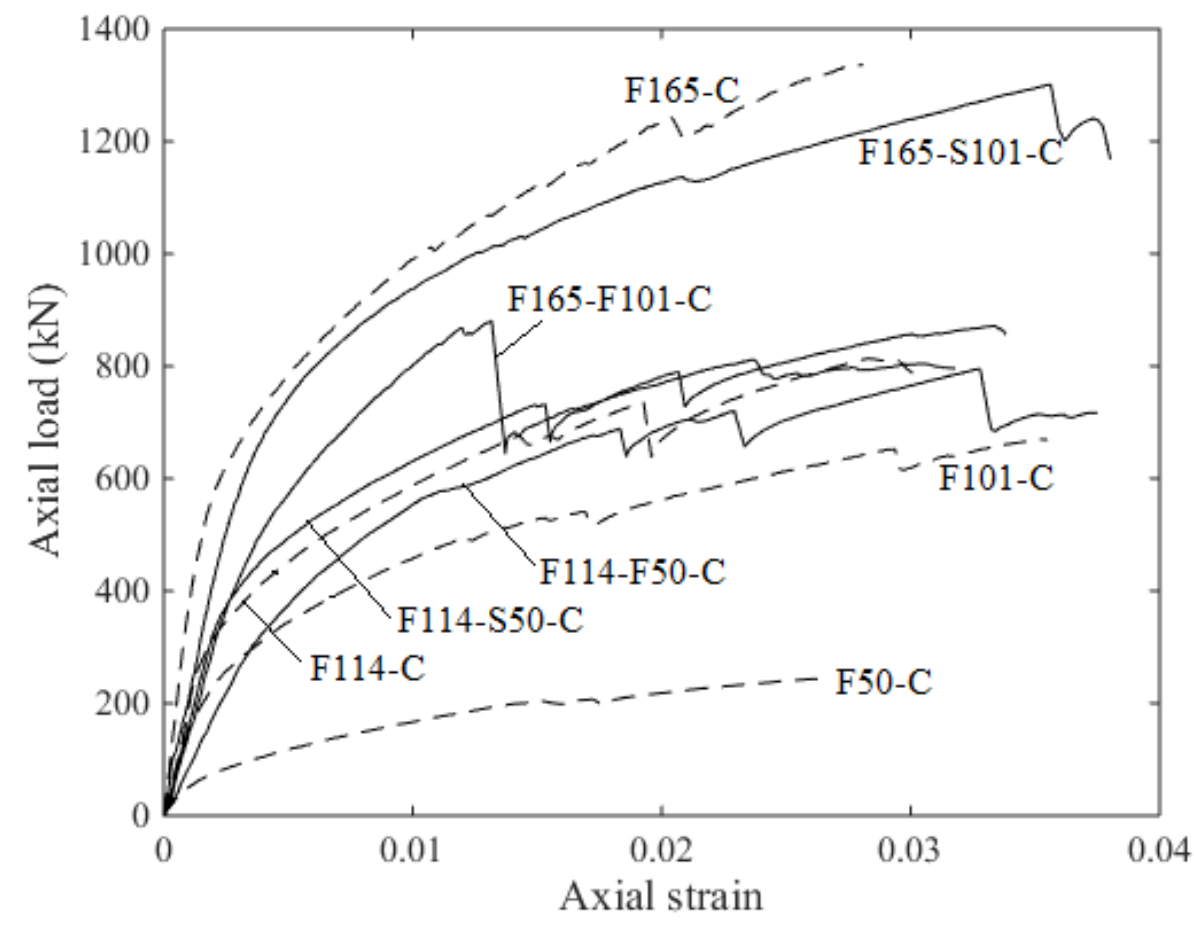

(b) SWSSC-filled GFRP tubes (fully filled and double-skin with GFRP as the outer tube)

Fig. 11 Load-strain curves of concrete-filled tubes 


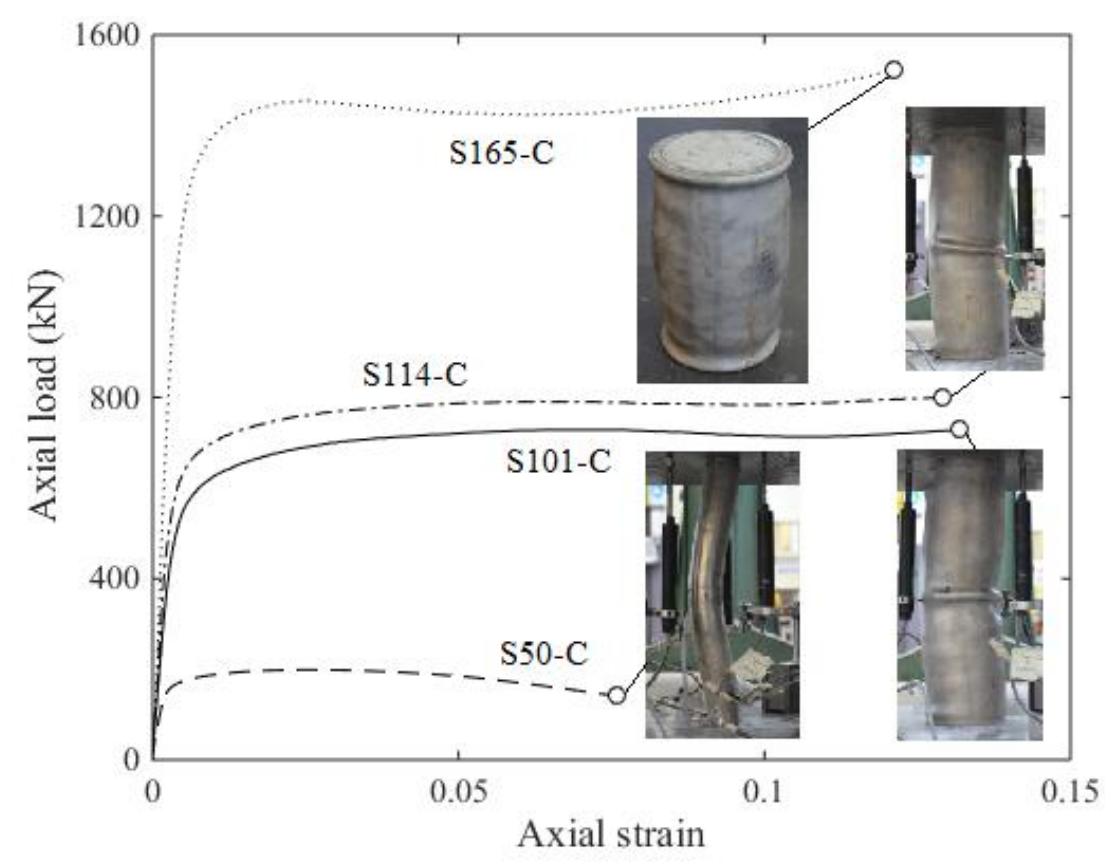

(a) Fully filled SS tubes

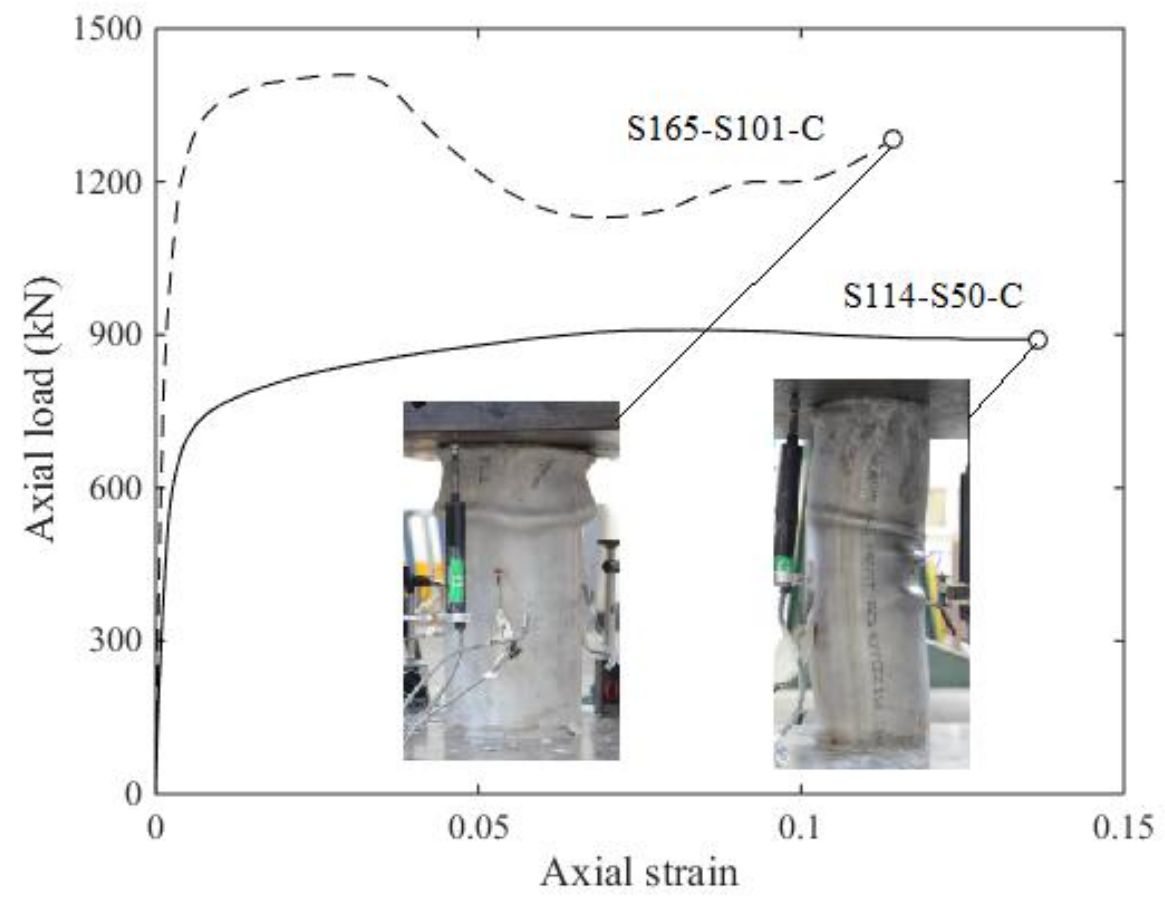

(b) Double-skin tubes (SS as both inner and outer tubes) 


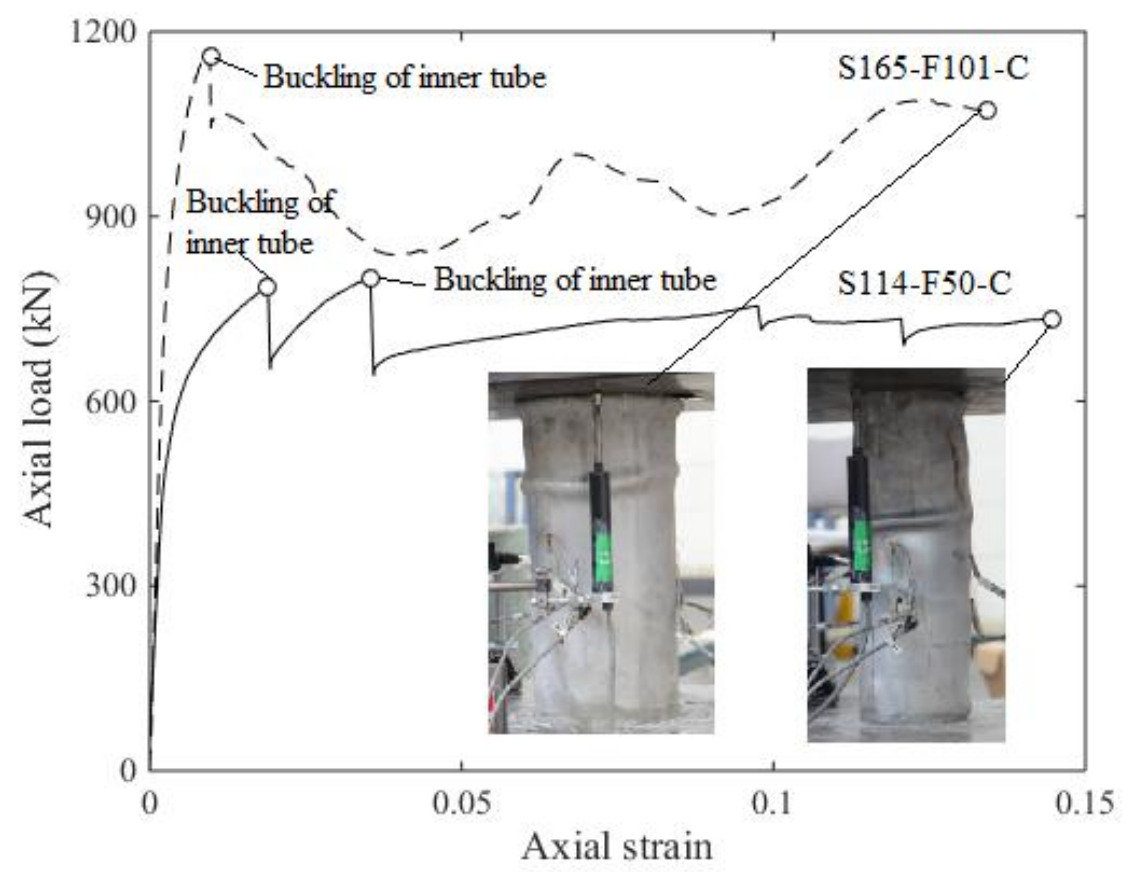

(c) Double-skin tubes (SS as the outer tube and GFRP as the inner tube)

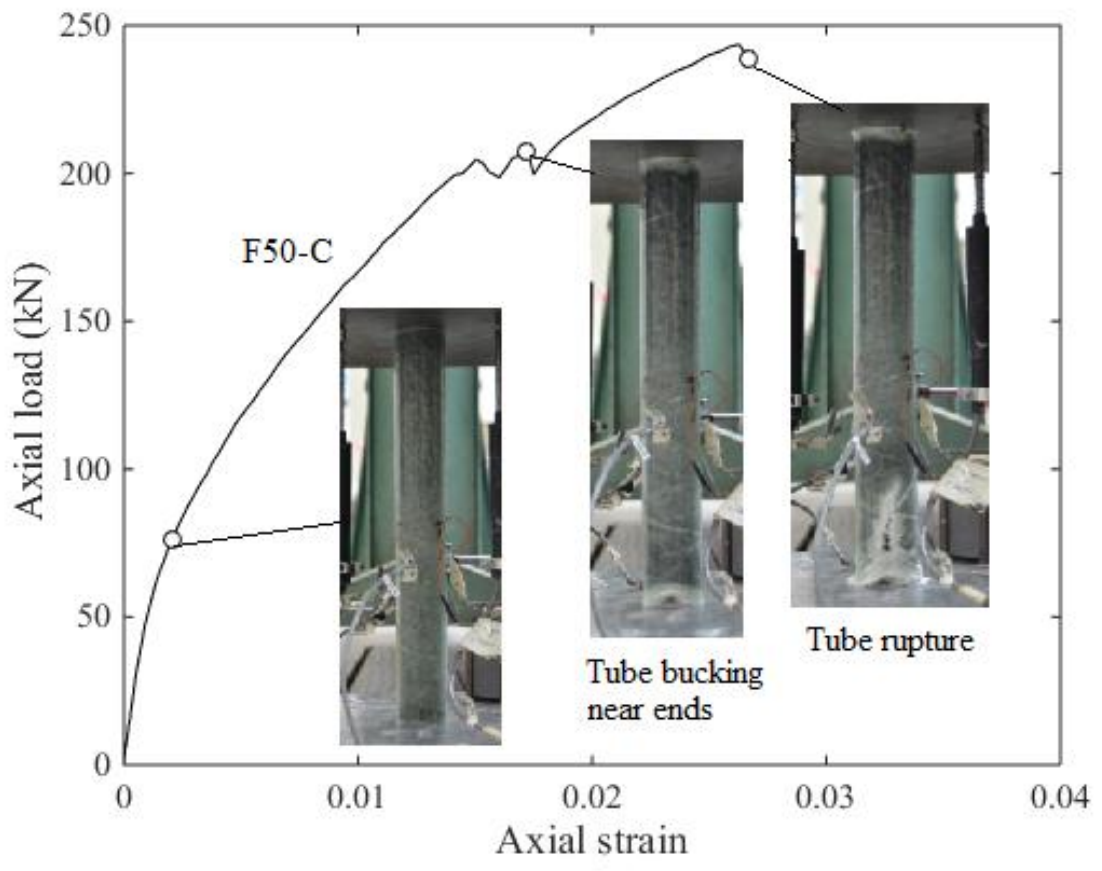

(i) 


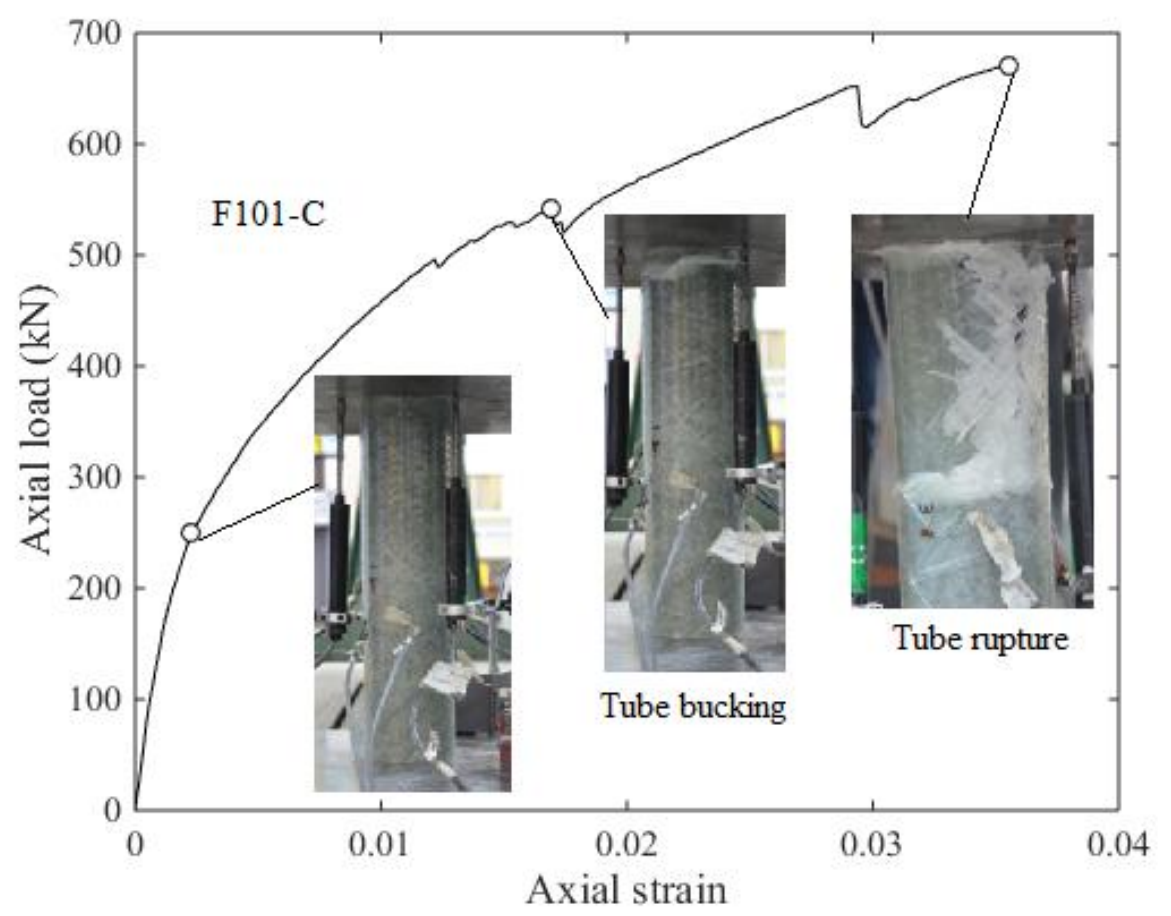

(ii)

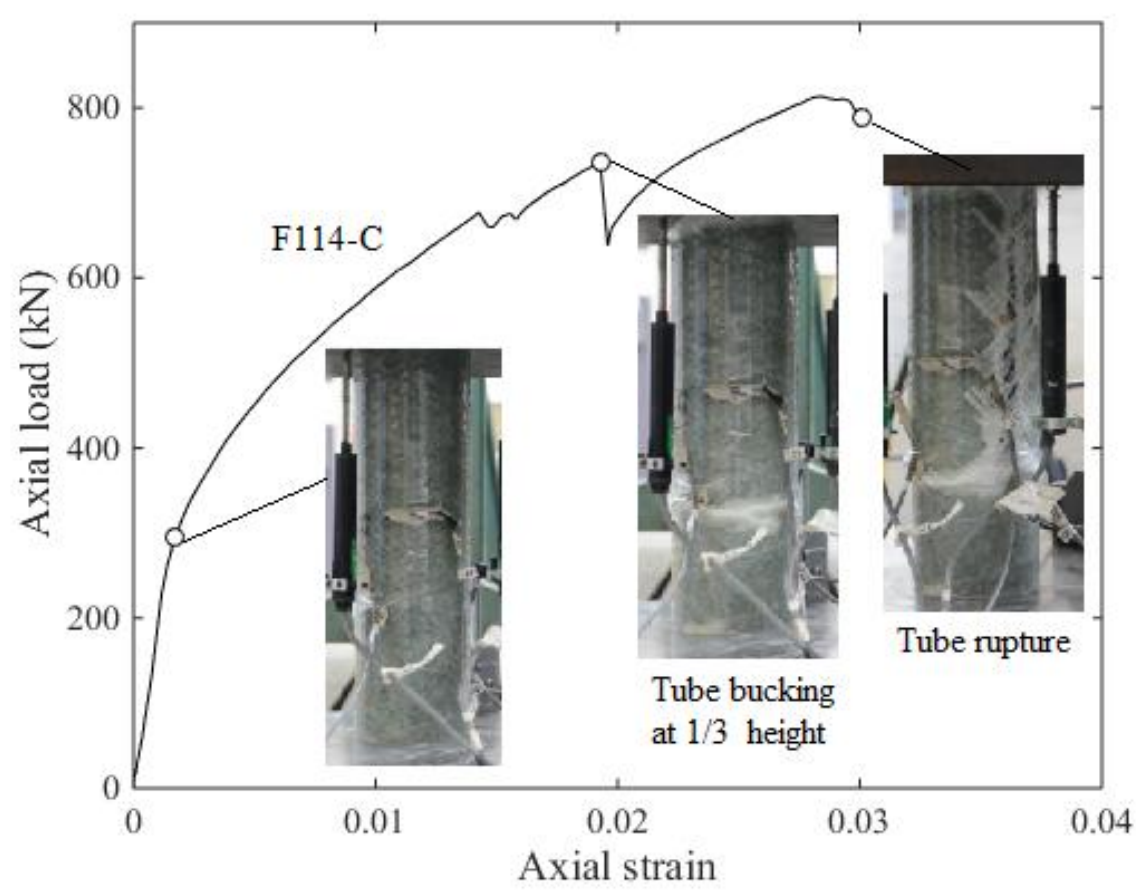

(iii) 


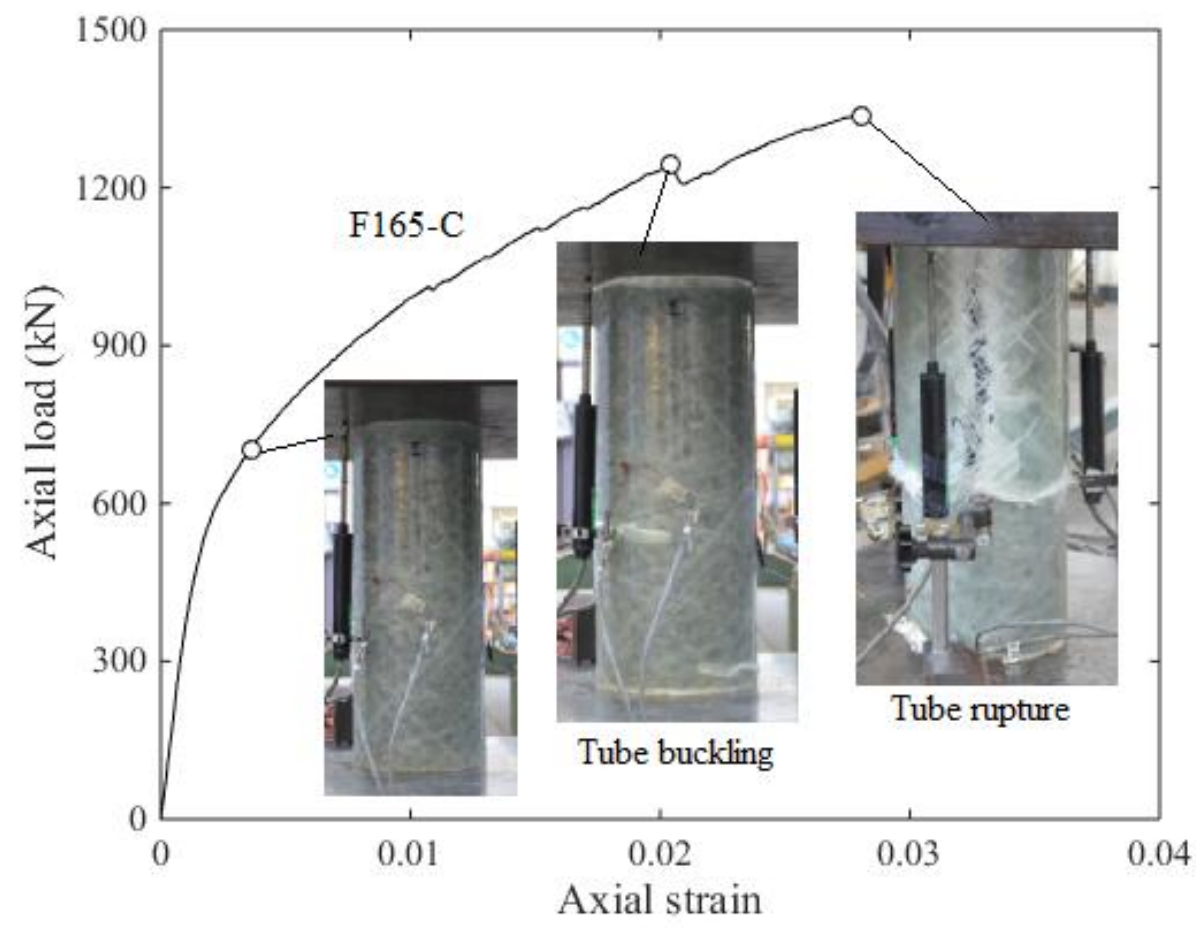

(iv)

(d) Fully filled GFRP tubes

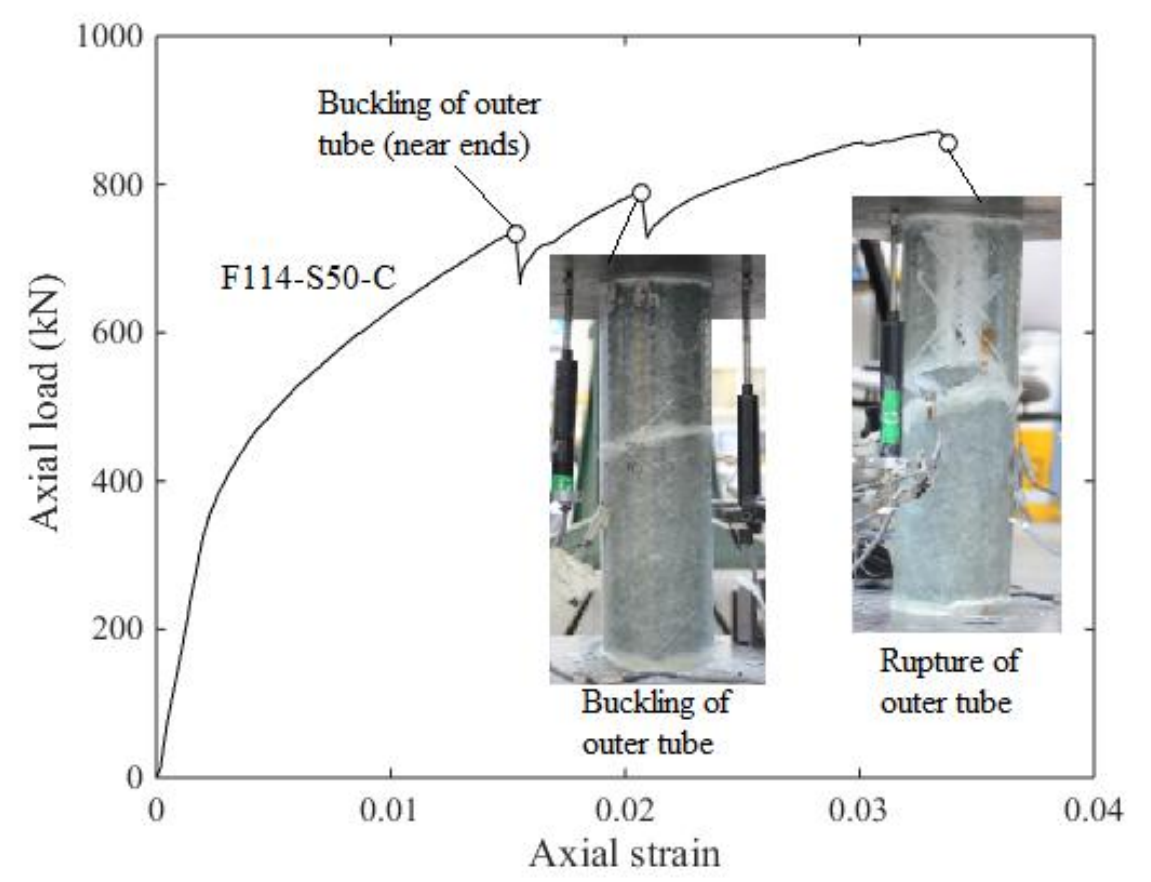

(i) 


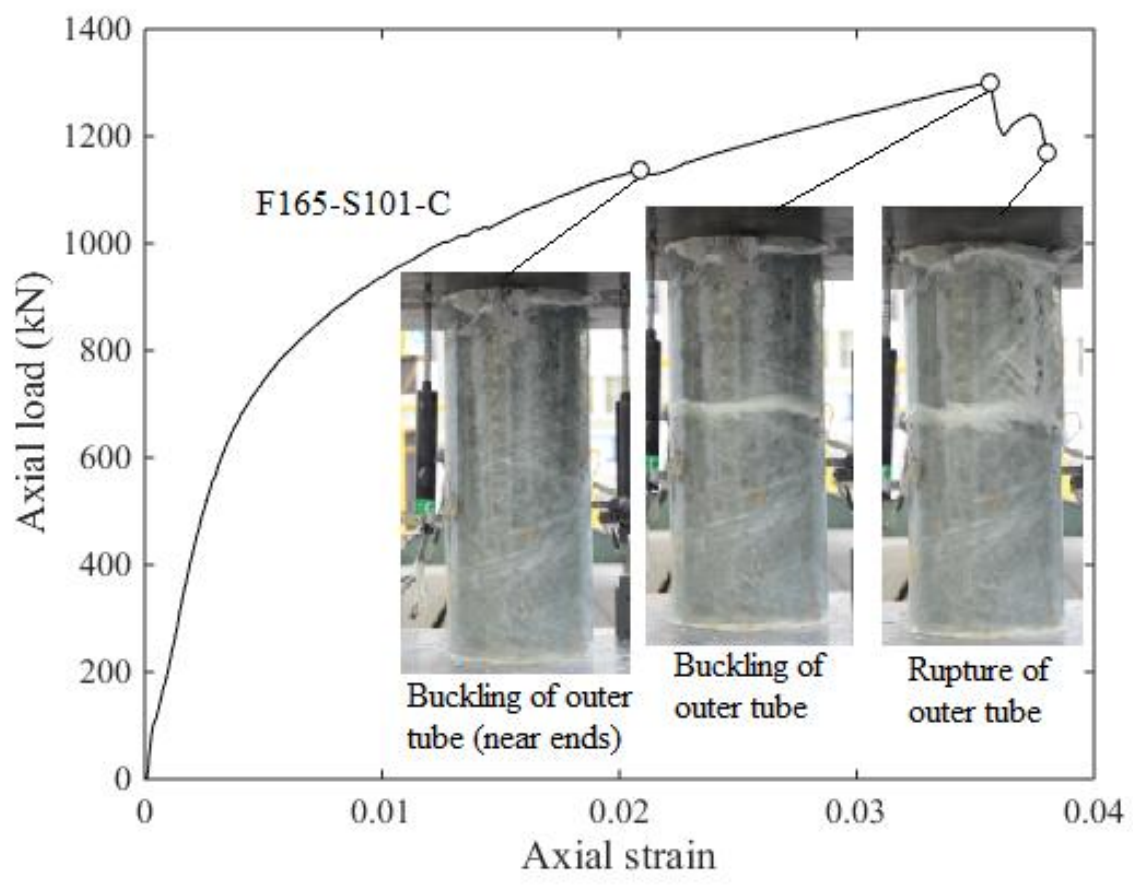

(ii)

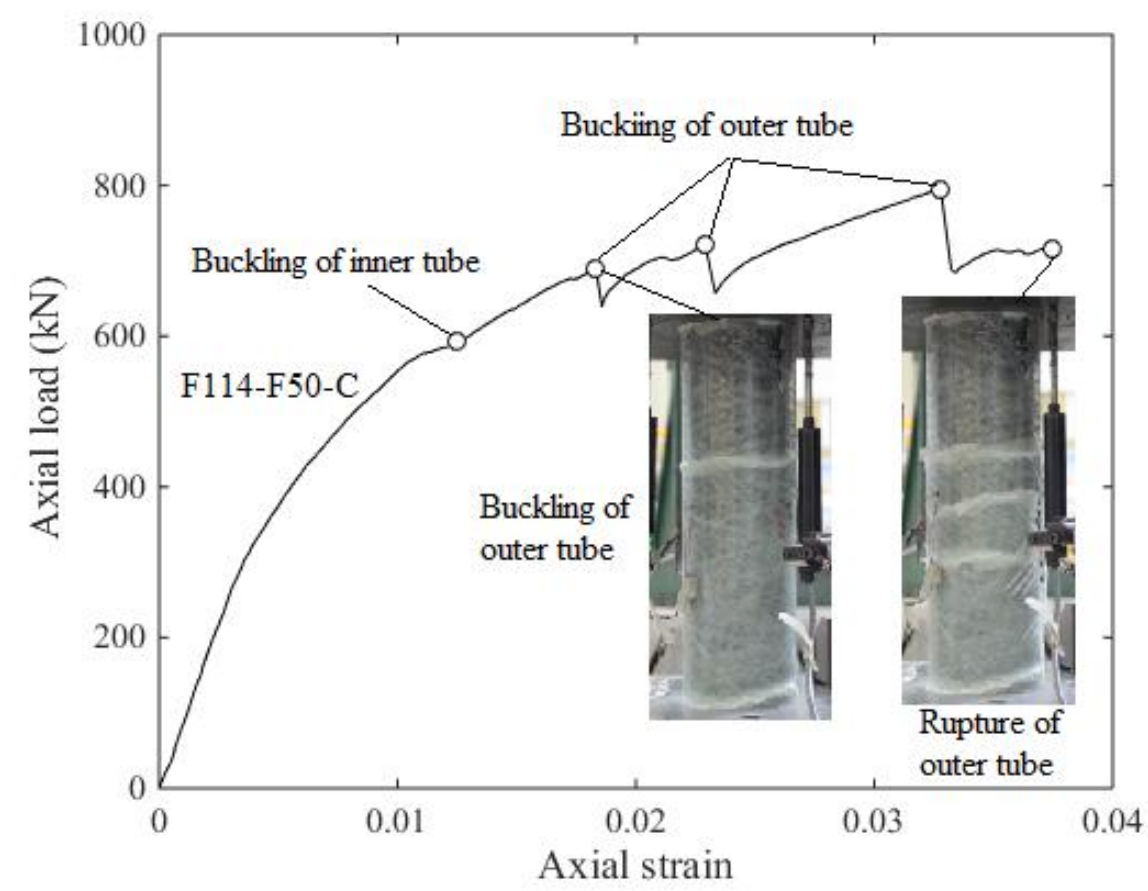

(iii) 


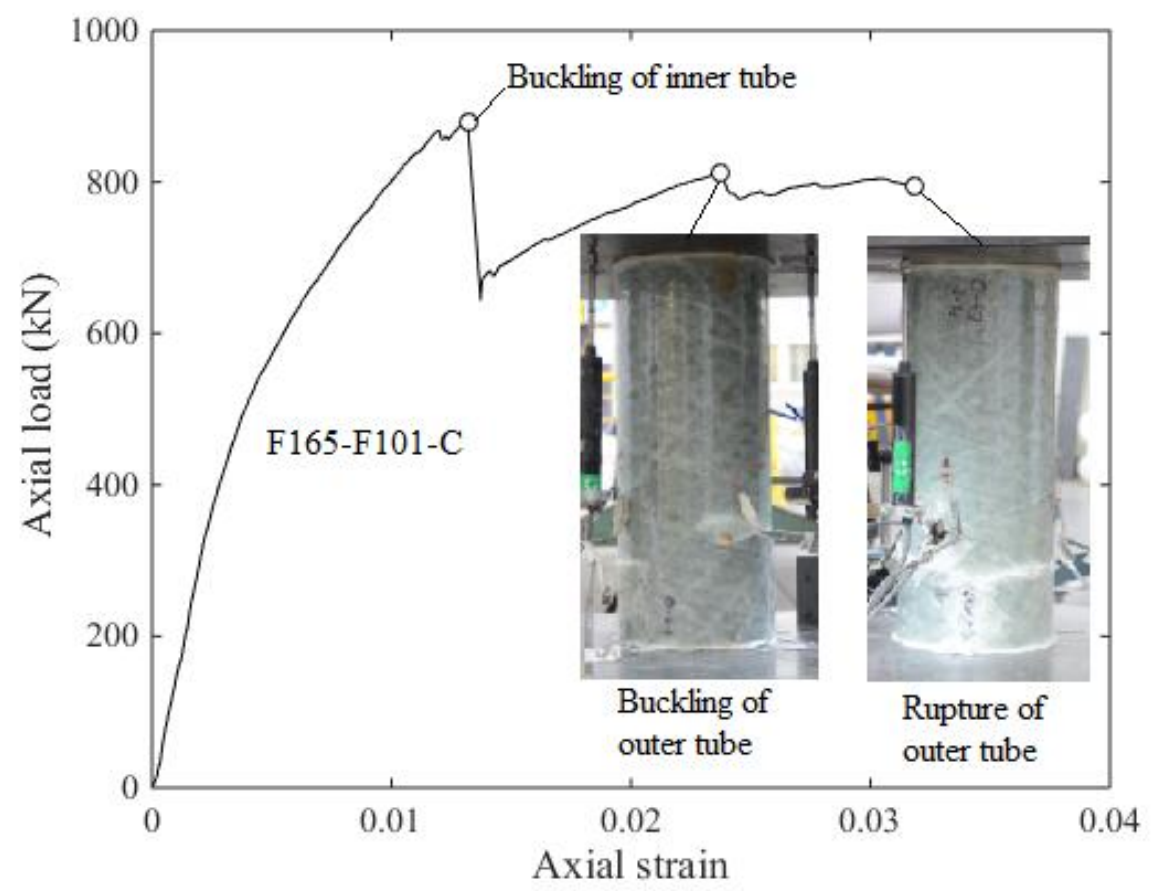

(iv)

(e) Double-skin tubes (GFRP as the outer tube)

Fig. 12. Load-strain curves and failure modes 


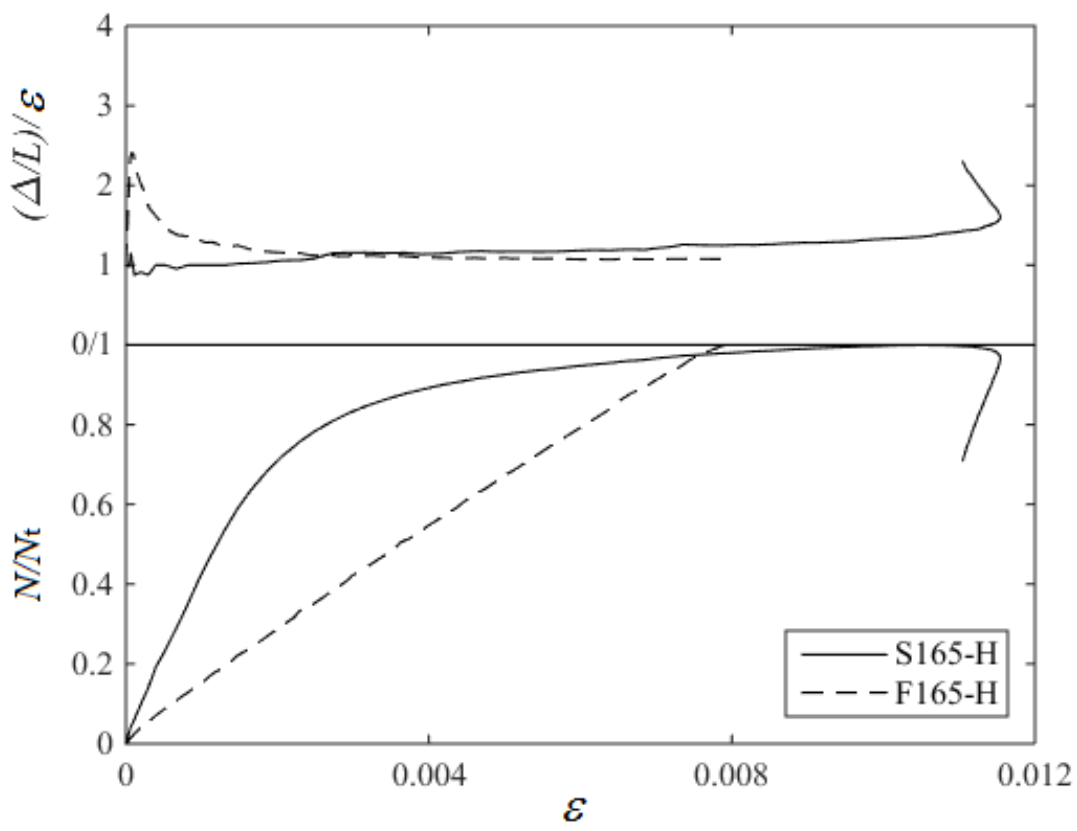

(a) Hollow tubes

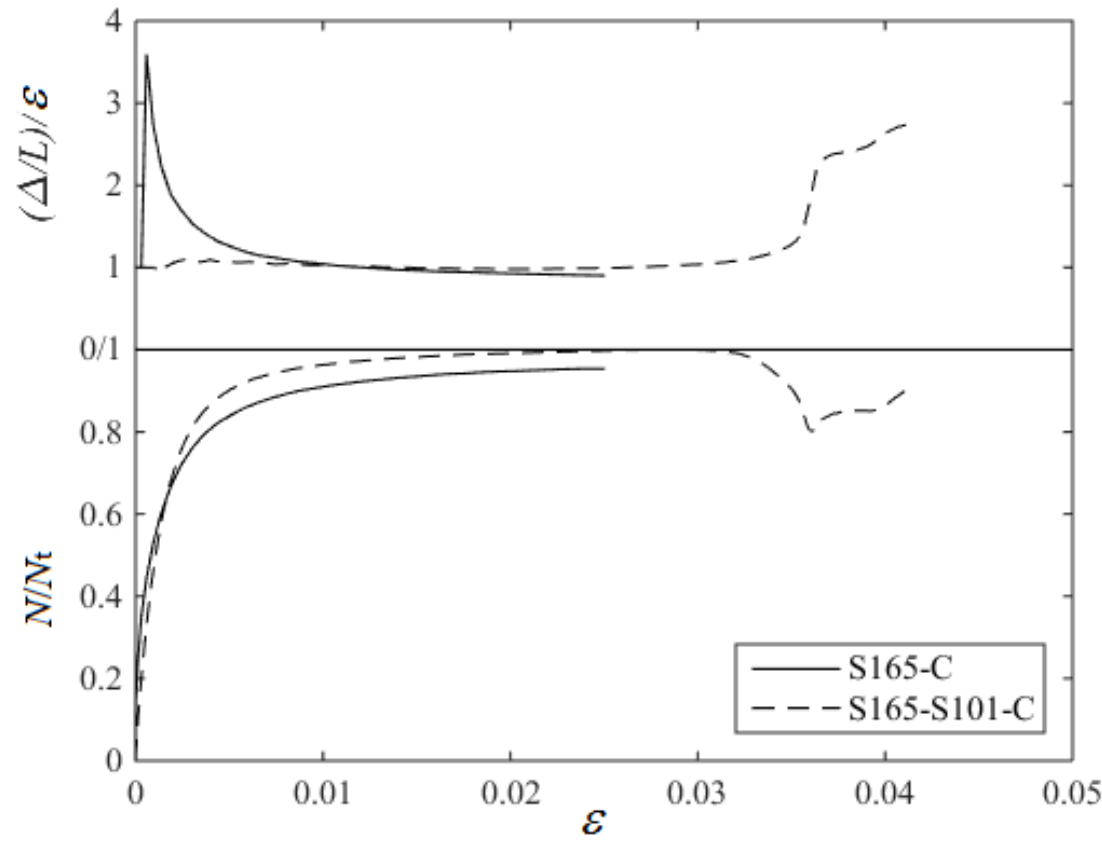

(b) Fully filled SS tube and double-skin tube (SS as both inner and outer tubes) 


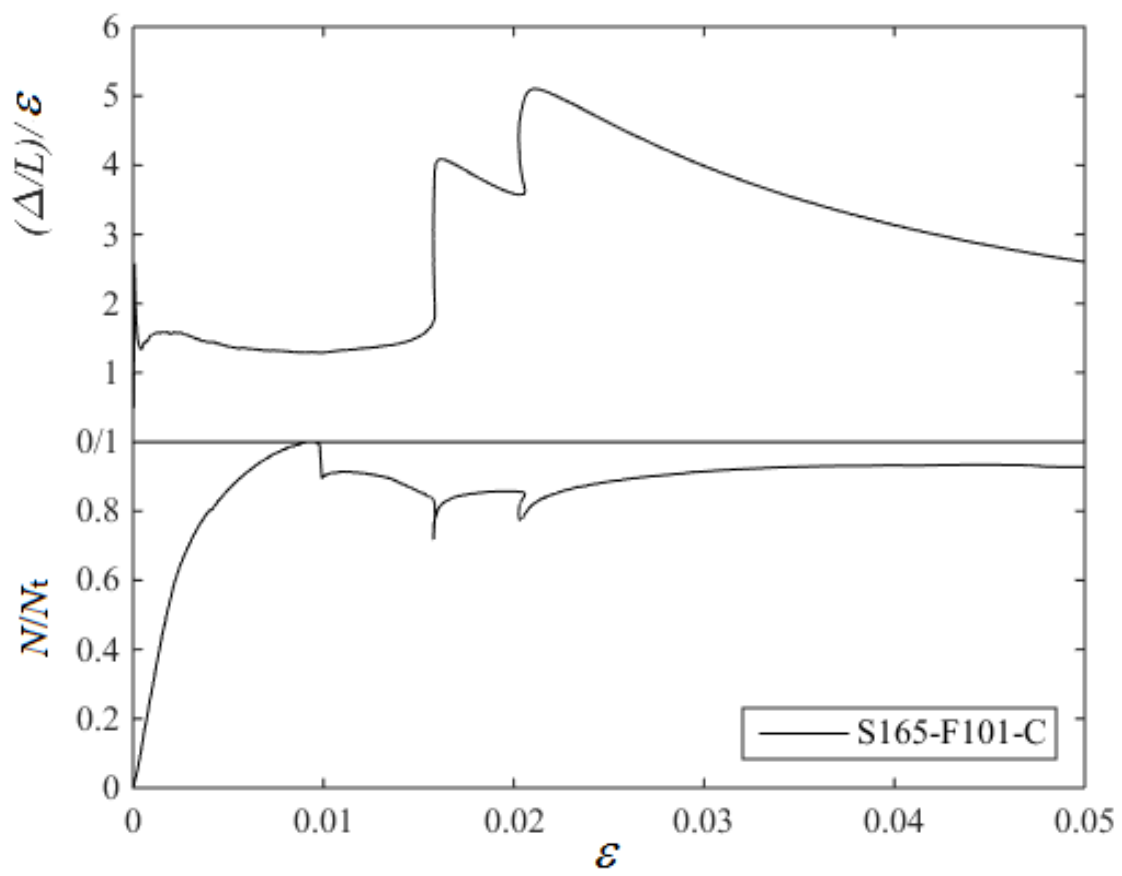

(c) Double-skin tube (SS as the outer tube and GFRP as the inner tube)

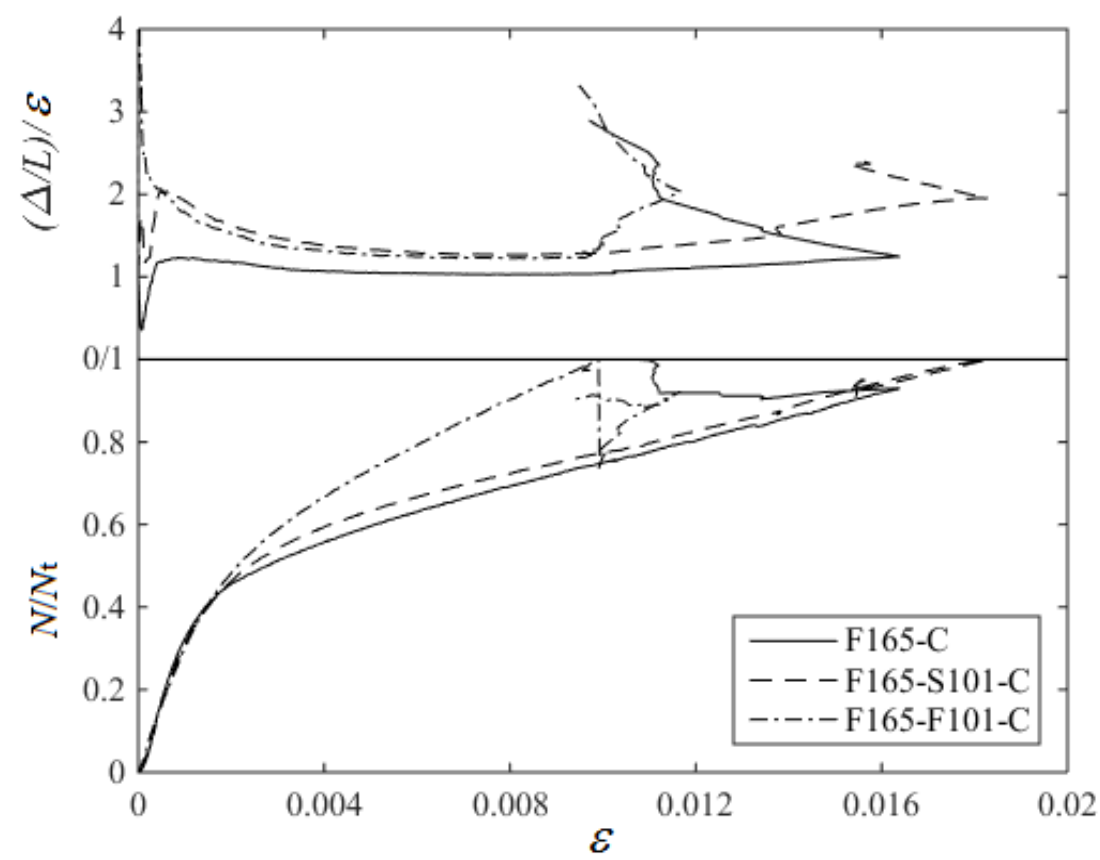

(d) Fully filled GFRP tube and double-skin tube (GFRP as the outer tube)

Fig. 13. Comparison between overall strain $(\Delta / L)$ and localized strain $(\varepsilon)$ 


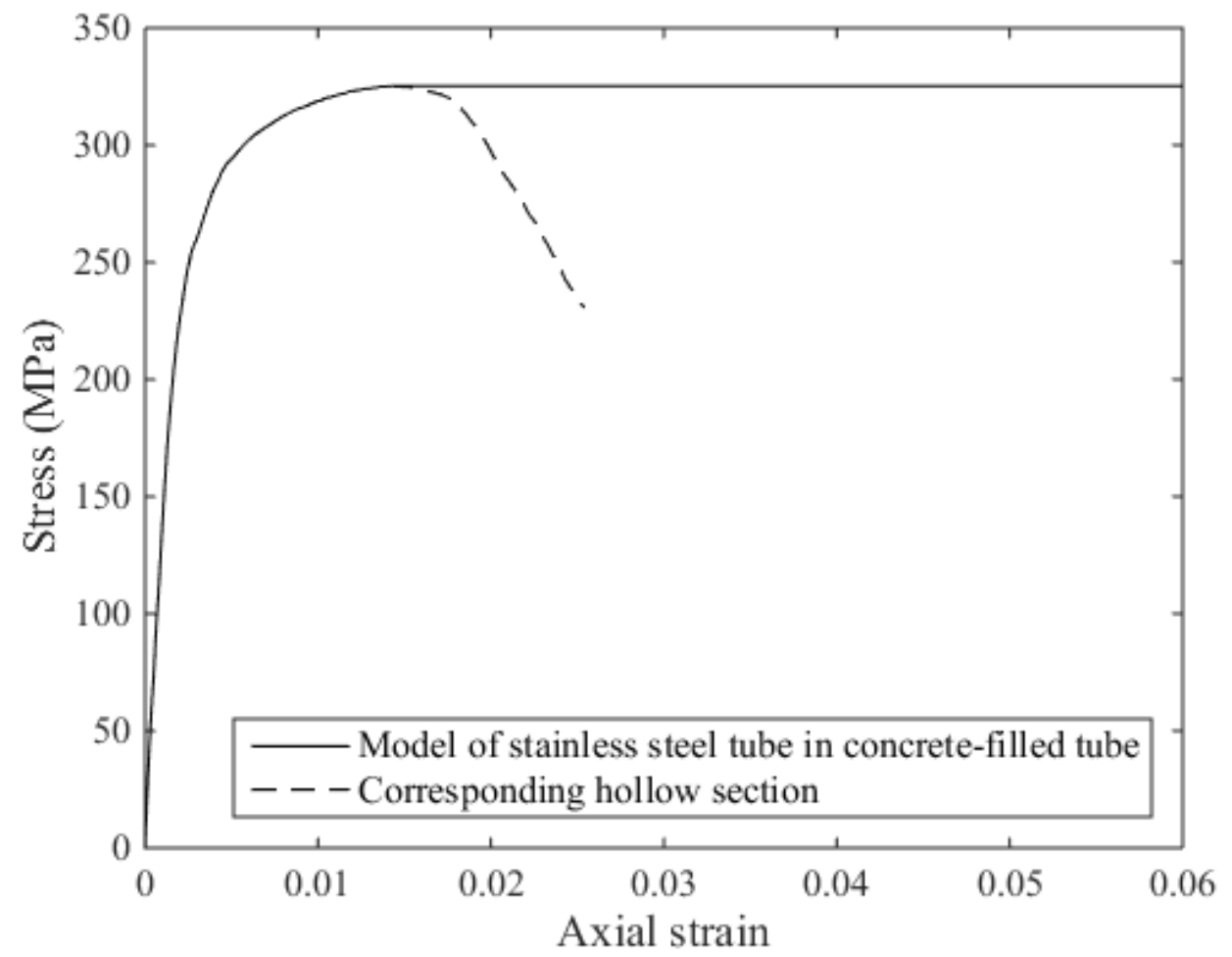

Fig. 14. Stress-strain model for stainless steel tube 


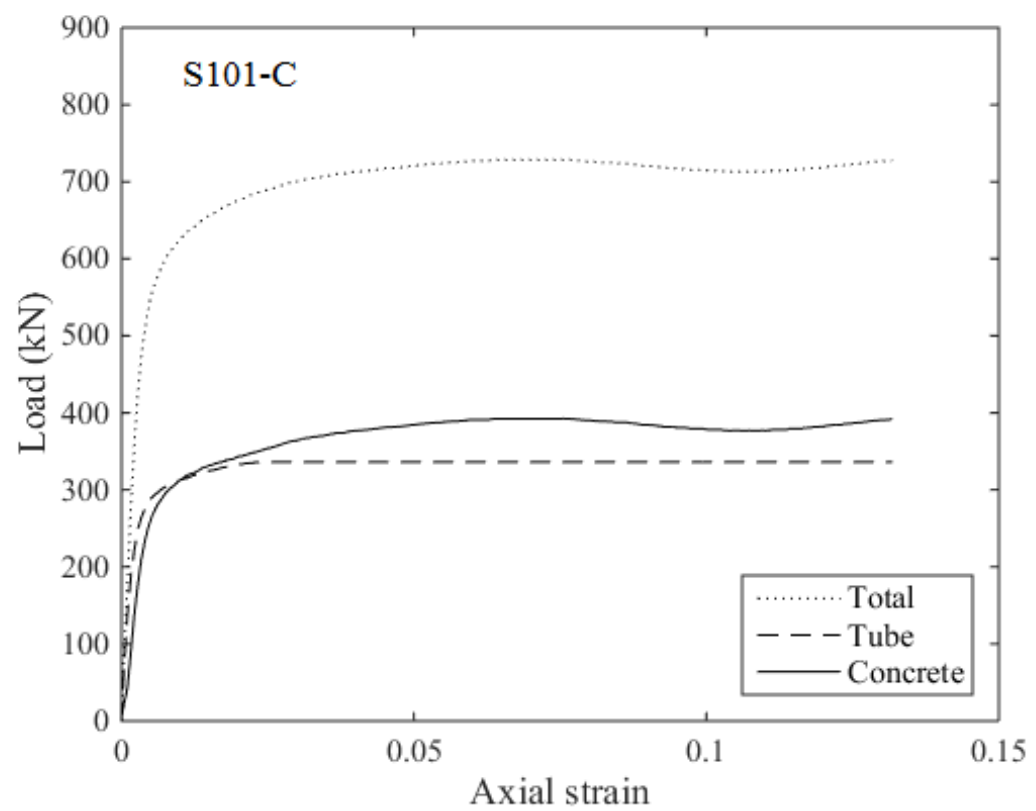

(i)

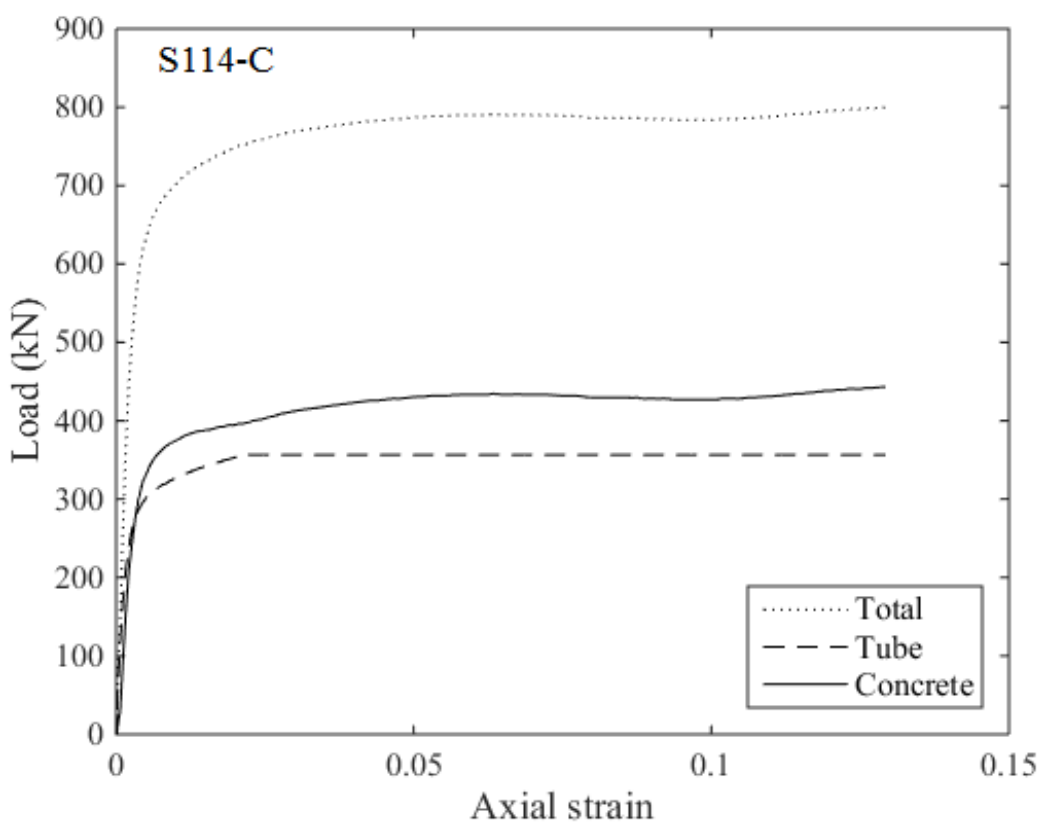

(ii) 


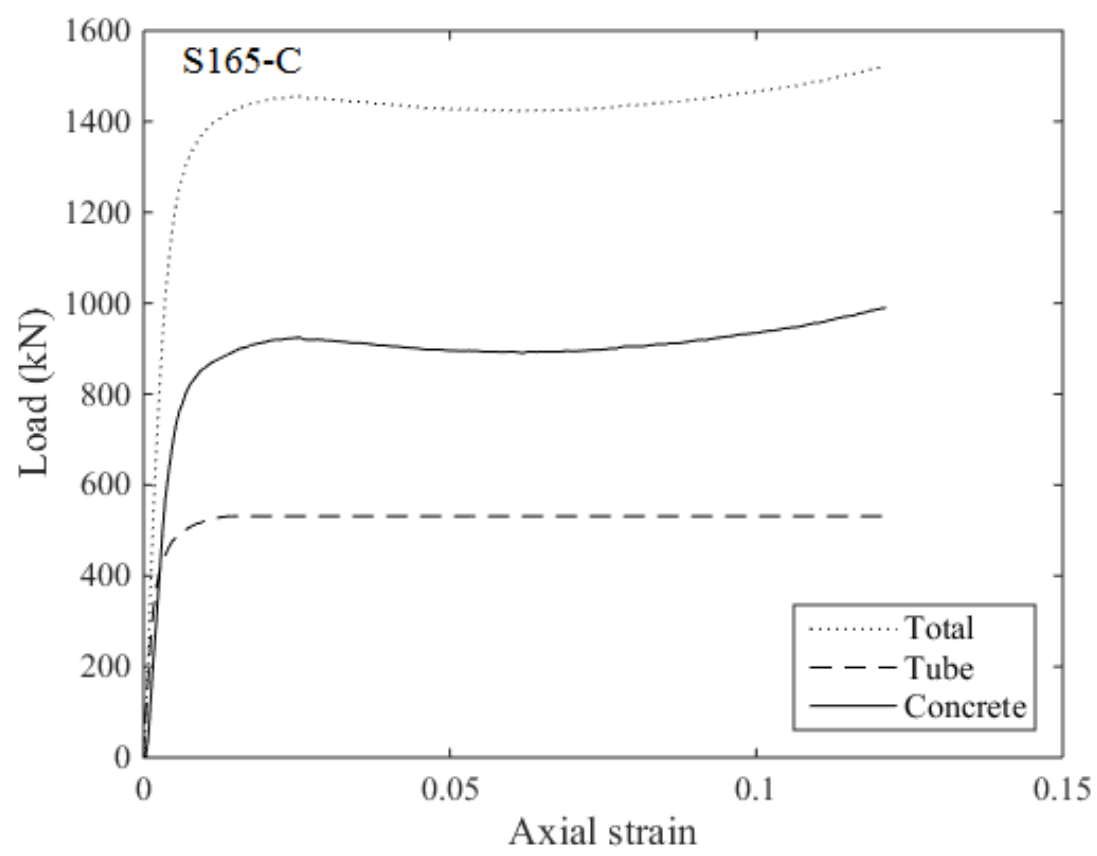

(iii)

(a) Fully filled SS tubes

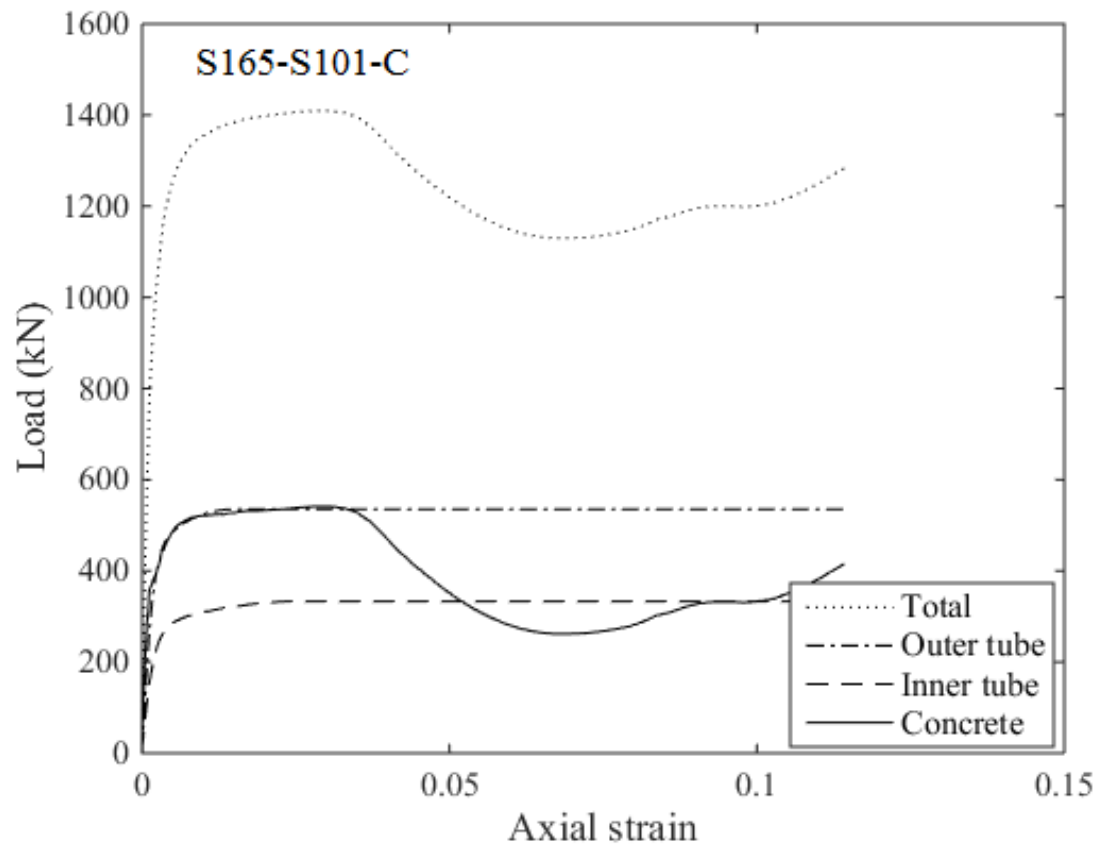

(b) Double-skin tube (SS as both inner and outer tubes) 


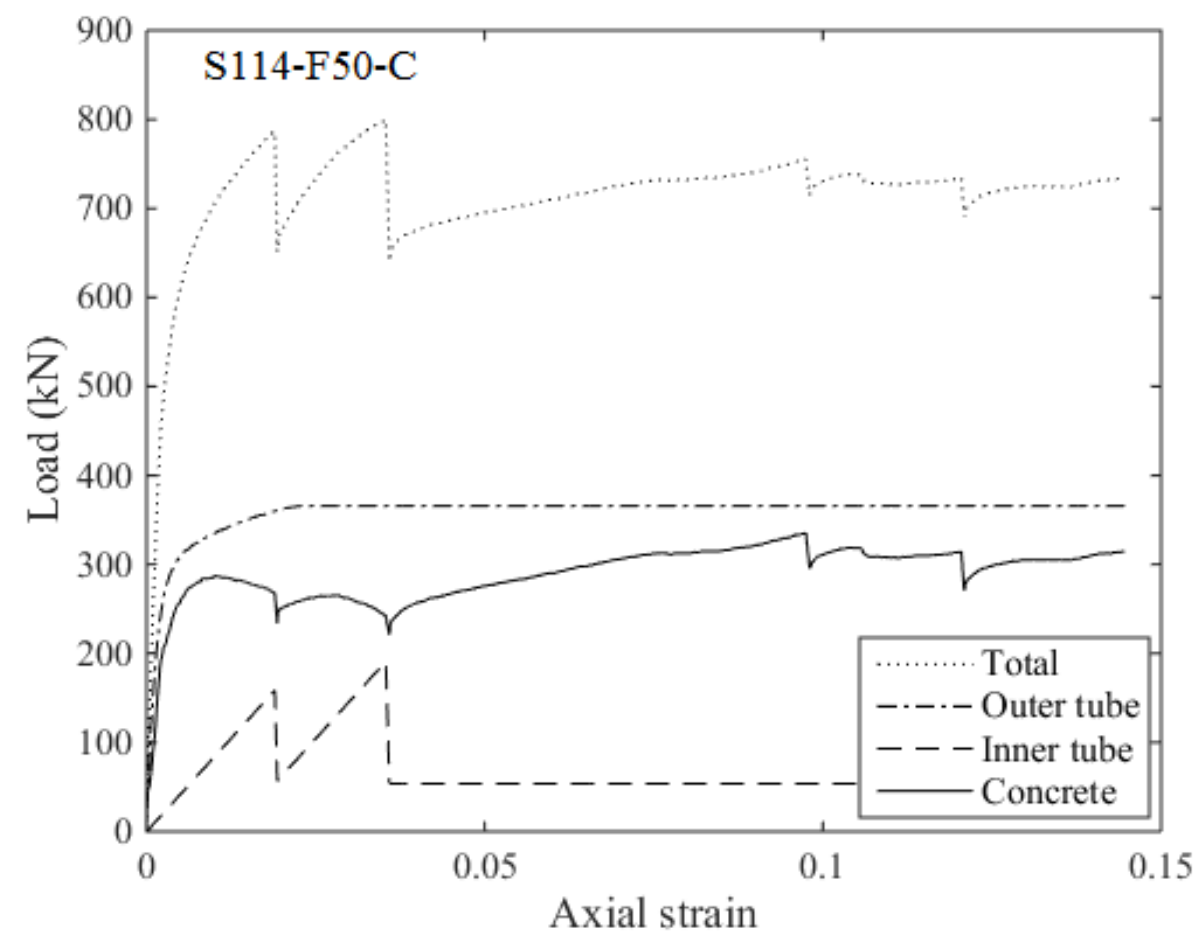

(i)

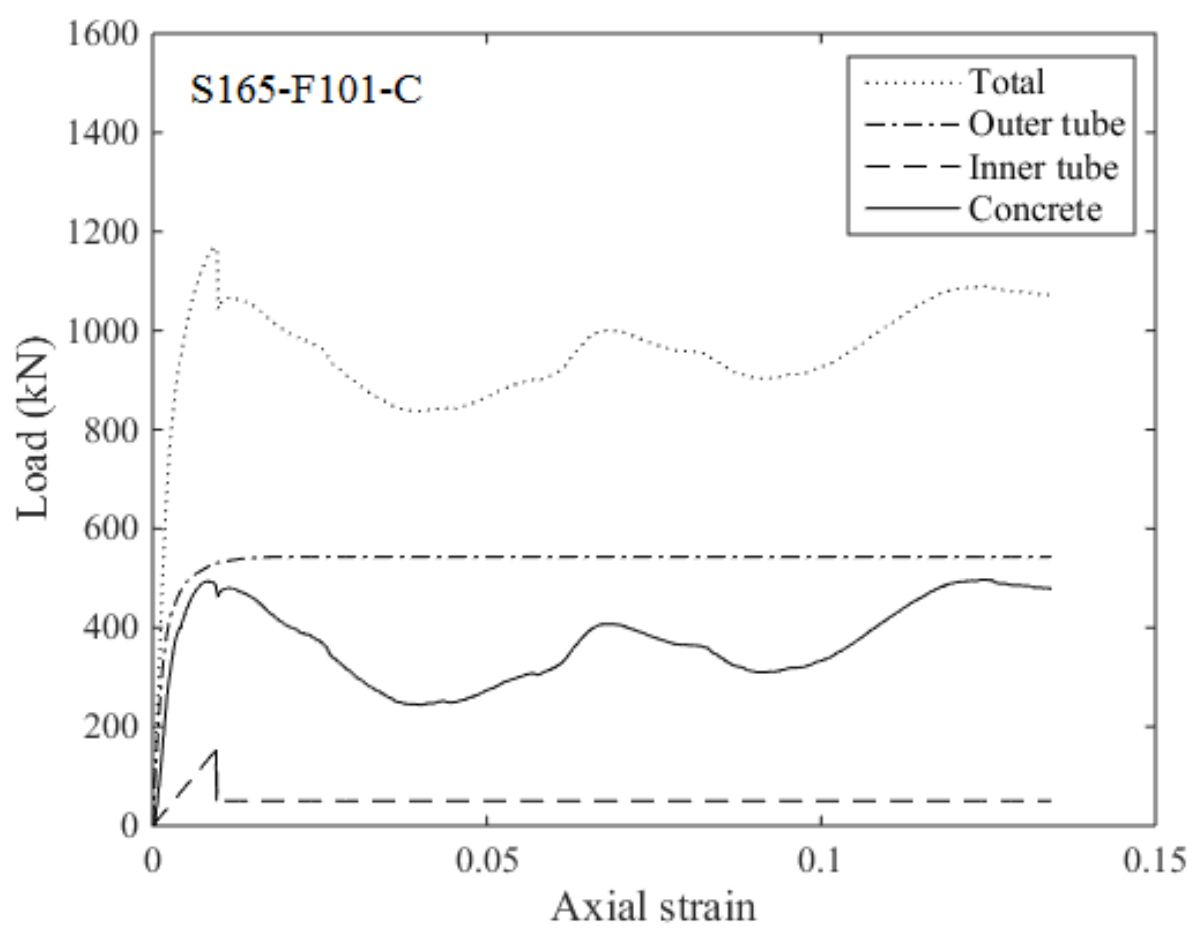

(ii)

(c) Double-skin tube (SS as the outer tube and GFRP as the inner tube) 


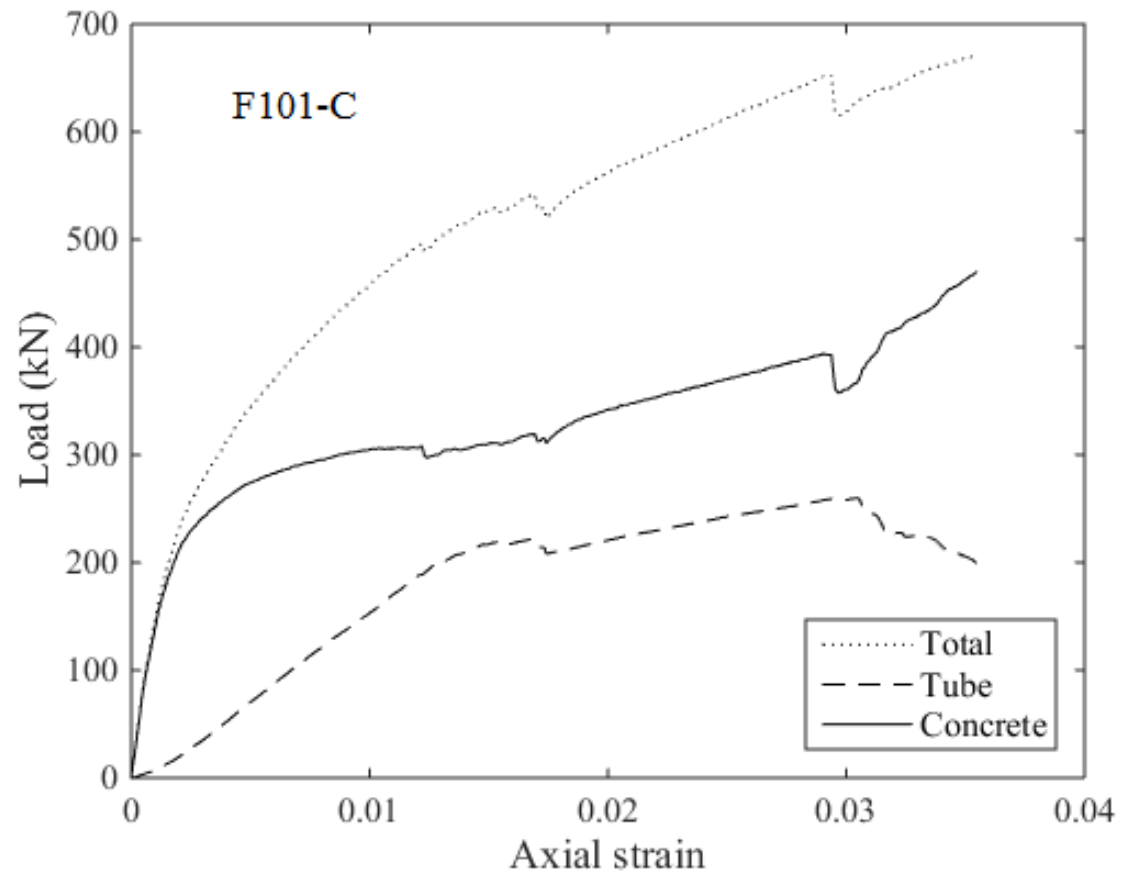

(i)

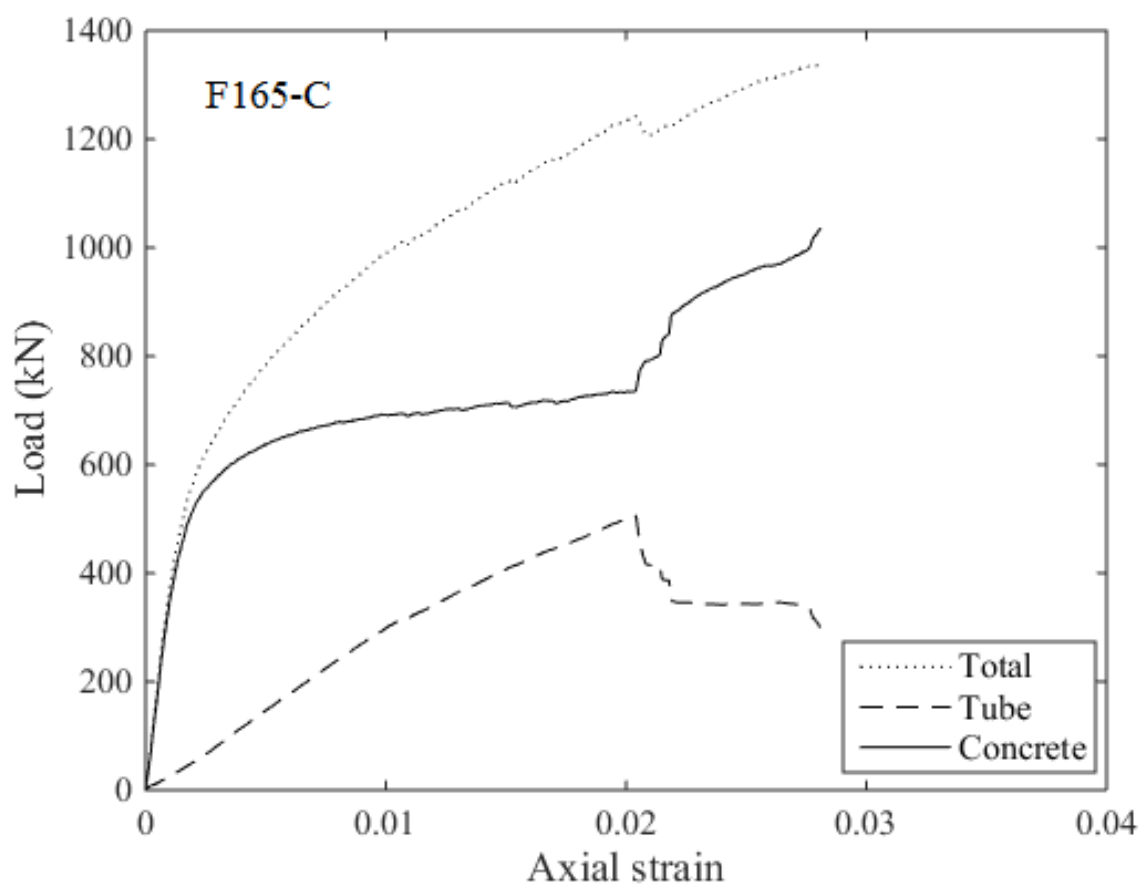

(ii)

(d) Fully-filled GFRP tubes 


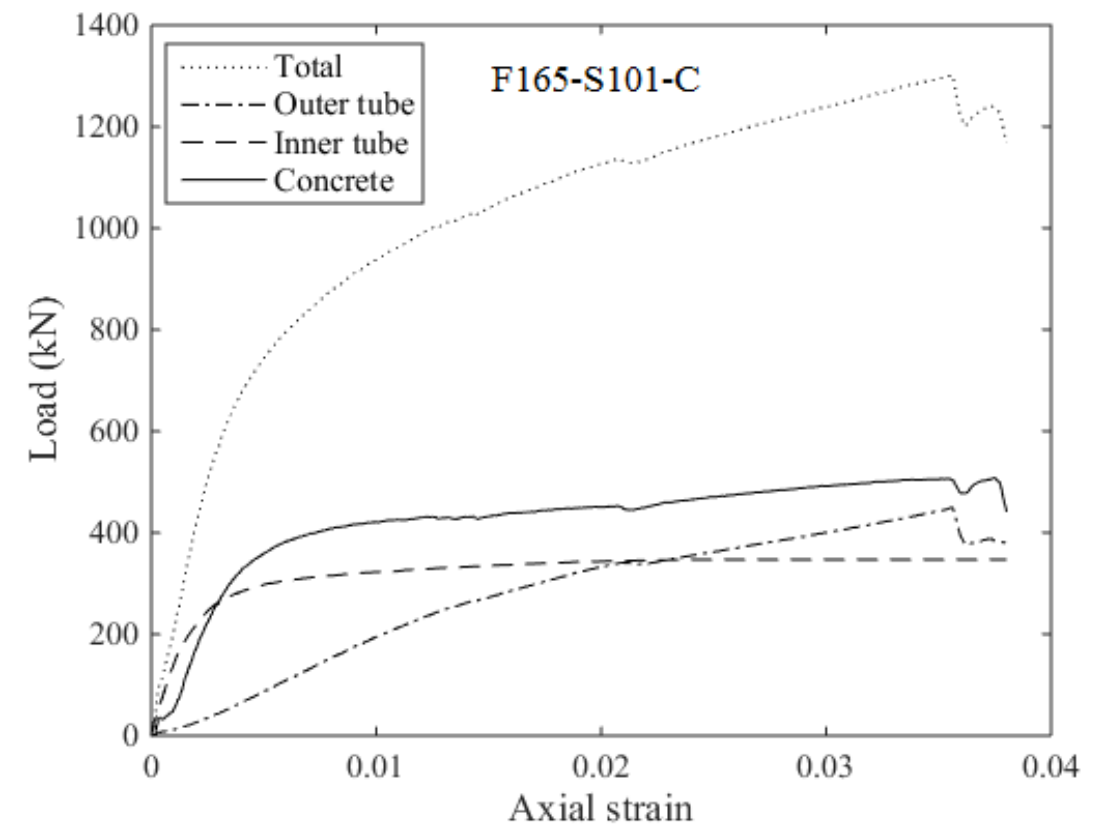

(i)

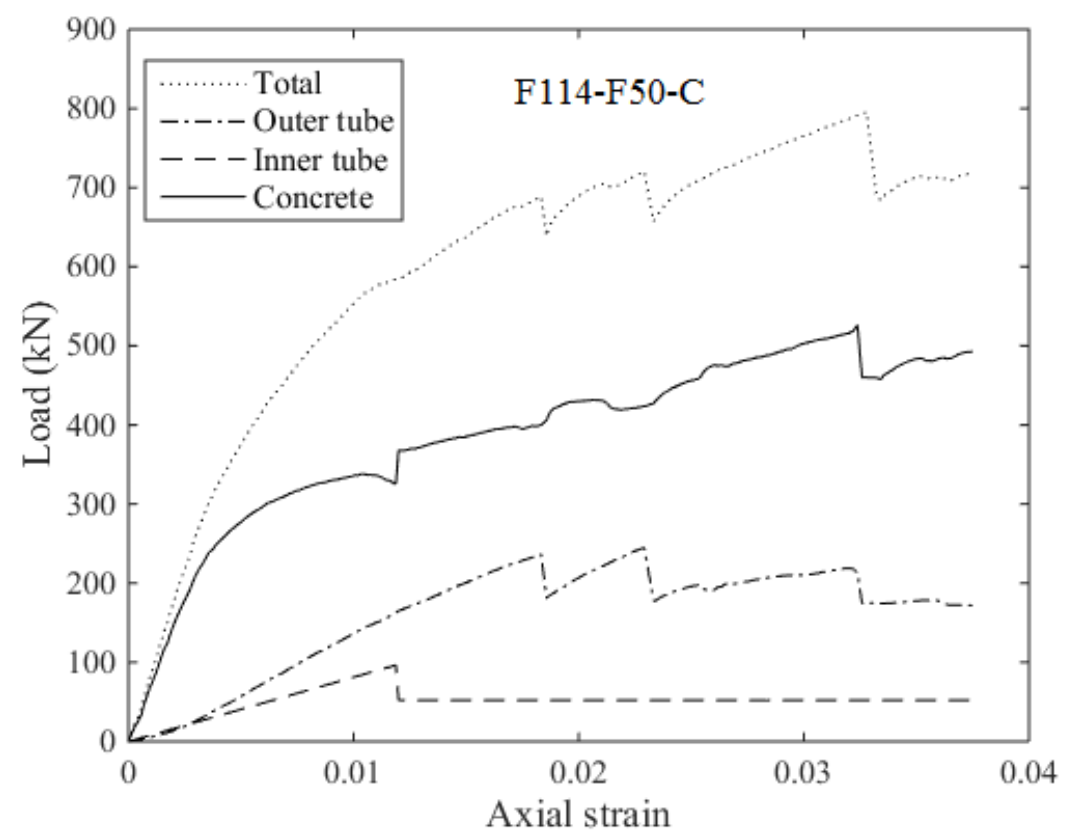

(ii) 


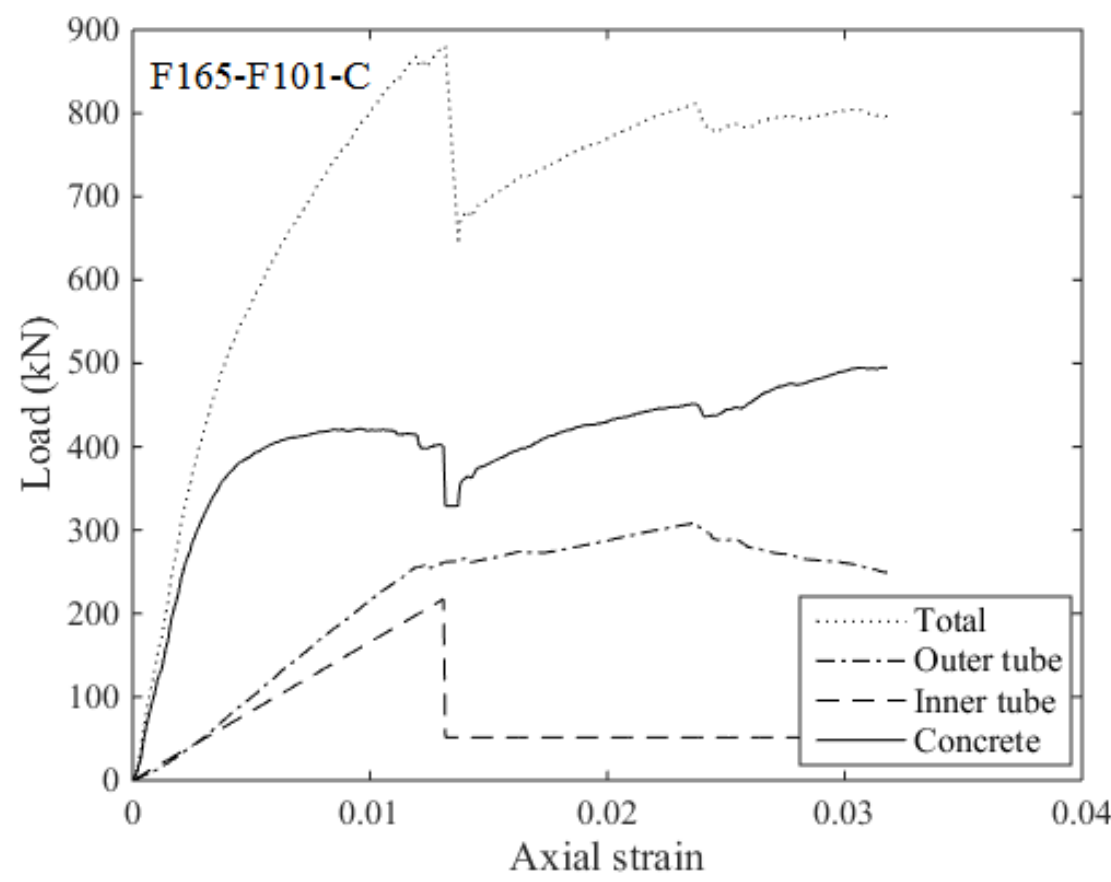

(iii)

(e) Double-skin tubes (GFRP as the outer tube)

Fig. 15. Load distribution in typical specimens 


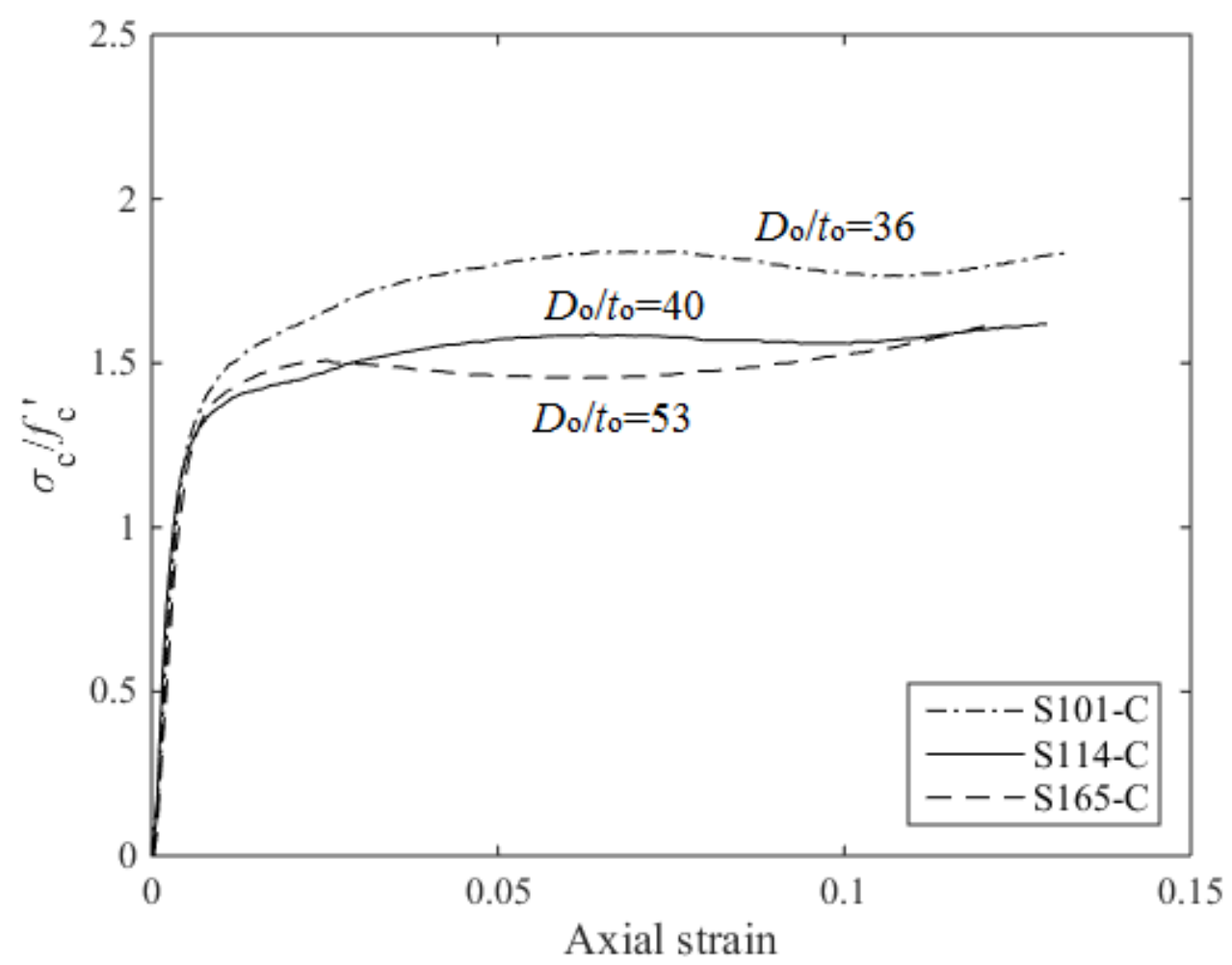

(a)

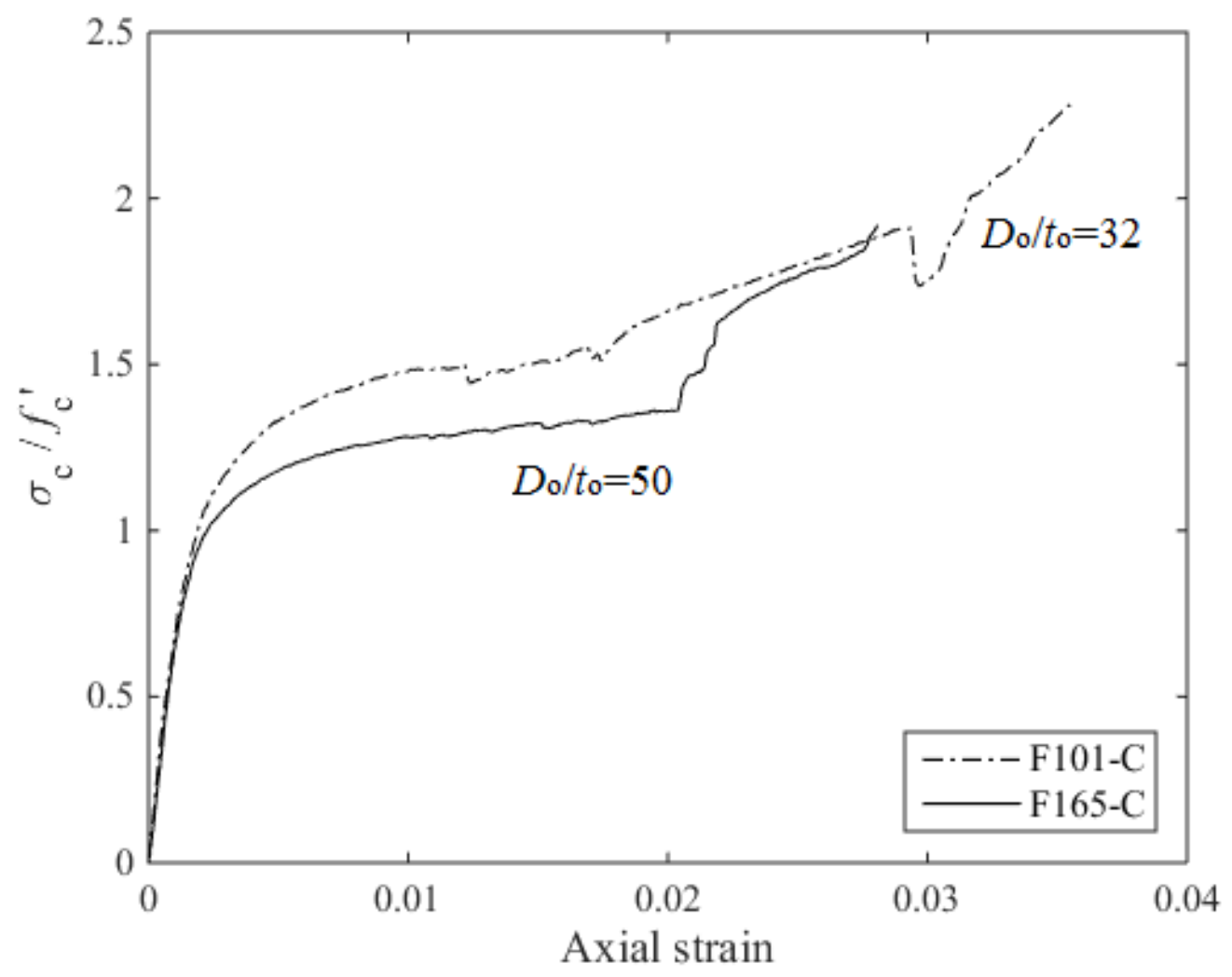

(b)

Fig. 16. Effects of tube diameter on $\sigma_{\mathrm{c}} / f_{\mathrm{c}}$ '-strain curves 


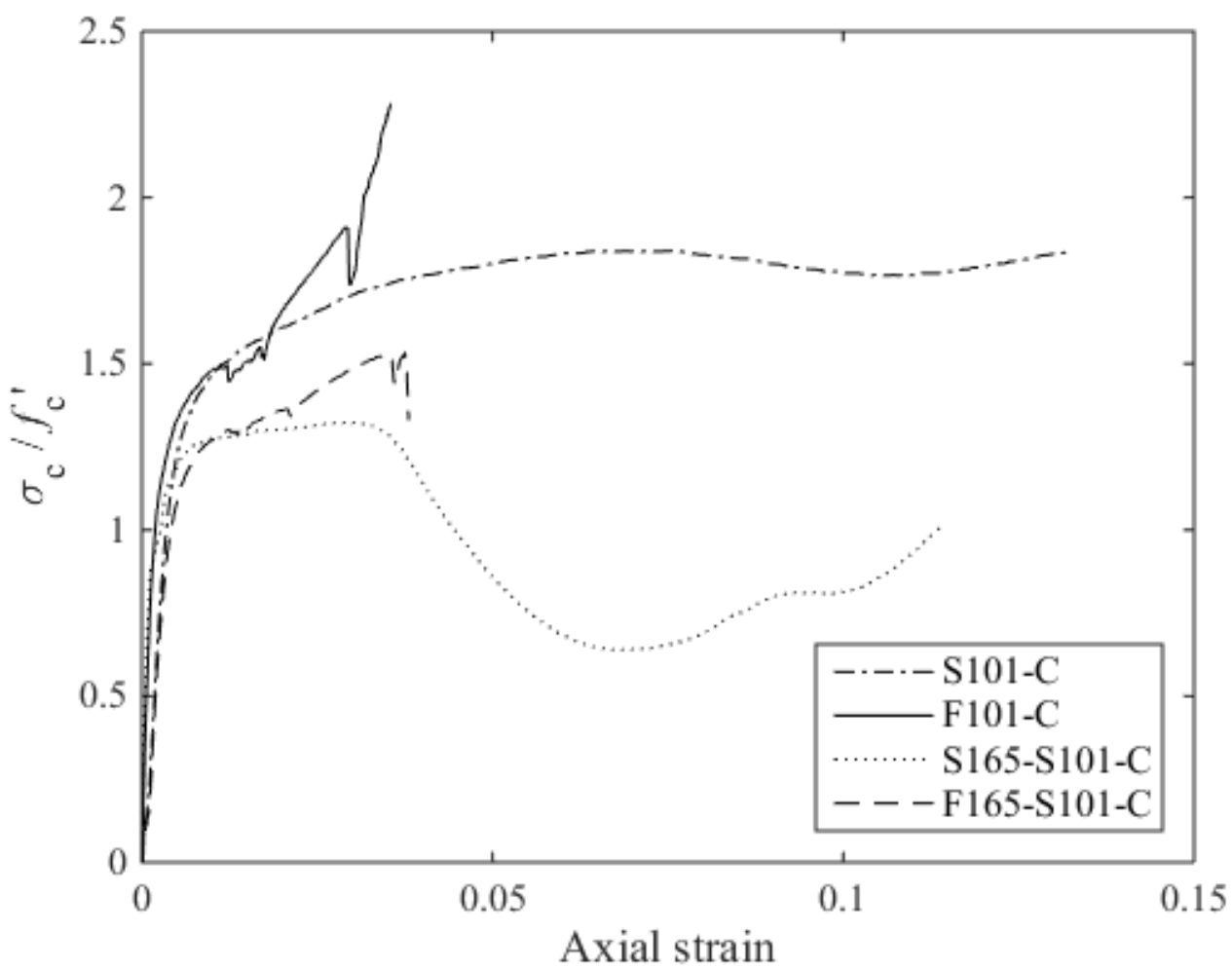

Fig. 17. Effects of the outer tube types on $\sigma_{\mathrm{c}} / f_{\mathrm{c}}$ '-strain curves 


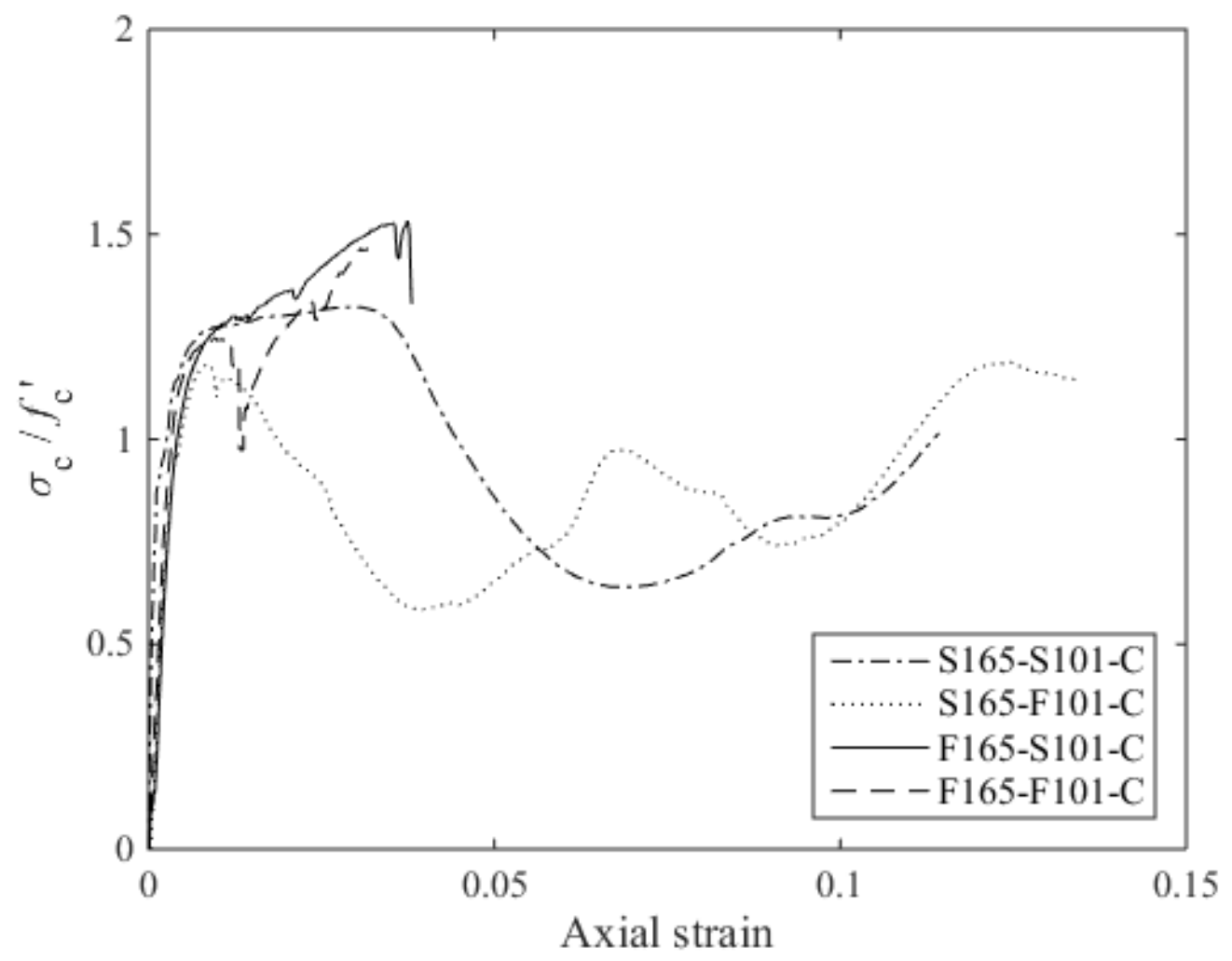

Fig. 18. Effects of the inner tube type on $\sigma_{\mathrm{c}} / f_{\mathrm{c}}$ '-strain curves 


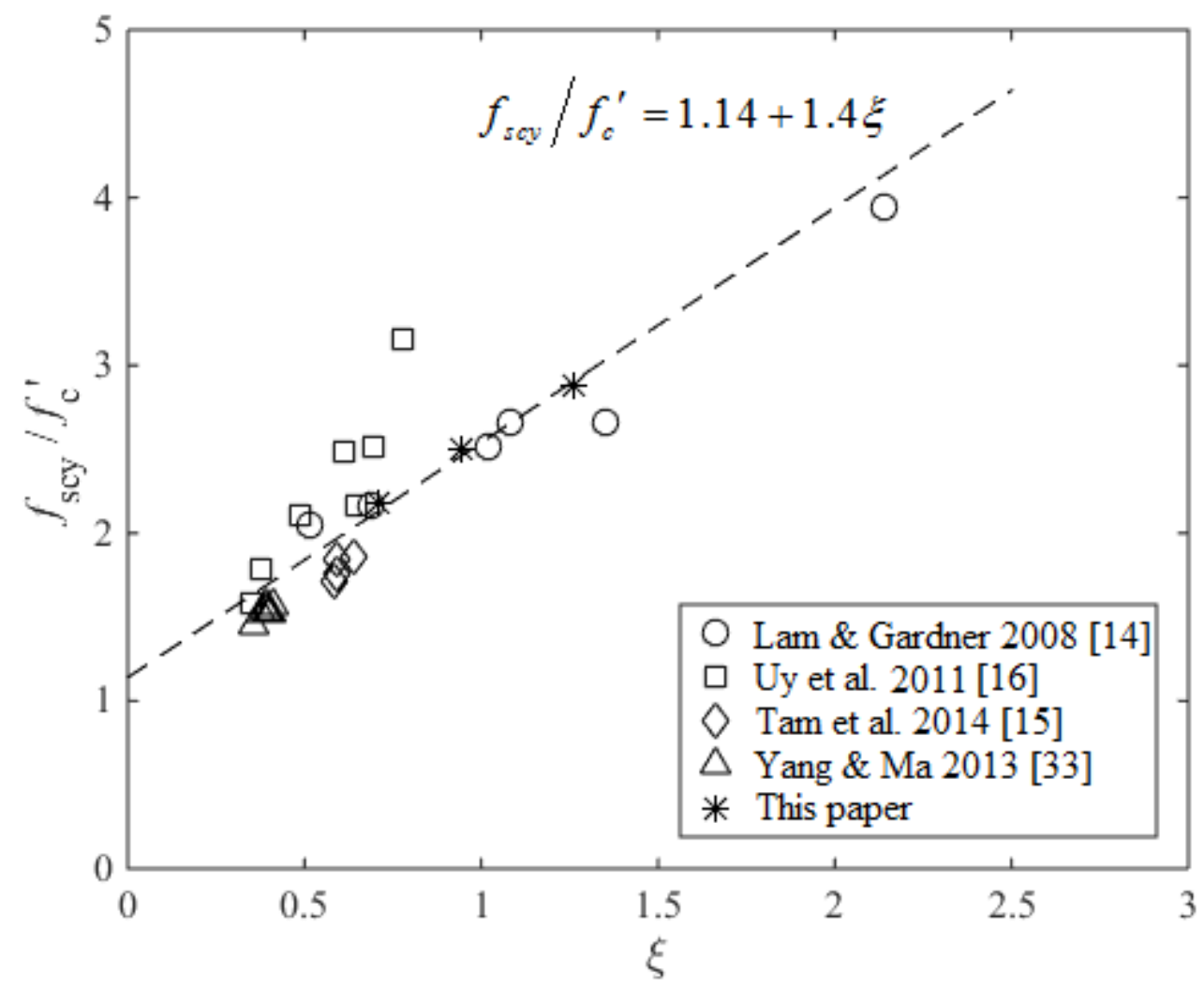

Fig. 19. Regression analysis of existed data 


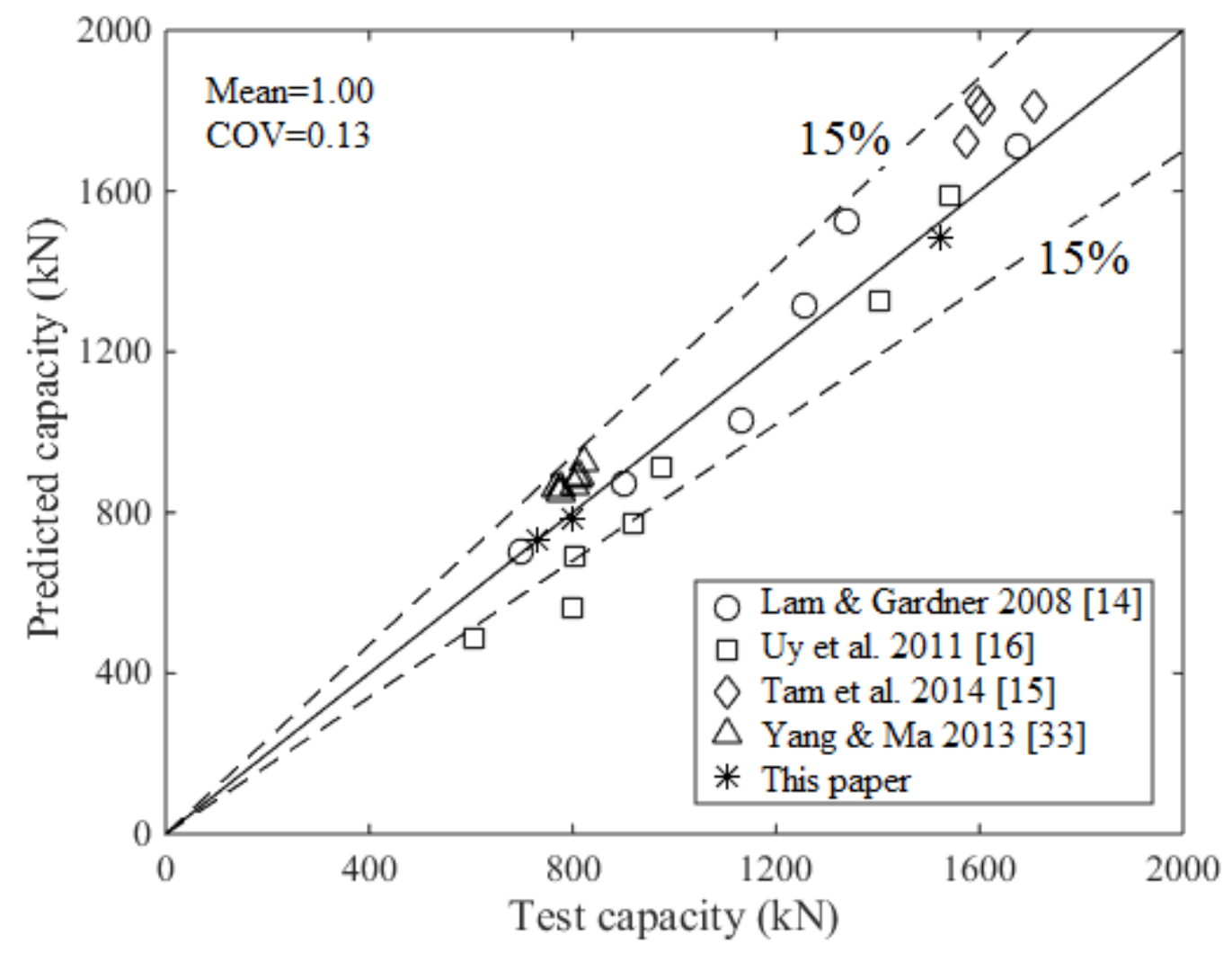

Fig. 20. Comparison between predicted capacity and test capacity 


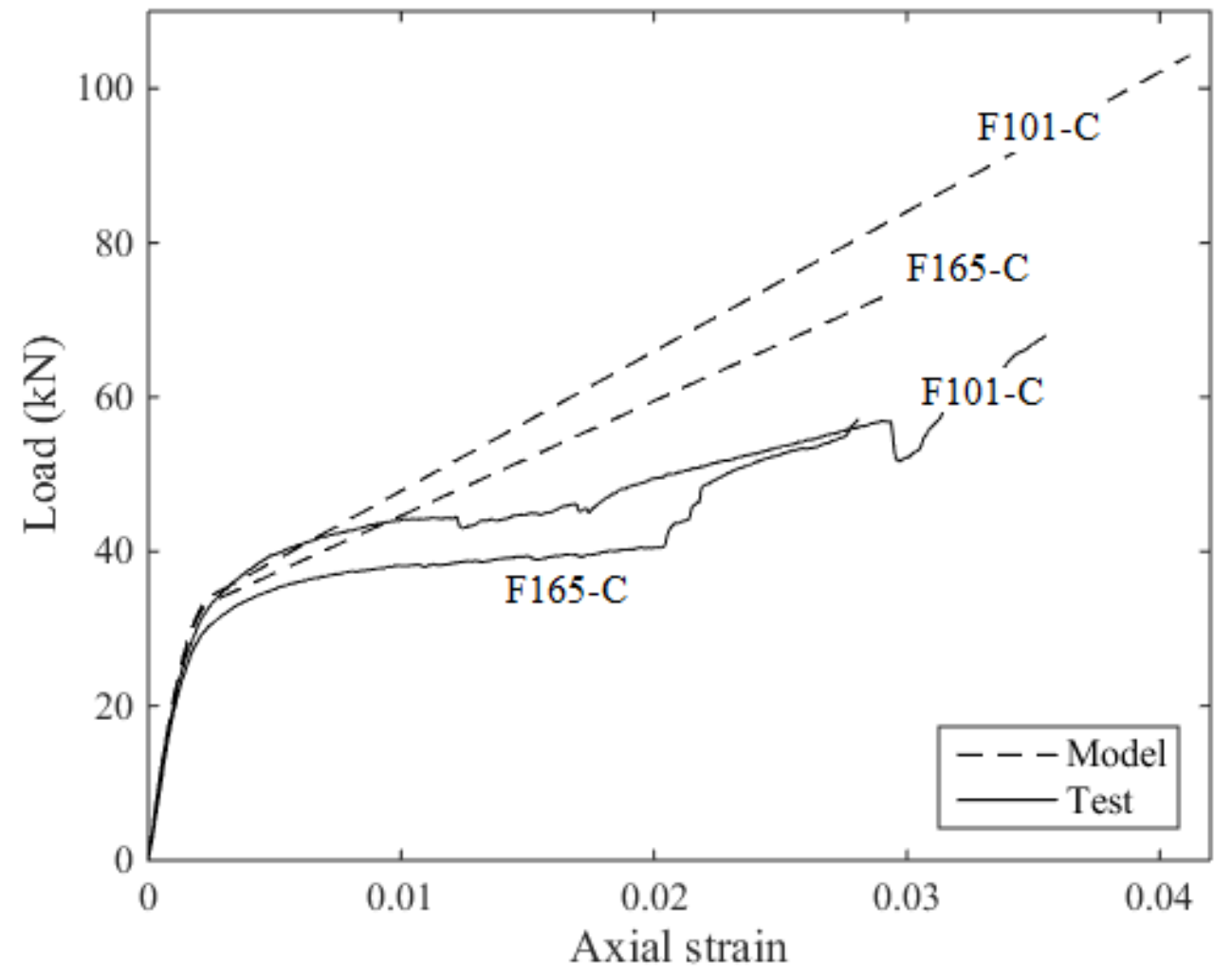

Fig. 21. Comparison of stress-strain curves from Teng's model and test results 


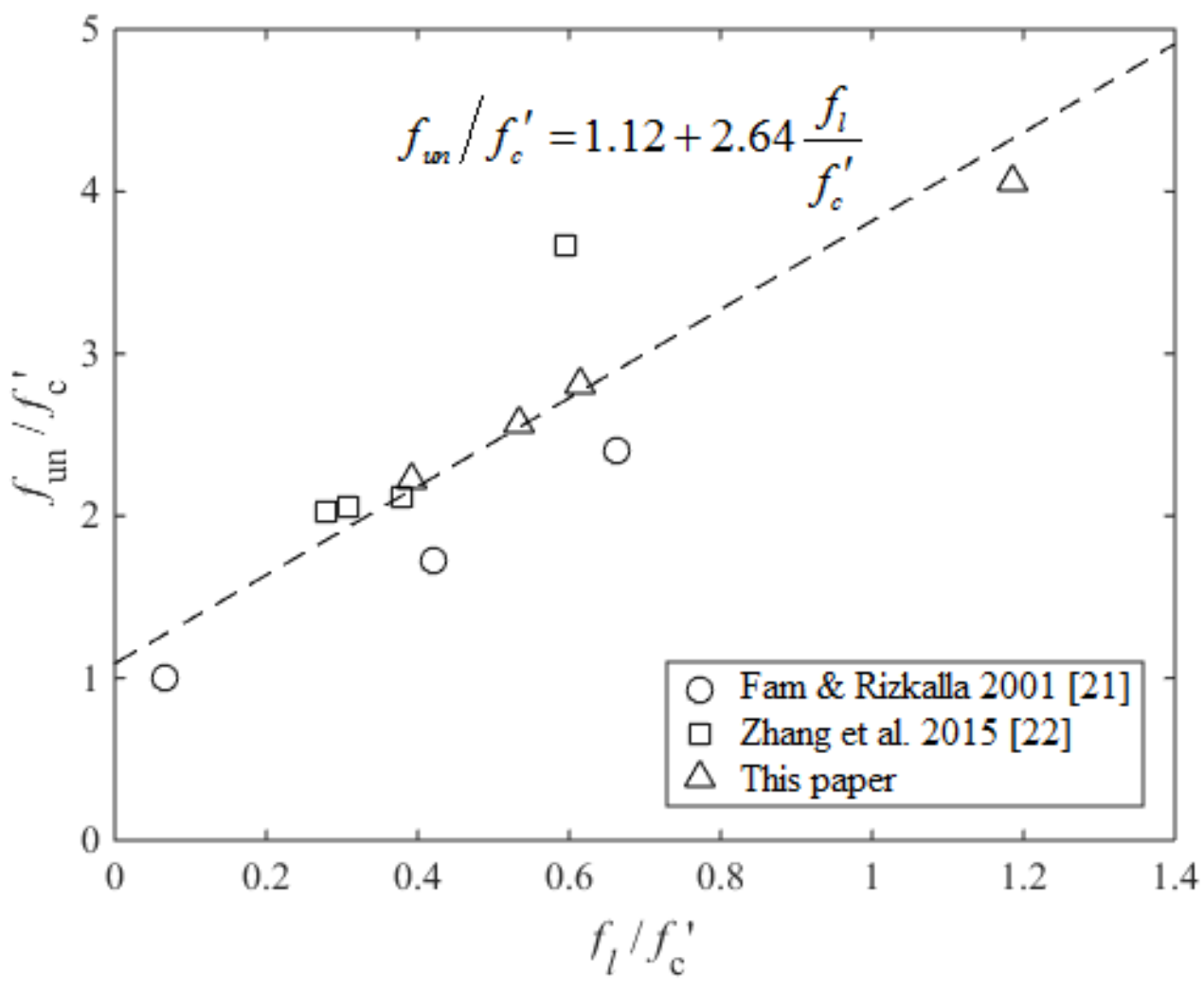

Fig. 22. Regression analysis of available data 


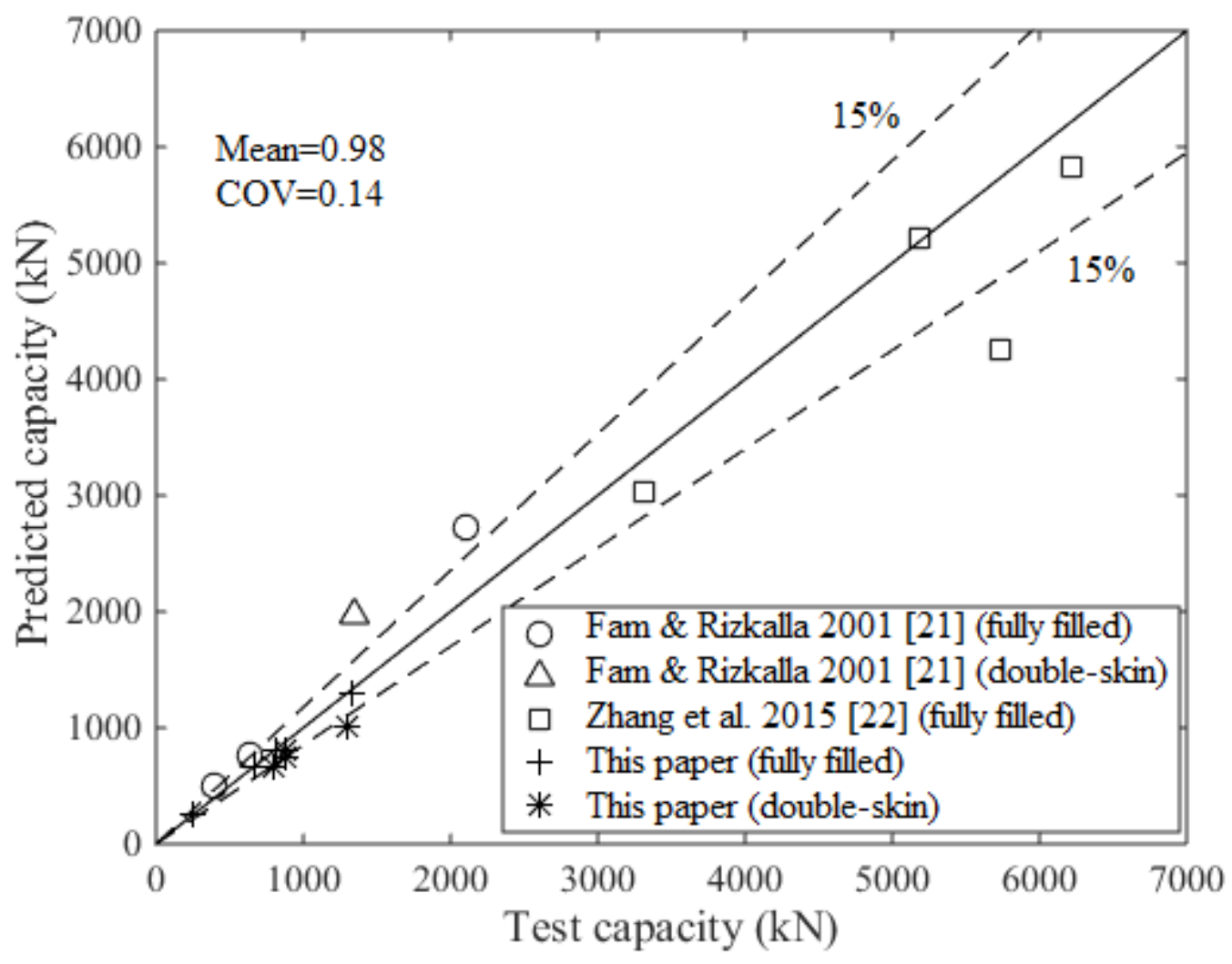

Fig. 23. Comparison between predicted capacity and test capacity 


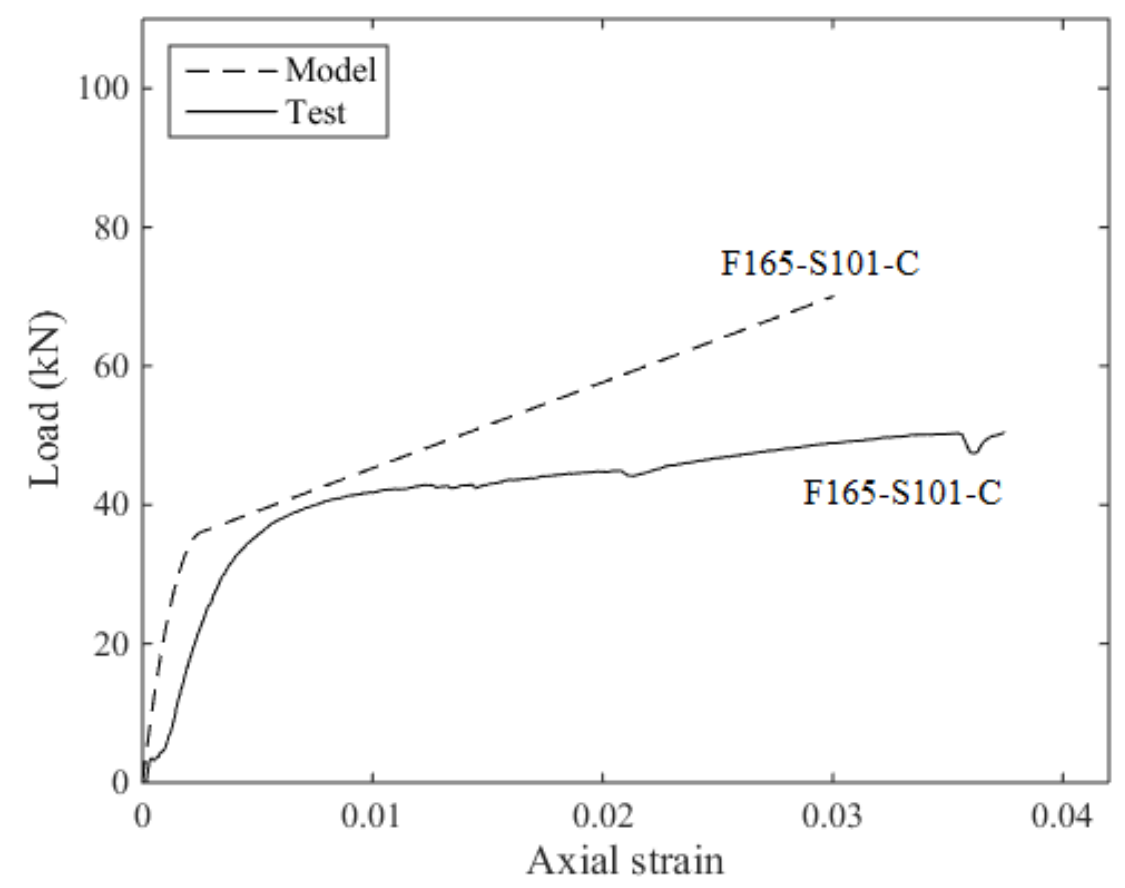

(a)

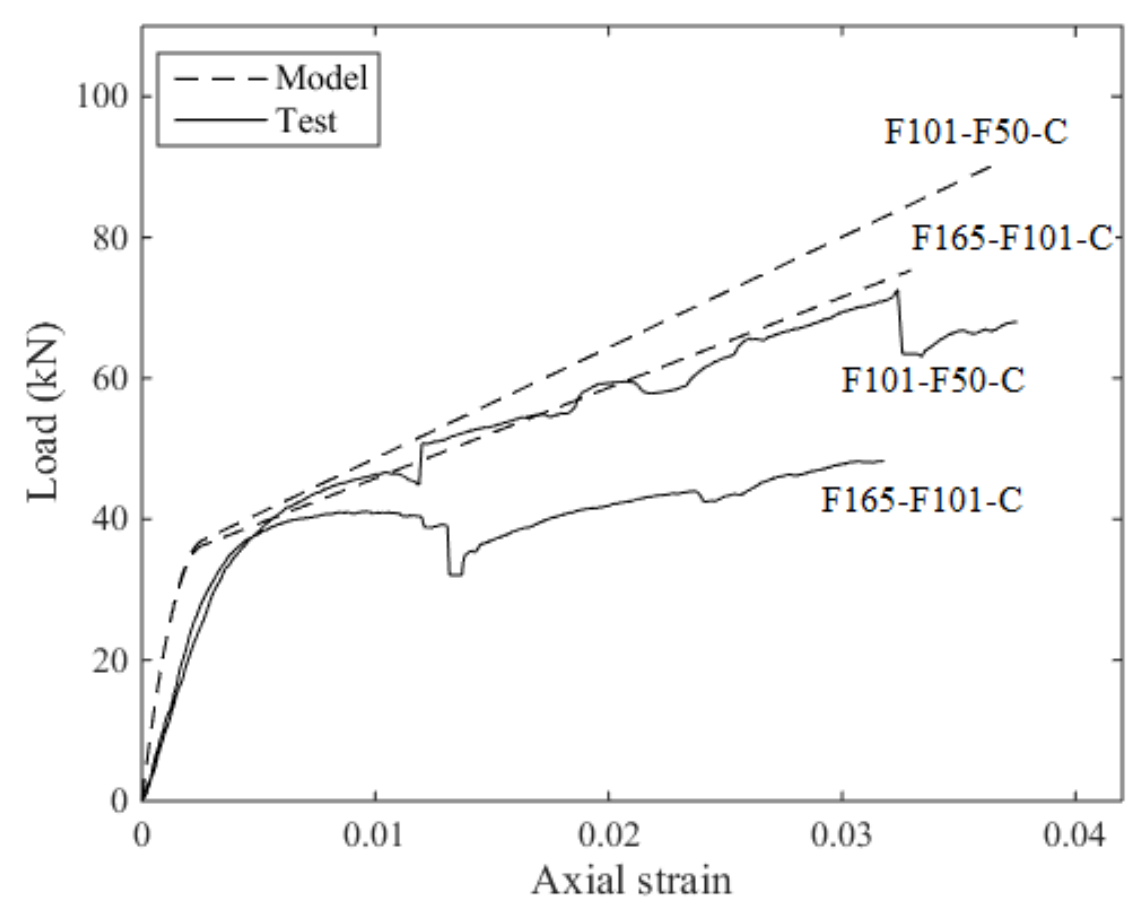

(b)

Fig. 24 Comparison of stress-strain curves from modified Teng's model and test results 